\title{
Comparison of In-use Emissions Measurement using PEMS, FTIR and Full-scale Dilution Method
}

\author{
Satya Ravi
}

Follow this and additional works at: https://researchrepository.wvu.edu/etd

\section{Recommended Citation}

Ravi, Satya, "Comparison of In-use Emissions Measurement using PEMS, FTIR and Full-scale Dilution Method" (2017). Graduate Theses, Dissertations, and Problem Reports. 6484.

https://researchrepository.wvu.edu/etd/6484

This Thesis is protected by copyright and/or related rights. It has been brought to you by the The Research Repository @ WVU with permission from the rights-holder(s). You are free to use this Thesis in any way that is permitted by the copyright and related rights legislation that applies to your use. For other uses you must obtain permission from the rights-holder(s) directly, unless additional rights are indicated by a Creative Commons license in the record and/ or on the work itself. This Thesis has been accepted for inclusion in WVU Graduate Theses, Dissertations, and Problem Reports collection by an authorized administrator of The Research Repository @ WVU. For more information, please contact researchrepository@mail.wvu.edu. 
Comparison of In-use Emissions Measurement using PEMS, FTIR and Full-scale Dilution Method

\title{
Sri Satya Ravi
}

\author{
Thesis submitted to the \\ College of Engineering and Mineral Resources \\ at West Virginia University \\ in partial fulfillment of the requirements \\ for the degree of
}

\author{
Master of Science \\ in \\ Mechanical Engineering
}

\begin{abstract}
Arvind Thiruvengadam Padmavathy, Ph.D., Chair
V'yacheslav (Slava) Akkerman, Ph.D.

Marc Cyrill Besch, Ph.D.

Department of Mechanical and Aerospace Engineering

Morgantown, West Virginia

2017
\end{abstract}

Keywords: Diesel Engines; Natural Gas Engines; In-use emissions; On-road testing;

PEMS; FTIR; TWC; SCR

Copyright 2017 Ravi, Sri Satya 


\section{Abstract \\ Comparison of In-use Emissions Measurement using PEMS, FTIR and Full-scale Dilution Method}

\section{Sri Satya Ravi}

With an increasing focus on implementing low emission heavy duty (HD) vehicles in the booming freight transportation sector, engine manufacturers have started prompting studies on addressing the technical challenges of measuring these virtually near zero levels of gaseous and particulate emissions. Moreover, from a regulatory perspective, beginning 2005, the United States Environmental Protection Agency (EPA) promulgated the in-use testing program for HD diesel engines in addition to the regular compliance testing protocol. The rule mandates the engine manufacturers to measure gaseous and particulate matter emissions using a portable emissions measurement system (PEMS) during real-world driving conditions, and verify that they meet emission standards. With the tightening regulation standards, approaching a near zero limit it has become imperative to improve the measurement capabilities for application at such low limits of exhaust gas emissions concentration determination.

The objective of this study was to both quantitatively and qualitatively evaluate the PEMS to that of laboratory grade constant volume sampling (CVS) system with respect to the measurement of criteria pollutants mainly Total Hydrocarbons (THC) and oxides of nitrogen (NOx), and to investigate into using Fourier transform infrared spectroscopy (FTIR) as an alternative to PEMS instrumentation. The present study was conducted in two heavy duty engine platforms- viz., diesel and natural gas (NG), across three different route types which were widely used for freight transportation across California. The routes were chosen in a way that they would aptly represent near-dock, local and highway operations of a typical class- 8 truck. The vehicles used in the study, were tested using West Virginia University's Transportable Emissions Measurement System (WVU-TEMS). The WVU-TEMS houses an entire full-scale CVS dilution tunnel and a range of laboratory-grade emission analyzer systems inside a trailer container, hauled by the chosen vehicle. Raw exhaust emissions from these vehicles were simultaneously measured using Semtech-DS (PEMS) and MKS 2030-HS FTIR.

The study revealed that, NOx emissions were higher for both diesel and natural-gas vehicles during near-dock (start - stop) operation mainly due to low after-treatment temperatures, however compressed NG vehicle had 95\% lower NOx emissions when compared to the diesel counterpart. $\mathrm{CO}$ and THC emissions was near zero for diesel vehicle and higher for NG. 85-88\% of THC emissions from NG vehicle was methane $\left(\mathrm{CH}_{4}\right)$. NOx emissions for diesel from FTIR were within 5-9\% when compared to CVS system and higher when compared to PEMS instrumentation due to the difference in measurement techniques between the two instruments while the THC emissions from CNG were within 1-4\% of PEMS during the test period and higher when compared to CVS due to comparatively low emission rates. 


\section{Acknowledgements}

First and foremost, my family has been and will always be my greatest strength. Your love, affection and motivation has always been my driving force behind me. I thank my mom, dad and chinna from the bottom of heart for their vision and their sacrifices to make their vision a reality. Bunny, thank you for being patient and bearing with me. I am sorry but you must till the end of your life sister. Dad, thank you for being the greatest source of inspiration in my life, your knowledge and passion never seizes to amaze me. Amma, thank you for your unconditional love and affection, you are the strongest person I know. Chinna, thanks would be a small word to tell you for all the love and affection you showered upon me. You will always be as a dad in my heart. I am so blessed to have such a wonderful family.

I would like to express my sincere gratitude to my advisor Dr. Arvind Thiruvengadam (Arvi) although I have never called you as Dr. Arvind for your valuable guidance and support in earning me a higher degree in my career. I consider it a great opportunity to have worked with you and thank you for preparing me for a better future. You and Marc will always be my idols in the field of emissions technology. Arvi I know how many problems I have created to you but you have always helped me in every possible way. It was you who laid path to achieve my dreams.

Marc, you are a great inspiration to me. Thanks for all the help with a smile. I know I have troubled you many times for all the doubts I had although they might seem stupid to you but you have always helped me clarify those. Thanks for all the late-night rides to my home. It was lucky to have you as my committee member. Your guidance helped me a lot.

I would like to thank Dr. V'yacheslav Akkerman for being my committee member and for your valuable suggestions. Thanks, are due to all the people (Brad, Aaron, Richard) in the ERC at WVU who have helped me during my studies here at WVU.

Saroj and Pragladh, you guys helped me a lot during my work at ERC. Thanks for always staying cool and your valuable inputs helped me a lot. Yashwanth - it was because of you I started my real work for CAFEE. Thanks for taking time in helping me teach stuff which made me fascinated about CAFEE when you were still learning yourself.

Madhu- I would like to thank you from the bottom of my heart. Thanks for all the support, care and affection. Thank you for being a great sister as you will always continue to be. I am so blessed to have you in my life. Puja, Deepesh, Rahul bro, Bobba, Aliya, Vishnu and Shiva - these loving buddies without you guys the fun wouldn't have been continuing so long. Thank you all for the support.

Mohana- It was with you I had the most fights in my entire life. If it wasn't those my stay here wouldn't be as wonderful as it was. Thank you for your support and help. I always wondered how a short span of 6 months created such a great friendship among us but all I can say was I am lucky.

Morgantown has given me a lot of friends and great memories to cherish. I would like to thank each and every one who made my stay here at WVU wonderful. Morgantown will always be my $2^{\text {nd }}$ hometown. It will be the place which laid the foundation for a wonderful journey in my life. 


\section{Table of Contents}

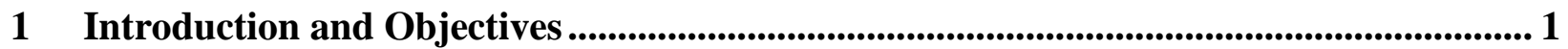

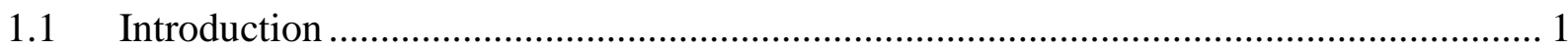

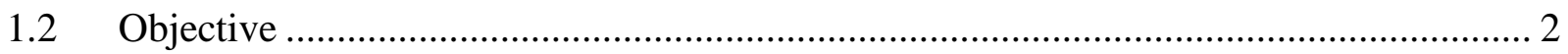

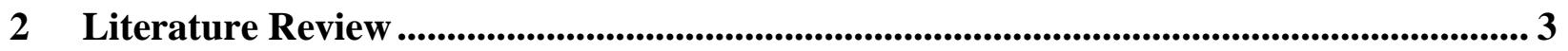

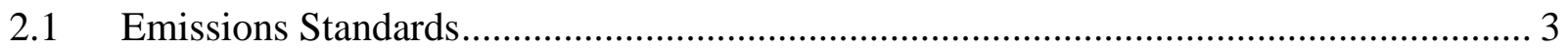

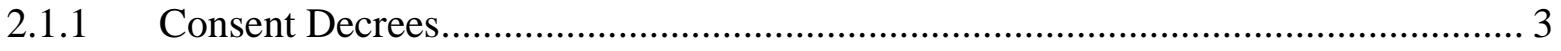

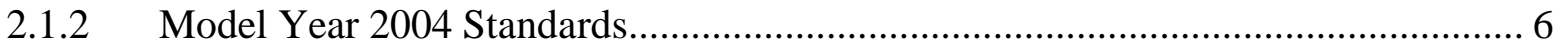

2.1.3 Model Year 2007 and Later Standards .......................................................... 6

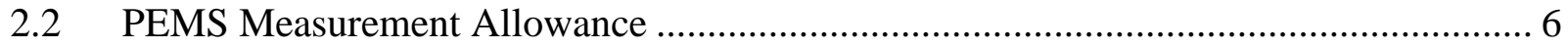

2.2.1 Laboratory Evaluation of PEMS .................................................................. 9

2.2.2 Statistical Modeling and Simulation of Error Propagation................................ 14

2.2.3 Validation of Measurement Allowance Model Simulation Results ..................... 18

2.2.4 EPA PEMS Measurement Allowance Testing Procedure ................................. 22

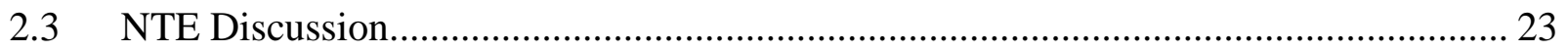

2.4 Previous In-use PEMS Measurement Systems ................................................ 26

2.5 Previous In-use FTIR Measurement Systems .......................................................... 30

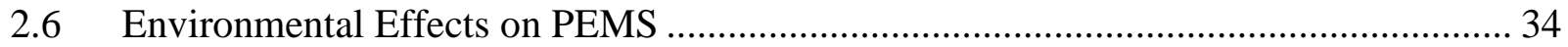

$2.7 \quad$ Factors Affecting Heavy-Duty Vehicle Emissions ................................................. 36

3 Experimental Equipment Review and Procedures............................................................ 38

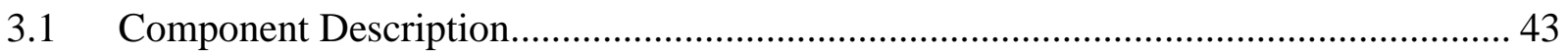

3.1.1 Fourier Transform Infrared Spectrometer (FTIR) ........................................ 43

3.1.2 Chemiluminescent Detector (CLD) .......................................................... 46

3.1.3 Non-dispersive Ultraviolet Photometer (NDUV) ........................................... 47

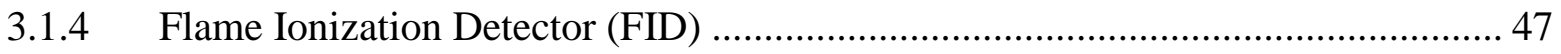


3.1.5 Non-Dispersive Infrared Detector (NDIR) ………......................................... 48

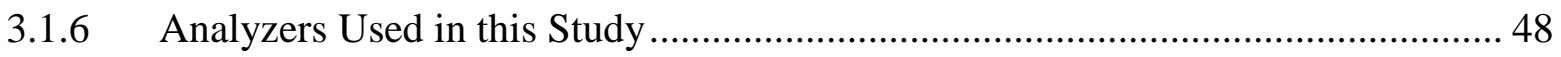

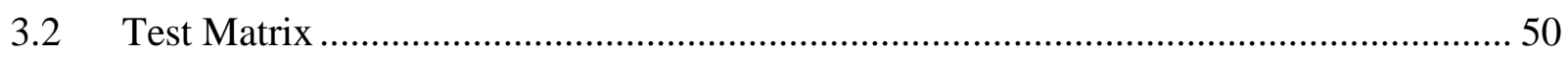

3.2.1 Test Engine and Vehicle Specifications …………............................................. 50

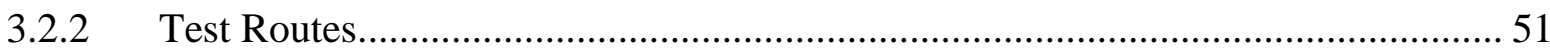

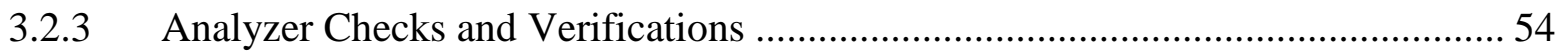

3.2.4 Engine Speed and Torque Measurement …………....................................... 56

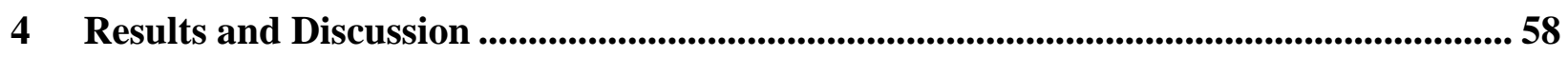

4.1 Emissions Analyzed by CVS on Route Basis ............................................................. 58

4.2 Emissions Analyzed by 3 Different Measurement Techniques on Route Basis ............. 64

4.3 NOx and THC Raw Emissions Comparison between PEMS \& FTIR ……………….... 73

4.4 Effect of Time-Alignment on NOx Emissions from FTIR …………………….......... 86

4.4.1 Time-Alignment based on Regression Method ................................................... 86

4.4.2 Time-Alignment based on Visual Method............................................................... 87

4.4.3 Effect of Time-Alignment on Emissions ............................................................. 88

5 Conclusion ................................................................................................................................................ 90 


\section{List of Figures}

Figure 1. Engine operating points for FTP with NTE region ........................................... 24

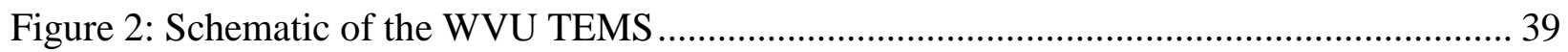

Figure 3: WVU TEMS performing real-world emissions testing ......................................... 39

Figure 4: Schematic of CVS sampling setup for gaseous and PM sampling systems............... 40

Figure 5: Components of an FT-IR spectrometer............................................................... 46

Figure 6: Testing route indicating Near- Dock driving ................................53

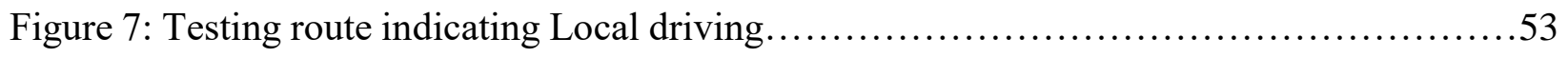

Figure 8: Testing route indicating Regional Highway driving conditons................................ 53

Figure 9: Brake-specific emission rates from diesel and natural gas vehicle for near-dock route.

Figure 10: Brake-specific emission rates from diesel and natural gas vehicle for local driving route.

61

Figure 11: Brake-specific emission rates from diesel and natural gas vehicle for highway driving

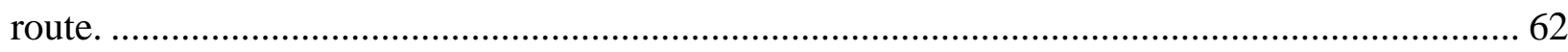

Figure 12: Comparison of NOx emissions rates $\mathrm{b} / \mathrm{w}$ test vehicles based on driving routes......... 63

Figure 13: Emissions from Diesel and Natural Gas Vehicle for Near-dock route. .................... 66

Figure 14: Emissions from Diesel and Natural Gas Vehicle for Local driving route.................. 69

Figure 15: Emissions from Diesel and Natural Gas Vehicle for Highway driving route............ 71

Figure 16: NOx emissions from PEMS and FTIR during Near-dock operation for Diesel vehicle.

Figure 17: Quantile-Quantile plot between FTIR and PEMS during near-dock operation for diesel vehicle. 76

Figure 18: NOx emissions from PEMS and FTIR during Local operation for Diesel vehicle..... 77 Figure 19: Quantile-Quantile plot between FTIR and PEMS during local operation for diesel vehicle. 78

Figure 20: NOx emissions from PEMS and FTIR during Highway operation for Diesel vehicle. 79

Figure 21: Quantile-Quantile plot between FTIR and PEMS during highway operation for diesel vehicle. 80 
Figure 22: THC emissions from PEMS and FTIR during Near-dock operation for CNG vehicle.

Figure 23: Quantile-Quantile plot between FTIR and PEMS during near-dock operation for

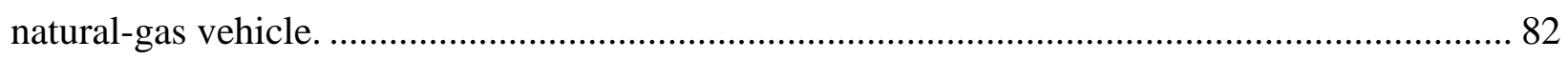

Figure 24: Quantile-Quantile plot between FTIR and PEMS during local operation for natural-gas

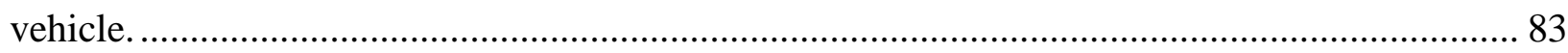

Figure 25: Quantile-Quantile plot between FTIR and PEMS during highway operation for natural-

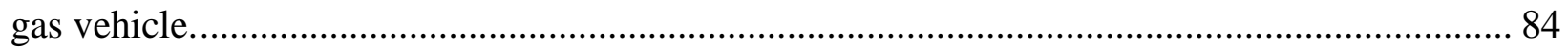

Figure 26: THC and $\mathrm{CH}_{4}$ emissions during Highway testing for $\mathrm{CNG}$ vehicle....................... 85

Figure 27: Error caused due to time-alignment in NOx emissions from FTIR. ....................... 89 


\section{List of Tables}

Table 1: EPA emissions standards for heavy-duty engines over FTP in g/bhp-hr ..................... 5

Table 2: California emissions standards for heavy-duty engines over FTP in $\mathrm{g} / \mathrm{bhp}-\mathrm{hr}$.............. 5

Table 3: Current EPA specified lifetime for heavy-duty truck engines.................................... 5

Table 4: Current emissions standards for heavy-duty engines over FTP cycle .......................... 6

Table 5: Measurement Allowance Program - Laboratory Reference Methods .......................... 13

Table 6: Measurement Allowance Program - 1065 Lab \& PEMS Audit Tests ........................ 13

Table 7: Measurement accuracy margins for gaseous emissions using PEMS testing................ 18

Table 8: Summary of Model Validation Results .............................................................. 21

Table 9: Components used for emissions measurement in the analyzers............................... 48

Table 10: Test vehicles specifications for chassis TEMS testing. ......................................... 50

Table 11: Comparison of test routes and driving characteristics between test vehicles.............. 52

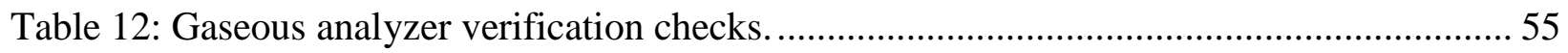

Table 13: Gaseous and PM measurement system verification checks. .................................. 55

Table 14: Brake-specific emission rates of regulated pollutants during sepcific route operations.

Table 15: Emissions comparision between 3 different instruments in grams/mile during Near-dock

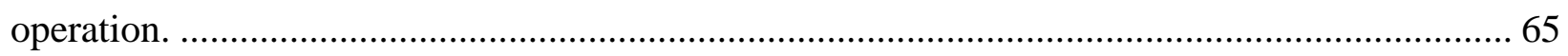

Table 16: Emissions comparison between 3 different instruments in grams/mile during Local operation. 67

Table 17: Emissions comparison between 3 different instruments in grams/mile during Highway

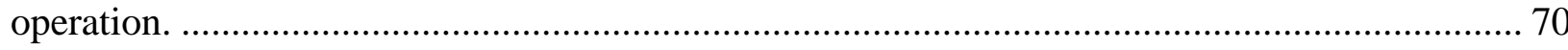

Table 18: FTIR NOx and THC calculations for Diesel Fuel............................................... 72

Table 19: FTIR NOx and THC calculations for Natural gas Fuel......................................... 72

Table 20: NOx emissions analyzed from diesel vehicle using regression time-alignment technique.

Table 21: NOx emissions analyzed from diesel vehicle using visual time-alignment technique. 88 


\section{Introduction and Objectives}

\subsection{Introduction}

Continuous expansion of the use of diesel engines in light-duty and heavy-duty vehicles and the uncertainties associated with the effects of exhaust emissions on human health have focused attention on risk assessments of diesel engine exhaust. The complexity of chemical and physical composition of diesel exhaust emissions makes the assessment a very daunting task. Particulate matter (PM), organic compounds such as unburned or partially burned hydrocarbons ( $\mathrm{HC})$, oxides of nitrogen ( $\mathrm{NO}$ and $\mathrm{NO}_{2}$ - collectively known as $\mathrm{NOx}$ ), carbon monoxide (CO), and sulfur oxides are recognized as major pollutants in diesel engine exhaust emissions (US EPA 2005). Particulate matter, organic compounds, NOx and carbon monoxide are primary products of the fuel combustion process. However, nitrates and sulfates are formed because of post combustion and post tailpipe reactions and therefore, not considered as direct products of combustion. Inorganic constituents of diesel exhaust such as metals, acids and salts are also among the chemical constituents hypothesized to be toxic (US EPA 2005).

Emissions from heavy-duty trucks make up a large portion of the mobile emissions inventory. Vehicles are classified as heavy-duty if their gross vehicle weight rating (GVWR) is greater than $8,500 \mathrm{lbs}$. Traditionally, the testing procedure to measure emissions output from these vehicles has been performed by loading the engine with a dynamometer. Loading may be applied by a dynamometer in a test cell if the engine is removed or by a chassis dynamometer through the drive wheels of the vehicle. These methods do not accurately represent actual driving conditions for most cases. In-use testing is the most realistic method of determining exhaust emissions over a certain driving route. On-road testing of diesel trucks presents many challenges. Diesel engine emissions are generally significantly different than those from a gasoline engine. Namely, NOx 
concentrations are typically much higher for diesels while $\mathrm{CO}$ and $\mathrm{HC}$ concentrations are much lower when compared to a gasoline engine.

In early June 2005, the Environmental Protection Agency (EPA) signed a rule implementing an in-use regulatory testing program for heavy-duty diesel engines (US EPA 2005). This regulation requires engine manufacturers to measure gaseous and particulate matter emissions in in-use operation using a portable emissions measurement system (PEMS). Regulations were in full effect in 2007. The program required that $\mathrm{CO}, \mathrm{HC}$, NOx, and PM emissions be monitored inuse with a PEMS. Compliance for the in-use program will be determined using current 30 second window not-to-exceed (NTE) criteria (US EPA 2005).

\subsection{Objective}

The global objective of this study is to evaluate PEMS instrumentation with respect to a laboratory grade Constant Volume Sampling (CVS) system and to investigate into using Fourier Transform Infrared Spectroscopy (FTIR) as an alternative to PEMS instrumentation. This study primarily focuses on the comparison of emissions from two different heavy-duty vehicles namely diesel and natural gas using FTIR, PEMS and a CVS system. To achieve such a strategy this study splits into two specific objectives:

- Comparison of criteria pollutants mainly Total Hydrocarbon (THC) and NOx emissions using PEMS and FTIR against a laboratory grade CVS system.

- Perform an assessment of different exhaust compositions based on driving routes pertaining to diesel and natural gas engines on PEMS and FTIR measurement of THC and NOx. 


\section{Literature Review}

There are different agencies around the world engaged in regulating vehicle emissions. In the United States, EPA is the main body regulating emissions standards. Certain states have their own stricter standards depending on various factors like vehicle population, geographic location etc. California is one of the states that has the strictest emissions regulations, which are enforced by CARB (Riddle 2001).

\subsection{Emissions Standards}

Emissions standards are a set of regulations issued by a government body to limit the pollutants in a vehicle's exhaust released into the environment. "Standards generally regulate the emissions of NOx, PM or soot, $\mathrm{CO}$, or volatile hydrocarbons. The main components of automobile exhaust, $\mathrm{CO}, \mathrm{CO}_{2}, \mathrm{NOx}$, and THC have so far been regulated by emission standards by EPA, and the European Union is moving towards mandatory $\mathrm{CO}_{2}$ standards which EPA has reflected in Greenhouse Gas Score” (US EPA 2016). The greenhouse gases (GHGs) are mandated by USEPA and will take into effect for 2017 and later MY engines.

\subsubsection{Consent Decrees}

Consent Decrees were issued in the late 1990's, because most of the heavy duty diesel engines produced before did not meet the NOx emission standards during on-road testing (Riddle 2001). Engine manufacturers were programming the ECU to get a high performance out of the engine in a steady-state condition, which could not be achieved without increasing the tail pipe emissions. This led to the signing of Consent Decrees where S-HDDE (Settling Heavy-Duty Diesel Engine) manufactures were required to provide funding for emission reduction in the future and were required to meet emissions standards for engines by 2004 (US EPA 2007). Consent Decrees are a set of rules which came from the court settlement between engine manufactures (Caterpillar 
Inc., Cummins Engine Company, Volvo Truck Corp., Detroit Diesel Corporation, International Truck Co., Mack Trucks Inc.) and EPA, Department of Justice and CARB. In addition to Federal Test Procedure (FTP), Supplemental Emission Test (SET) and NTE limits were implemented. Most manufactures had to modify their engines to meet the new emissions standards.

The SET is implemented to control emissions from heavy-duty engines during a steadystate type driving. It is a 13-mode steady-state test based on the Euro-III cycle. NTE testing is used to quantify heavy-duty engine emissions over a range of speed and load combinations which is explained in section 2.2.2. This test was conducted for the area (NTE zone) under the torque curve of an engine where emissions were not to exceed a specified value for any of the regulated pollutants (see section 2.2) (US EPA 2007). “The NTE test procedure involves driving of any type that could occur within the bounds of the NTE control area, including operation under steady-state or transient conditions and under varying ambient conditions. Brake-specific emissions are integrated over a minimum time of thirty seconds and then compared to the applicable NTE emission limits" (US EPA 2007).

According to current federal requirements heavy-duty vehicles do not have to be chassis certified. Instead, engines must be tested and certified on an engine dynamometer. For the certification, an engine must be tested over a Transient FTP dynamometer cycle and emissions should be expressed in g/bhp-hr (US EPA 2007). Table 1 shows EPA emissions standards for heavy-duty truck engines and Table 2 shows California emissions standards for heavy-duty truck engines. Vehicles must meet these standards for a specified lifetime of a vehicle as shown in Table 3. 
Table 1: EPA emissions standards for heavy-duty engines over FTP in g/bhp-hr. (US EPA 2007)

\begin{tabular}{|c|c|c|c|c|}
\hline Model Year & NOx & THC & CO & PM \\
\hline 1990 & 6.0 & 1.3 & 15.5 & 0.60 \\
\hline $1991-1993$ & 5.0 & 1.3 & 15.5 & 0.25 \\
\hline $1994-1997$ & 5.0 & 1.3 & 15.5 & 0.10 \\
\hline $1998-2003$ & 4.0 & 1.3 & 15.5 & 0.10 \\
\hline $2004-2007$ & 2.4 & 1.3 & 15.5 & 0.10 \\
\hline $2007-2010$ & 1.2 & 1.3 & 15.5 & 0.01 \\
\hline $2010-1$ later & 0.2 & 1.3 & 15.5 & 0.01 \\
\hline
\end{tabular}

Table 2: California emissions standards for heavy-duty engines over FTP in g/bhp-hr. (US EPA 2007)

\begin{tabular}{|l|c|c|c|c|c|}
\hline Model Year & NOx & THC & NMHC & CO & PM \\
\hline $1987-1990$ & 6.0 & 1.3 & - & 15.5 & 0.60 \\
\hline $1991-1993$ & 5.0 & 1.3 & 1.2 & 15.5 & 0.25 \\
\hline $1994-2003$ & 5.0 & 1.3 & 1.2 & 15.5 & 0.10 \\
\hline $2004-2007$ & 2.4 & 1.3 & - & 15.5 & 0.10 \\
\hline $2007-2010$ & 1.2 & 1.3 & 0.14 & 15.5 & 0.01 \\
\hline $2010-$ later & 0.2 & 1.3 & 0.14 & 15.5 & 0.01 \\
\hline
\end{tabular}

Table 3: Current EPA specified lifetime for heavy-duty truck engines. (US EPA 2007)

\begin{tabular}{|c|l|}
\hline Heavy-Duty Sub Class & \multicolumn{1}{|c|}{ EPA Specified Lifetime } \\
\hline Light & 10 years or 110,000 miles, whichever comes first \\
\hline Medium & 10 years or 185,000 miles, whichever comes first \\
\hline Heavy & 10 years or 435,000 miles, whichever comes first \\
\hline
\end{tabular}




\subsubsection{Model Year 2004 Standards}

From model year 2004 and later, EPA had new regulations for heavy-duty truck engine emissions. EPA required engine manufactures to maintain the level of NOx emissions at 2.0g/bhphr. Manufacturers had two options for the engine certification. Option one was to maintain NonMethane Hydrocarbons (NMHC) and NOx at a level of 2.4g/bhp-hr. The second option was to maintain NMHC at $0.5 \mathrm{~g} / \mathrm{bhp}-\mathrm{hr}$ while both NOx and NMHC could be at a level of $2.5 \mathrm{~g} / \mathrm{bhp}-\mathrm{hr}$. All the other emissions standards would continue per the 1998 agreement. The California standards were harmonized with the 2004 Federal standards except that engines had to go through SET and NTE limits of 1.5 times the FTP standards for California standards.

\subsubsection{Model Year 2007 and Later Standards}

EPA signed new emissions standards for model year 2007 engines and later, in December 2000 (US EPA 2007). "Emission certification requirements also include the SET test, with limits equal to the FTP standards, and NTE limits of $1.5 \times$ FTP standards" (US EPA 2007). In the 2007 the emissions standards, crankcase emissions must be considered as other exhaust emissions. Therefore, engine manufactures were required to route crankcase emissions back to the engine. Per the new regulations, the current HDDE emissions standards are as below:

Table 4: Current emissions standards for heavy-duty engines over FTP cycle. (US EPA 2007), (US EPA 2016)

\begin{tabular}{|c|c|}
\hline Constituents & Brake specific Values \\
\hline NOx & $0.2 \mathrm{~g} / \mathrm{bhp}-\mathrm{hr}$ \\
\hline $\mathrm{HC}$ & $1.3 \mathrm{~g} / \mathrm{bhp}-\mathrm{hr}$ \\
\hline NMHC & $0.14 \mathrm{~g} / \mathrm{bhp}-\mathrm{hr}$ \\
\hline $\mathrm{CO}$ & $15.5 \mathrm{~g} / \mathrm{bhp}-\mathrm{hr}$ \\
\hline $\mathrm{PM}$ & $0.01 \mathrm{~g} / \mathrm{bhp}-\mathrm{hr}$ \\
\hline $\mathrm{CO}_{2}$ & $460 \mathrm{~g} / \mathrm{bhp}-\mathrm{hr}^{1}$ \\
\hline
\end{tabular}

${ }^{1}$ Standard for MY 2017 tractor engines over SET test cycle. 


\subsection{PEMS Measurement Allowance}

In June 2003, the US EPA and Engine Manufacturers Association (EMA) agreed to an outline of a manufacturer operated in-use heavy-duty vehicle NTE testing program. This program was a result of a law suit filed by the EMA and other individual engine manufacturers against the EPA (US EPA, CARB and EMA 2005). The suit targeted the NTE emissions standards (US EPA, CARB and EMA 2005). The outline stated that the EPA, CARB, and EMA were to determine an emission accuracy margin for in-use PEMS. The need for this error band was expressed by the engine manufacturers before the in-use program becomes fully enforceable in 2007 . The in-use compliance program addressed problems encountered in using PEMS. Among the different lessons learned after the Mobile Emissions Measurement System (MEMS) system measurement campaign it was found that due to the use of either I/M or garage grade analyzers in PEMS devices the inuse emissions results were greatly influenced by the ambient conditions in which the emissions were measured along with other measurement biases when compared with laboratory-grade analyzers used for engine certification tests concurrent to 40 CFR Part 1065 measurement standards. The problems that were discussed in the program were a result of Memorandum of Agreement (MOA), which was signed by CARB, US EPA, and the heavy-duty engine companies. This led to the establishment of the PEMS measurement allowance program to determine an additive allowance to compensate for the errors in measuring emissions using PEMS. The program was a joint effort of US EPA, EMA, and the CARB. The additive measurement accuracy margin was determined experimentally using the Semtech-D PEMS device in comparison to laboratorygrade emissions measurement facilities provided by Southwest research institute (SwRI) (US EPA, CARB and EMA 2005). 
The main objective of the measurement allowance program was to experimentally determine and validate the additive accuracy margin to be used for in-use emissions compliance testing of heavy-duty vehicles using PEMS. Additionally, this program also served in standardizing the error in measuring emissions between the PEMS device and laboratory-grade emissions analyzer while promoting further development of PEMS to reduce the error margin. The measurement allowance program was conducted in three phases to determine the accuracy margin for gaseous emissions. The three phases involved laboratory evaluations of PEMS, statistical modeling and simulation of error propagation, and the final phase of model validation with in-use emissions results and determination of the final accuracy margin value. Laboratory evaluation of PEMS was conducted by comparing the results with test cell emissions measurement devices by running emissions certification tests in the laboratory. Furthermore, the PEMS device was subjected to environmental testing by placing the device in an environmental chamber that is capable of varying the temperature, pressure, electromagnetic radiation, background hydrocarbon levels, humidity and also inducing vibrations while measuring emissions from an engine and comparing the results with laboratory analyzers that are maintained under stable environmental conditions to study the influence of environmental conditions on the measurement accuracy of PEMS. Some of the major factors affecting PEMS instrumentation are explained in section 2.5 of this document. The statistical modeling and simulation of the error propagation involved modeling the error in emissions measurement between PEMS and laboratory analyzers for different factors and implementing the Monte Carlo technique to randomly select various sources of PEMS measurement error, the result of which is used to determine the additive accuracy margin. The final phase of validating the error propagation model and determining the accuracy margin involved testing the PEMS device against laboratory-grade emissions analyzer placed in a 
container which in-turn is transported on a regular class 8 tractor trailer powered by a heavy-duty diesel engine. The emissions from the in-use operation of the heavy-duty vehicle were simultaneously measured using the PEMS device and the laboratory-grade emissions analyzer and the difference between the measurements was validated against the statistical model to arrive at the final additive accuracy margin (US EPA 2008).

\subsubsection{Laboratory Evaluation of PEMS}

Laboratory evaluation of PEMS involved comparison of engine emissions measured using a commercial-grade PEMS device approved by the EPA for in-use emissions measurement with that of a laboratory-grade 40 CFR Part 1065 compliant emissions measuring equipment/facility. The error in measuring emissions between laboratory-grade emissions measuring equipment and PEMS were determined by running steady-state and transient engine tests in the prescribed NTE zone. The transient tests included a series of 30-second NTE events repeated several times in a random order. These experiments were conducted over three different engines belonging to MY 2005 and 2006, one Heavy Heavy-Duty (HHD) engine, one Medium Heavy-Duty (MHD) engine and one Light Heavy-Duty (LHD) engine while measuring emissions with three PEMS devices of the same type, simultaneously on each engine to capture the variability in the test articles as well as the unit-to-unit variability of PEMS. Note, that although test engines were pre-2007 MY engines, they were retrofitted with Johnson Matthey Continuously Regenerating Trap (CRT) particulate filters. The emissions measurement error between PEMS and laboratory-grade equipment determined in the tests above are paired for the given PEMS unit, test engine, steadystate test point, average emissions of a transient test mode, and other characteristics of the measuring equipment. Furthermore, the paired points of measurement errors are pooled together to develop error surfaces leading to an empirical relationship between different variables. An error 
surface can be visualized as a three-dimensional chart showing the error in measuring emissions or a factor used to quantify brake-specific emissions linked to the test condition. For example, the error in measuring NOx concentrations for steady-state tests is evaluated for a reference mean NOx concentration measured by the lab-grade analyzers. Note that the difference in the emissions between PEMS and the laboratory measurement is determined by subtracting laboratory results from PEMS values, and is referred as delta or error.

Laboratory evaluation of PEMS also included examining the influence of ambient conditions, in which a PEMS is operated on its measurement accuracy. This test was conducted by placing the PEMS in an environmental chamber where known gas concentration is measured while varying the temperature, pressure, humidity, and ambient hydrocarbon levels inside the chamber. Also, the influence of vibration and electromagnetic radiation on the measurement accuracy was quantified in a similar way. A total of 37 error surfaces were developed to be used in the statistical model to estimate the accuracy margin of PEMS emissions measurement. These error surfaces are classified broadly into six groups:

- Steady-State error surfaces - characterizes the precision and bias errors between PEMS and laboratory-grade emissions measurement system quantified over repeated steady-state engine tests.

- Transient error surfaces - characterizes only the precision errors between PEMS and reference emissions measurement method quantified over repeated transient testing of 30second NTE events. The order in which the NTE events were run in each repeat was also randomized. Transient error surfaces were generated for gaseous pollutants, exhaust flow rate as well as the dynamic errors in the Engine Control Module (ECM) broadcast signals such as engine speed, torque, and fueling rate. 
- Torque and Brake Specific Fuel Consumption (BSFC) error surfaces - since the brakespecific emissions determined by PEMS during in-use emissions measurement campaign are completely dependent on ECM broadcast, engine speed, and torque as well as quantifying emissions mass rate in the absence of exhaust flow meter depends on the fueling rate broadcasted by engine ECM, it becomes imperative to evaluate the accuracy of the ECM broadcasted parameters in reference to laboratory measurement system. These comparisons were performed using steady state tests in an engine dynamometer test cell capable of simulating various ambient conditions such as temperature, altitude, and humidity. Furthermore, the effect of fuel properties in predicting the engine torque and fueling rates were also quantified using three different fuels of varying properties representing a wide range of fuel being used in heavy-duty vehicles across the country.

- Exhaust Flow Measurement error surfaces - these error surfaces were generated by comparing the PEMS exhaust flow measurement values with laboratory reference flow meters using steady state tests in an engine dynamometer test cell. The error surfaces are generated by varying the measurement conditions such as the influence of wind speed downstream of the flow meter and increased backpressure upstream of the flow meter, as well as for different installation configurations including the optimum condition required for accurate flow measurement in addition to increased number of pipe bends upstream of the flow meter.

- Environmental Testing error surfaces - as PEMS is used to measure in-use emissions of heavy-duty diesel vehicles performing their intended activity, at various geographical locations over an eight-hour work day, it is subjected to different ambient operating conditions and other external factors such as vibration and electromagnetic radiation that 
could influence the emissions measurement accuracy. These sources of errors are characterized by configuring the PEMS to measure standard reference gases while subjecting it to environmental perturbations, such as temperature, pressure, humidity in an environmental chamber and quantifying the delta between PEMS measurement and the reference gas concentration being measured.

- Miscellaneous error surfaces - these error surfaces were generated using a diverse source of errors which includes time alignment of different emissions measurement data, PEMS unit-to-unit variability, engine production variability, etc. The error surfaces were developed using experimental data collected during the project as well as the engine manufacturer supplied data.

All the emissions error surfaces were generated using dilute laboratory measurements as the reference value. The laboratory reference values used for quantifying the delta of different PEMS measurement components required for quantifying brake-specific in-use emissions are summarized in Table 5. Laboratory evaluation of PEMS involved comprehensive auditing of the laboratory reference measurements as well as PEMS measurement system in accordance to 40 CFR part 1065 procedures as shown in Table 6. During the course of the laboratory evaluation of PEMS, there were several challenges in following the original test plan due to the fact that experimental results were different than anticipated leading to adaptation of the test plan to overcome these challenges. The change in the test plan along with decisions to include/exclude certain data points in the test results were made under the oversight of the steering committee. The steering committee was comprised of representatives from EPA, EMA, CARB and PEMS manufacturers (US EPA 2008). 
Table 5: Measurement Allowance Program - Laboratory Reference Methods. (US EPA 2008)

\begin{tabular}{|c|c|c|}
\hline PEMS Measurement & Laboratory Reference & Reference Method \\
\hline $\begin{array}{c}\text { Gaseous Analyzers - engine } \\
\text { testing }\end{array}$ & $\begin{array}{c}\text { Dilute Emission } \\
\text { Analyzers1 }\end{array}$ & $\begin{array}{c}\text { Dilute mass calculated using CVS flow, } \\
\text { then raw concentrations back-calculated } \\
\text { using laboratory raw exhaust flow }\end{array}$ \\
\hline Raw Exhaust Flow & $\begin{array}{c}\text { Measured Intake Air Flow } \\
\text { and Fuel Flow }\end{array}$ & $\begin{array}{c}\text { Air Flow measured using Laminar Flow } \\
\text { Element (LFE). }\end{array}$ \\
\hline Predicted Torque (from CAN) & Measured Torque & Shaft mounted in-line torque meter \\
\hline $\begin{array}{c}\text { Predicted BSFC (from CAN) } \\
\text { Gaseous Analyzers - } \\
\text { environmental chamber testing }\end{array}$ & $\begin{array}{c}\text { Measured Fuel flow and } \\
\text { power }\end{array}$ & $\begin{array}{c}\text { Fuel Flow measured using Coriolis type } \\
\text { meter. }\end{array}$ \\
\hline
\end{tabular}

${ }^{1}$ Reference non-methane hydrocarbon (NMHC) levels were based on laboratory raw measurements due to very low levels.

Table 6: Measurement Allowance Program - 1065 Lab \& PEMS Audit Tests. (Feist, Sharp and Spears 2009)

\begin{tabular}{|c|c|c|c|c|}
\hline Description & CFR Reference & Lab Raw & Lab Dilute & PEMS \\
\hline Linearity & 1065.307 & $\mathrm{x}^{1}$ & $x^{1}$ & $x^{2}$ \\
\hline Torque Meter & 1065.310 & $\mathrm{x}$ & $\mathrm{X}$ & \\
\hline Fuel Flow & 1065.320 & $\mathrm{x}$ & & \\
\hline Intake Flow & 1065.325 & $\mathrm{X}$ & & \\
\hline Exhaust Flow & 1065.330 & $\mathrm{x}$ & & \\
\hline CVS Verification & 1065.341 & & & $\mathrm{x}$ \\
\hline $\mathrm{H}_{2} \mathrm{O}$ Interference on $\mathrm{CO}_{2}$ & 1065.350 & & $\mathrm{x}$ & \\
\hline $\mathrm{H}_{2} \mathrm{O}$ and $\mathrm{CO}_{2}$ Interference on $\mathrm{CO}$ & 1065.355 & $\mathrm{x}$ & $\mathrm{x}$ & $\mathrm{x}$ \\
\hline FID Optimization & 1065.360 & $\mathrm{x}$ & $\mathrm{X}$ & $\mathrm{x}$ \\
\hline Non-stoichiometric raw FID $\mathrm{O}_{2}$ Interference & 1065.362 & $\mathrm{x}^{3}$ & $\mathrm{x}^{3}$ & $\mathrm{x}^{3}$ \\
\hline Non-methane cutter penetration fractions & 1065.365 & $\mathrm{x}$ & & $\mathrm{x}$ \\
\hline $\mathrm{CLD} \mathrm{H}_{2} \mathrm{O}$ and $\mathrm{CO}_{2}$ quench & 1065.370 & $\mathrm{x}$ & $\mathrm{X}$ & \\
\hline NDUV $\mathrm{HC}$ and $\mathrm{H}_{2} \mathrm{O}$ Interference & 1065.372 & & & $\mathrm{x}$ \\
\hline Chiller $\mathrm{NO}_{2}$ penetration & 1065.376 & & & $\mathrm{x}$ \\
\hline $\mathrm{NO}_{2}$-to-NO converter check & 1065.378 & $\mathrm{X}$ & $\mathrm{X}$ & \\
\hline
\end{tabular}

${ }^{1}$ Linearity for laboratory on gas analyzers, flow meters, torque meter, pressures, temperatures.

${ }^{2}$ Linearity for PEMS on gas analyzers, exhaust flow meters.

${ }^{3}$ Verify methane response factors only, THC instruments. 
In conclusion to the laboratory evaluation of the PEMS, it was found those PEMS measurement errors in reference to the laboratory measurement were inconclusive as it did not follow any trend for most of the key measurement parameters. These manifested in the form of abrupt changes in error magnitudes at similar reference levels over three different engines. The data used to generate error surface for NMHC and CO emissions were collected over a narrow range of engine operation as their values were close to the detection limit of the PEMS analyzers due to the use of after treatment device to reduce PM. The environmental chamber testing of PEMS also resulted in inconclusive data due to functional failure of the testing; or the observed effects were small relative to other error sources. Hence, environmental test data had a negligible effect in calculating the final measurement allowance.

\subsubsection{Statistical Modeling and Simulation of Error Propagation}

As per the test plan, 35 error surfaces representing steady-state test precision and bias errors, transient test precision errors of brake specific-emissions using PEMS in relation to laboratory reference standards including the error in measuring reference emissions concentrations under the influence varying environmental conditions in which a PEMS device operates was determined in the aforementioned laboratory evaluation of PEMS. In addition to the 35 error surfaces, two more error surfaces representing the effect of time misalignment of emissions concentration with exhaust flow values and ECM torque and speed signals were also considered as a potential source of error leading to a total of 37 sources of error. Note that the time alignment error was not considered as an additive error like other error sources; instead it is used as a multiplicative adjustment factor and applied to the brake-specific emissions results after all other error terms are added to the result. The Monte Carlo simulation method was chosen to determine the incremental error in measuring brake-specific emissions using PEMS in reference to 
laboratory-grade measuring equipment because it would have been prohibitively expensive in terms of time as well as resources to determine the same using experimental method. The experimental method of determining measurement allowance would have involved quantifying the error in quantifying brake-specific emissions using PEMS against a mobile laboratory standard reference method on a large number of vehicles. Furthermore, the Monte Carlo simulation method allows for random selection of error sources resulting in a normal distribution of brake-specific emissions differences in reference to the ideal brake-specific emissions quantified using the laboratory reference method. During the program of determining the measurement allowance for in-use emissions measurement, it was recognized that the in-use brake-specific emissions could be calculated using one of the three different methods. The three methods used to quantify in-use brake specific emissions using PEMS include direct measurement of emissions concentrations, exhaust flow using a flow meter, and engine brake torque and speed using either inline sensors or ECM broadcast values.

Method 1 referred to as "Torque-Speed" method uses exhaust flow values and ECM broadcast torque and speed values to quantify brake-specific emissions. Method 2 involves the use of brake-specific fuel consumption values along with carbon balance of the fuel to determine the engine work instead of engine speed and torque; it is referred to as "BSFC" method. This method requires the exhaust flow meter values to be linear with engine load. In Method 3, the in-use brakespecific emissions are determined completely based on ECM signals and do not have the influence of exhaust flow meter error; it is referred to as the "ECM Fuel Specific" method. The general equations used to calculate brake-specific emissions in the above three methods are illustrated in the following equations: 


\section{Method 1:}

$$
\text { eemissions }=\frac{M_{x} \cdot \sum_{i=1}^{N} x_{i .} n_{i . \Delta t}}{\sum_{i=1}^{N} \frac{2 \prod N T}{60.3600} \cdot \Delta t}
$$

\section{Method 2:}

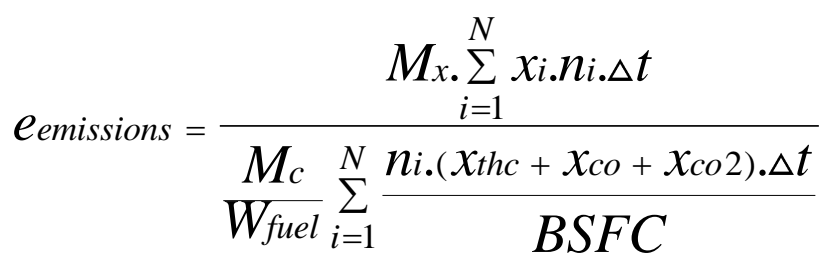

\section{Method 3:}

$$
e_{\text {emissions }}=\frac{\frac{M_{x} . W_{\text {fuel }}}{M_{c}} \sum_{i=1}^{N} \frac{x_{i . m_{\text {fueli }}}}{\left(x_{\text {thc }}+x_{\text {co }}+x_{\text {co } 2)} . \Delta t\right.}}{\sum_{i=1}^{N} \frac{2 \prod N T}{60.3600} . \Delta t}
$$

Eq. (3)

The Monte Carlo simulation results were based on emissions values and operating data of reference NTE events to which the additive measurement errors are applied randomly from the repository of experimentally determined empirical error models or surfaces. The simulation is repeated up to 30,000 times for each reference NTE event applying measurement error values to the brake-specific (BS) emissions determined using laboratory measurement standards referred to as "ideal" BS emissions. The ideal BS emissions after applying errors are referred to as BS emissions "with errors." The simulation was run for 195 reference NTE events that were sourced from transient lab experiments run at SwRI for the measurement allowance program, pre-pilot inuse emissions measurements data, and the experimental data provided by the five settling engine 
manufacturers. The determination of measurement allowance and other aspects of the simulation such as convergence, elimination of simulation results due to drift etc. were based on the BS emissions threshold values of each pollutant. To deal with the uncertainty regarding the allowed specific accuracy margins for the in-use testing program with the PEMS instruments used during the test program as PEMS were not rigorously tested, EPA promulgated interim accuracy allowances for use during the pilot programs. The interim values represent the upper boundary of the possible instrumentation variability. The interim additive accuracy margins for the pilot test programs were NMHC $=0.17 \mathrm{~g} / \mathrm{bhp}-\mathrm{hr}, \mathrm{NOx}=0.50 \mathrm{~g} / \mathrm{bhp}-\mathrm{hr}, \mathrm{CO}=0.60 \mathrm{~g} / \mathrm{bhp}-\mathrm{hr}$ and $\mathrm{PM}=0.10$ g/bhp-hr (US EPA 2008). More details in relation to the development of simulation model, convergence criteria, periodic drift check criteria, etc. are detailed in the final report of measurement allowance program or the reference (Buckingham, Mason and Spears 2009).

Monte Carlo simulation runs to produce BS emissions with errors for 195 reference NTE events for regulated emissions based on three different calculation methods resulted in nine distributions of $95^{\text {th }}$ percentile delta or error in emissions using PEMS with reference to laboratory measurement standards. One measurement allowance is determined per distribution resulting in three measurement allowance values for each pollutant for each emissions calculations method. The measurement allowance is determined either by using the regression or median method. Regression method involves correlation of the 95th percentile difference with the ideal emissions values of the reference NTE events. The $\mathrm{R}^{2}$ and root mean squared error (RMSE) value of the regression model should be greater than 0.90 and less than $5 \%$ of the median ideal emissions results respectively in order to use regression method for determining the measurement allowance value. Whereas, in the median method the median value of the 95th percentile delta from 195 reference NTE events is considered as the measurement allowance for the given emissions constituent and 
calculation method. Therefore, Monte Carlo methodology of error simulation based on assorted sources of errors resulted in nine measurement allowance values, corresponding to each pollutant and calculation methods. To determine the final additive measurement allowance for each pollutant the maximum error (in percent) based on the calculation method for each pollutant is multiplied with the corresponding threshold value to result in actual measurement allowance in engineering units. The percent measurement values for each pollutant and the calculation method along with the final values for each pollutant are shown in Table 7 . The final measurement allowance is based on the Method 1 calculation as it was the only method which was validated during the experimental validation of the simulation results.

Table 7: Measurement accuracy margins for gaseous emissions using PEMS testing. (US EPA 2008)

\begin{tabular}{|c|c|c|c|c|c|}
\hline \multirow{2}{*}{ Pollutant } & $\begin{array}{c}\text { Method - 1 } \\
\text { (\% Threshold) }\end{array}$ & $\begin{array}{c}\text { Method - 2 } \\
\text { (\% Threshold })\end{array}$ & $\begin{array}{c}\text { Method - 3 } \\
\text { (\% Threshold) }\end{array}$ & \multicolumn{2}{|c|}{$\begin{array}{c}\text { Accuracy margins } \\
\text { (g/bhp-hr) }\end{array}$} \\
\cline { 2 - 6 } & Torque-Speed & BSFC & $\begin{array}{c}\text { MY } \\
\text { ECM Fuel } \\
\text { Specific } \\
\text { 2007- '09 } \\
\text { engines }\end{array}$ & $\begin{array}{c}\text { MY } 2010 \\
\text { and later } \\
\text { engines }\end{array}$ \\
\hline NMHC & 22.30 & 4.45 & 6.61 & 0.02 & 0.01 \\
\hline CO & 10.08 & 8.03 & 8.44 & 0.5 & 0.25 \\
\hline NOx & 2.58 & 1.99 & 2.11 & 0.45 & 0.15 \\
\hline NOx + NMHC & 24.88 & 6.44 & 8.72 & 0.47 & - \\
\hline
\end{tabular}

\subsubsection{Validation of Measurement Allowance Model Simulation Results}

The final goal of the Monte Carlo simulation, the validation of measurement allowance results, was to experimentally verify the error in measuring in-use emissions using PEMS with reference to a mobile laboratory measurement standard such that it is below 95 and above 5 percentiles of the measurement allowance values of the simulation results for the corresponding calculation methods. CE-CERT's Mobile 
Emissions Laboratory (MEL) facility was chosen to be the in-use laboratory standard to validate the measurement allowance simulation results. The MEL comprises a trailer equipped with full-flow CVS dilution tunnel whose samples are analyzed using laboratory-grade analyzers. The tractor trailer, who's inuse emissions must be quantified, is driven in specified routes to yield a considerable number of NTE events while measuring emissions simultaneously using a PEMS device. The delta between the PEMS and MEL measurements lies within the range of delta determined by the simulation model, and then the simulation results are validated experimentally. Before using the MEL for validating the Monte Carlo simulation results, it was correlated with the SwRI test cell measurements, which were used to generate the error surfaces used in the simulation model. The correlation of MEL and SwRI lab was performed using a heavy heavy-duty 14 -liter DDC S60 engine by measuring both steady state and transient emissions separately by the two laboratories; the exhaust system was configured to switch between SwRI and MEL CVS tunnel, which was parked close to the test cell. The correlation work was carried out three days by running both steady-state and specially created transient NTE cycle in triplicates between the two facilities. The transient NTE cycle included a set of 30 short NTE events mixed with short periods of light load operation outside the NTE zone. The test results showed that the two laboratories correlated within $2 \%$ of NOx emissions.

The on-road validation of the model results was conducted using a test truck provided by Caterpillar, Inc. The test vehicle emissions were measured simultaneously by CE-CERT's MEL and one of the PEMS devices used for laboratory evaluation. The on-road testing was conducted over a period of nine days on different routes representing a wide variety of driving conditions and potential PEMS measurement noise factors. The vehicle emissions were measured by installing the PEMS in the truck cab as well as on the truck frame to study the influence of different ambient operating conditions on the measurement accuracy. A total of 429 NTE events were recorded during the nine-day test campaign, of which 100 NTE events were chosen for model validation purposes. The down sampling of NTE events were done to equally weigh and evenly represent the NTE events recorded with PEMS devices being mounted in the cab and on the truck frame, and all the operating conditions of the vehicle as well as the ambient conditions in which the NTE events were generated respectively. Furthermore, down sampling also addressed the biasing error 
when comparing the field data to model results as some test routes resulted in more NTE events than others, when recorded at similar ambient conditions. In order to validate the model results with the experimental in-use emissions data, some of the error surfaces were excluded in the Monte Carlo error validation model as they were not recorded during on-road comparison of PEMS and laboratory reference emissions measurement systems. The excluded error surfaces were mainly Torque and BSFC error surfaces and the transient dynamic error surfaces used in capturing the variance between the ECM broadcast speed and fueling rate, since it is cumbersome and difficult to measure engine torque and fueling rate using laboratory reference measurement system while measuring in-use emissions. The BS emissions were generated by the model by disregarding the ECM vs. laboratory measurement error surfaces. This is referred to as the "BS emissions with validation error." The Delta BS emissions are generated based on Eq. (4) with respect to ideal emissions measured in the laboratory and are used to compare the delta BS emissions calculated between PEMS and the CE-CERT MEL's reference emissions measurement system to validate the model. All the three methods of determining BS emissions for all regulated emissions are validated in the aforementioned way.

$\Delta B$ Semissions $=$ BSemissions with validationerror - Ideal BSemissions

Eq. (4)

$\triangle B$ Semissions $=$ PEMS BSemissions - CECERT MEL BSemissions

Eq. (5)

The 5th and 95th percentile delta BS emissions values is determined based on 195 reference NTE events using the validation model and they are arranged from smallest to highest for each emission constituent and the corresponding calculation method to form an empirical distribution function $(\mathrm{EDF})$. The region between the 5th percentile and 95th percentile EDF serves as the validation region for the Monte Carlo model using experimental data. The delta error in measuring BS emissions using PEMS is validated if $90 \%$ of the measurement error determined from the onroad experimental data lies between the 5 th and 95 th percentile delta error derived from the Monte Carlo model for each emission constituent and the calculation method (Sharp et al. 2009). A 
summary of model validation results for each pollutant and corresponding calculation is illustrated in Table 8.

Table 8: Summary of Model Validation Results. (Buckingham, Mason and Spears 2009)

\begin{tabular}{|c|c|c|c|}
\hline $\begin{array}{c}\text { Pollutant (Brake- } \\
\text { Specific) }\end{array}$ & Method 1 (Torque-Speed) & Method 2 (BSFC) & $\begin{array}{c}\text { Method 3 (ECM Fuel } \\
\text { Specific) }\end{array}$ \\
\hline NOx & Yes & NO & No \\
\hline NMHC & Yes & Yes & Yes \\
\hline CO & No & No & No \\
\hline
\end{tabular}

It was found that delta error for NOx was validated only for Method 1 calculations, and $\mathrm{CO}$ emissions errors were not validated for any calculation method while NMHC emissions errors were validated for all three calculation methods. Therefore, the steering committee decided to use the measurement allowance determined based on Method 1 calculations as the final value since two of the regulated emissions experimental results validated the model. The lack of validation of $\mathrm{CO}$ emissions error derived by the model using experimental results was not considered critical since the $\mathrm{CO}$ emissions were close to noise levels due to the use of catalyzed DPFs. After the measurement allowance program, the final additive error margin for using PEMS to measure inuse emissions were given as the percentage value of the threshold emissions determined by the Monte Carlo simulation model based on the Method 1 BS emissions calculation method. The values are illustrated in Table 7. The Accuracy margins were split into two classes (Table 7) which have different accuracy margins for MY 2007-2009 and for MY 2010 and later engines (US EPA 2008). 


\subsubsection{EPA PEMS Measurement Allowance Testing Procedure}

The following guidelines are set forth by EPA when testing with PEMS instruments for measurement allowances against a laboratory grade CVS system (US EPA, CARB and EMA 2005):

- Measure raw as well as CVS-dilute emissions.

- Measure engine inlet airflow through use of LFE or equivalent method.

- Measure instantaneous fuel consumption and torque.

- Ensure purging of the DPF system as often as needed to ensure negligible impact on emissions variability.

- Capture ECM broadcast channels and other common diagnostic channels, as recommended by engine manufacturer(s), to ensure proper engine operation.

- Stabilization time $=120$ seconds. Data acquisition $=30$ seconds, after stabilization.

- Zero and span PEMS at beginning of day following manufacturer's guidelines. Do not re-span PEMS analyzers again during the day, unless PEMS manufacturer provides a way to do this automatically, so it is realistic with real-life in-use testing practices. Rezeroing should be allowed if and only if done automatically by the PEMS for the same reasons.

- Zero and spanning of the instrument laboratory analyzer can be repeated as often as

- laboratory common practices and re-start start-up process every day.

- Perform carbon balance checks on CVS emissions data to ensure data quality.

- Always power off PEMS equipment at end of each day.

Zeroing and spanning was performed in between tests on the PEMS, unlike the guideline stating this was to be done only once a day. This ensures repeatable data from test to test. 


\subsection{NTE Discussion}

Not-to-exceed testing procedures resulted from consent decrees between EPA and the six major engine manufacturers (Shade et al. 2008). The engine brake-specific emissions, when operating in this zone, must be lower than the in-use emissions standards, which are determined based on the engine certification standards and the method of in-use emissions measurement. The engine's lug curve determines its NTE zone and it is bounded by the following. Figure 1 below shows an NTE zone of an engine. The NTE zone is a region under the engine maximum torque curve (also known as lug curve) whose upper bounds are defined by the maximum torque curve and the lower bound by engine speed, torque, and power. Furthermore, the NTE zone is defined by the US EPA in consensus with the EMA as representing an area under the speed and torque curve where the engine operates the majority of the time and the steady state test modes of a SET, an emission compliance test introduced under the consent decrees. Once the NTE zone is defined for a given engine, a NTE operating point is validated against a set of common exclusions. The exclusions are based upon the ambient conditions in which a vehicle is operating, the technology used in an engine to meet engine certification standards, the amount of time an engine operates in the NTE zone consecutively, and any other engine manufacturer negotiated limited testing regions under the lug curve, including time-weighted limited testing regions (LTRs).

- Torque upper boundary - lug curve.

- Torque lower boundary $-30 \%$ of maximum torque.

- Engine speed lower limit - nlo $=$ lowest engine speed at $50 \%$ of maximum power.

- Engine speed upper limit $-\mathrm{nhi}=$ highest engine speed at $70 \%$ of maximum power.

- All engine speeds $15 \%$ above the European Stationary Cycle (ESC) speeds -

$$
\mathrm{n} 15=\text { nlo }+0.15 \times(\text { nhi }- \text { nlo })
$$


- Power Boundary -30\% maximum power.

When the engine is running in the described region the emissions are averaged over a 30 second period. Then these values are compared to FTP emissions levels that were found when the engine was certified. Engine compliance is determined by the pass ratio which is the ratio of compliant NTE events observed during the testing to the total NTE events observed. The compliant NTE events are defined as emissions levels not exceeding 1.25 times the respective engine family's emissions limit for Model Year (MY) 2004-2006 engines and 1.5 times the respective engine family's emissions limit for MY 2007 and later engines.

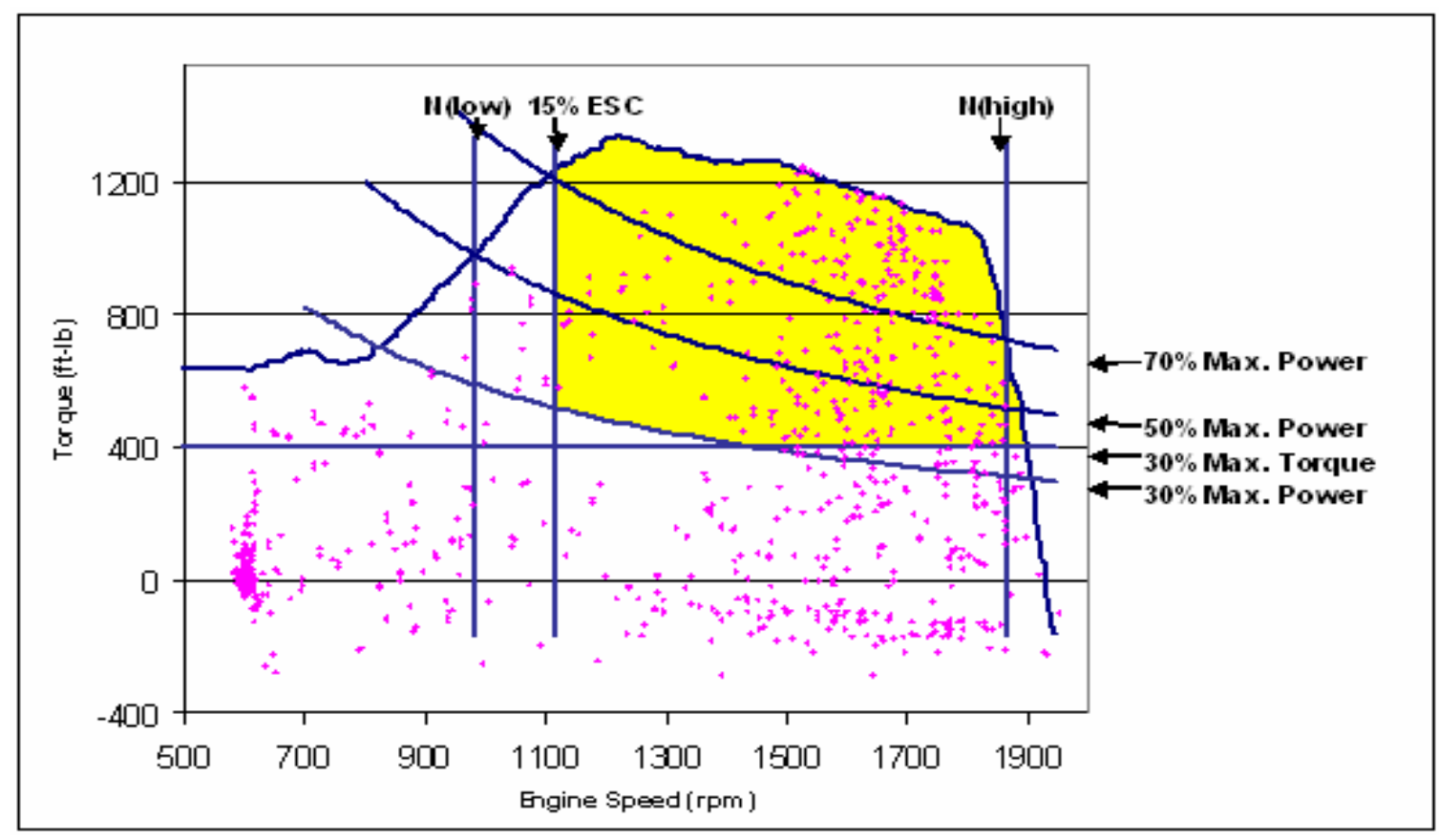

Figure 1. Engine operating points for FTP with NTE region. (Shade et al. 2008)

The driving conditions show an impact on engine emissions on NTE regions. Factors like after-treatment temperature plays an important role. Caterpillar and Bourns College of Engineering conducted a comparison study of commercial PEMS and the Mobile Emissions Laboratory on MY 2004 heavy-duty diesel truck in different heavy traffic driving conditions in California. They 
identified 17 NTE events during the study (Johnson et al. 2008). The NTE data was calculated using three different methodologies. The first method used reported speed and torque to determine emission factors. The second and third methods added the ratio of carbon balance fuel consumption divided by ECM fuel consumption. Method 2 uses the ratio in the denominator and vice-versa for Method 3. The brake specific NOx emissions relative to the NTE standard for the specific engine varied between 6 to $25 \%$ for method 1, 7 to $19 \%$ for method 2 and 7 to $19 \%$ for method 3 between the PEMS instrument and the Mobile Emissions Lab. The brake-specific NMHC and CO emissions were very low relative to the in-use NTE standards (Johnson et al. 2008). WVU conducted tests on 170 different vehicles between 1999 and 2006 over different specified routes. The vehicle emissions over 30 second NTE windows were measured (Thompson et al. 2008). Majority of the data is from Class 8 trucks and busses with engine rating between 150 to $600 \mathrm{hp}$. The emission results show that post Consent Decree engines have reduced brake-specific NOx emissions (Thompson et al. 2008). The study also showed that the 2003 and later model year engines tested have in-use brake-specific $\mathrm{NO}_{\mathrm{x}}$ values below the 30 second NTE window NOx standards in suburban and highway routes (Thompson et al. 2008).

Time-alignment of gaseous concentrations and the exhaust flow is important for accurate emissions calculation during NTE events. Misalignment of gaseous concentrations and the exhaust flow has shown to produce a difference of up to 11 percent for $\mathrm{CO}_{2}$ and 18 percent for NOx with shifts of 2 seconds (Bougher et al. 2010). Research has also showed that a little as 1 second shift can produce errors up to 5 percent for $\mathrm{CO}_{2}$ and NOx over a single NTE event (Bougher et al. 2010). 


\subsection{Previous In-use PEMS Measurement Systems}

A thorough review into literature about previous portable systems was conducted to understand different technologies that have been used. In-use emissions technique was available for long. In 1982, Caterpillar built a portable bag collection system to measure fuel specific $\mathrm{NO}_{\mathrm{x}}$ from diesel engines (Englund 1982). Ten years later in 1992, Southwest Research Institute created another integrated bag system that could measure undiluted $\mathrm{CO}$, $\mathrm{NOx}, \mathrm{CO}_{2}, \mathrm{O}_{2}$, and PM separately with a mini dilution tunnel. The drawbacks to this system were that it could only test vehicles with automatic transmissions, and it could not be used for continuous monitoring of emissions, since it used an integrated bag for sampling (Human and Ullman 1992).

Ford and General Motors(GM) came out with emissions measurement systems for gasoline engines. The GM system used a Horiba infrared-based analyzer for $\mathrm{CO}_{2}, \mathrm{HC}, \mathrm{CO}$, and $\mathrm{NO}$. Exhaust flow measurements were made with a Kurz flow meter (Kelly and Groblicki 1993). The Ford system measured $\mathrm{CO}_{2}, \mathrm{HC}$, $\mathrm{CO}$, and NOx. An infrared analyzer was used to measure concentrations of $\mathrm{CO}_{2}, \mathrm{HC}, \mathrm{CO}$, and $\mathrm{O}_{2}$, while a nondispersive ultraviolet detector was used for NOx. The Ford system was within 3\% difference for $\mathrm{CO}_{2}$, while the $\mathrm{NOx}$ measurement was $10 \%$ off of a laboratory grade analyzer (Kelly and Groblicki 1993).

Marine emissions were tested by the Coast Guard in 1997 using a system capable of measuring $\mathrm{CO}_{2}, \mathrm{HC}, \mathrm{CO}, \mathrm{NO}, \mathrm{NO}_{2}$, and $\mathrm{SO}_{2}$. A Short Ridge Instruments Electronic Flow hood provided airflow measurements (Bentz and Weaver 1994), (Bentz 1997).

In 1997 the University of Pittsburgh used an analyzer from OTC SPX to measure $\mathrm{CO}_{2}, \mathrm{HC}$, CO, NOx, and $\mathrm{O}_{2}$ from natural gas-fueled vans (Vojtisek-Lom and Cobb 1998). Exhaust flowrate came from ECM fuel and intake air flows. The same year, the Flemish Institute for Technological Research created a system to measure diluted emissions from gasoline and diesel-fueled vehicles. 
The system incorporated a non-dispersive infrared for $\mathrm{CO}$ and $\mathrm{CO}_{2}$, a heated flame ionization detector for $\mathrm{HC}$, and a chemiluminescent analyzer for $\mathrm{NOx}$. $\mathrm{NOx}$ and $\mathrm{CO}_{2}$ results were reported to be within $10 \%$ of a laboratory grade analyzer. A calculated exhaust flowrate came from ECM fuel, engine speed, and lambda values (Vojtisek-Lom and Cobb 1998).

The US EPA created a system called ROVER (Real-Time On-Road Emissions Recorder) in 1999. The system was capable of measuring $\mathrm{CO}_{2}, \mathrm{HC}, \mathrm{CO}, \mathrm{NO}$ using an Andros micro bench. The exhaust flowrate was measured using an Annubar differential pressure device.

Ford along with WPI-Microprocessor, Inc. created a new portable system called PREVIEW (Portable Real-Time Emission Vehicular Integrated Engineering Workstation). Ultraviolet and infrared-based analyzers were used to measure $\mathrm{CO}_{2}, \mathrm{HC}, \mathrm{CO}, \mathrm{NOx}$. Comparisons to lab grade analyzers were very good for $\mathrm{CO}_{2}$ and NOx (both less than $2 \%$ difference) (Butler et al. 1999).

In 2000, Horiba, Ltd. and NGK Insulators, Ltd. created an on-board system to measure NOx for diesel engines. The system used zirconium oxide sensors to measure NOx concentrations. Intake air was measured using a Karman vortex volumetric flowmeter. Results were favorable with NOx mass measurements within $4 \%$ agreement of the laboratory (Kihara et al. 2000).

Clean Air Technologies International, Inc. released an on-board mass exhaust measurement emissions monitoring system with $\mathrm{NO}_{\mathrm{x}}, \mathrm{CO}_{2}$, and qualitative PM abilities in 2001 (Vojtisek-Lom and Allsop 2001). A Non-Dispersive Infrared Detector (NDIR) analyzer was used for $\mathrm{HC}, \mathrm{CO}$, and $\mathrm{CO}_{2}$. Electrochemical cells were used for $\mathrm{NO}$ and $\mathrm{O}_{2}$. $\mathrm{NO}_{2}$ was estimated from $\mathrm{NO}$ measurements, knowing that $\mathrm{NO}_{2}$ comprises less than $5 \%$ of total $\mathrm{NOx}$ in non-after treatment equipped diesel engines. Flow and concentration alignment problems caused errors to be as high as $25 \%$ for $\mathrm{NO}$ and $\mathrm{CO}_{2}$. Exhaust flowrate was indirectly calculated using intake air and mass 
balance equations. Authors concluded that the use of a 'minimized' system sacrificed the accuracy (Vojtisek-Lom and Allsop 2001).

In 2001, Engine, Fuel, and Emissions Engineering, Inc. created a "Ride-Along Vehicle Emission Measurement" system. The system utilizes a partial flow dilution system capable of measuring $\mathrm{CO}, \mathrm{CO}_{2}$, NOx, and PM. NDIR detection was used for $\mathrm{CO}$ and $\mathrm{CO}_{2}$, while chemiluminescence was used for $\mathrm{NO}_{\mathrm{x}}$. Particulate matter was collected on a $37 \mathrm{~mm}$ filter. The system diluted a portion of the exhaust stream, as compared to a typical laboratory tunnel. Results for $\mathrm{CO}_{2}$ and NOx have been presented as system repeatability over a driving cycle within $6 \%$ and within 10\% for PM (Weaver and Balam-Almanza 2001).

In 2002, Horiba Instruments Inc. created an onboard system capable of measuring CO, $\mathrm{CO}_{2}, \mathrm{HC}$, and NOx. It utilized a static Pitot tube to provide a real-time measurement of the exhaust mass flowrate, which was related to mileage. A heated NDIR was used for $\mathrm{HC}, \mathrm{CO}$, and $\mathrm{CO}_{2}$, while NOx was measured with a zirconium oxide $\left(\mathrm{ZrO}_{2}\right)$ sensor. In 2004, the Horiba On-Board Measurement System (OBS 1000) was compared to the WVU's MEMS system and the WVU engine laboratory. The conclusions were that the NOx measurements were up to $11 \%$ different, $\mathrm{HC}$ were within $7 \%$ and $\mathrm{CO}_{2}$ concentrations were within $3 \%$ (Oestergaard et al. 2004).

In 2002 Sensors Inc. also unveiled their on-board emission system, the first generation SEMTECH. The following year, Sensors, Inc. announced a five-year cooperative agreement with Ford to develop the next generation SEMTECH-G and SEMTECH-D. SEMTECH-G was used for the gasoline vehicles, and the SEMTECH-D tested the diesel engines. The difference between the two systems was the measurement of $\mathrm{HC}$ and the exclusion of an $\mathrm{NO}_{2}$ measurement with the SEMTECH-G. The SEMTECH-G measures HC with NDIR, while the SEMTECH-D uses a Heated Flame Ionization Detector (HFID). 
In 2005, Horiba Instruments Inc. released a paper discussing the latest on-board system; the OBS 2200. The system used partial-vacuum FID, chemiluminescence detection, and NDIR analyzers (Akard et al. 2005). All analyzers were heated and placed upstream of the sample pump. The heated NDIR also measures water to quantify water interference with other analyzers. Exhaust flowrate measurement was achieved with a dual pressure transducer pitot tube system (Akard et al. 2005). It was concluded that this PEMS analyzers and flow meter meet the linearity check requirements (Akard et al. 2005).

In 2010, AVL created an onboard system, MOVE - 493 which is capable of measuring CO, $\mathrm{CO}_{2}, \mathrm{HC}$, and NOx. It utilized a static Pitot tube to provide a real-time measurement of the exhaust mass flowrate. A heated FID analyzer was used for THC emissions. The $\mathrm{NO} / \mathrm{NO}_{2}$ Measurement is carried out with an UV Analyzer, which can measure $\mathrm{NO}$ and $\mathrm{NO}_{2}$ simultaneously and directly without the need of any converter like a CLD analyzer. $\mathrm{CO}$, and $\mathrm{CO}_{2}$ was measured with a NDIR analyzer.

In 2014, Horiba created an onboard measurement system, OBS-ONE which is capable of measuring $\mathrm{CO}, \mathrm{CO}_{2}, \mathrm{HC}$, and $\mathrm{NOx}$ and $\mathrm{NO}_{2}$ for both light-duty (LD) and heavy-duty vehicles (HDVs). The FID is optional on fewer models typically used in HD applications. It utilized a static Pitot tube to provide a real-time measurement of the exhaust mass flowrate. A heated FID analyzer was used for THC emissions. The $\mathrm{NO} / \mathrm{NO}_{2}$ Measurement is carried out with a heated-dual CLD Analyzer, which can measure $\mathrm{NO}$ and $\mathrm{NO}_{\mathrm{X}}$ simultaneously $\mathrm{CO}$, and $\mathrm{CO}_{2}$ was measured with a heated NDIR analyzer. OBS-ONE is a wet measurement system. 


\subsection{Previous In-use FTIR Measurement Systems}

A thorough review into literature about previous FTIR systems was conducted to understand the evolvement of FTIR measurement systems and techniques in emissions measurement. FTIR was first proposed as a technique for the analysis of exhaust emissions in 1981. Optimized methods were developed by Nicolet and Volkswagen (1981-1985), which resulted in one-second time resolution for up to twenty different components (Dickerson, Delany and Wartburg 1984). In the year 1992, several researchers conducting catalyst studies have reported FTIR data for hydrocarbon and NOx speciation (Shore and deVries 1992).

(Roberts and Lowry 1994) used a Nicolet REGATM FTIR analyzer for determining NonMethane Organic Gases (NMOG) emissions to meet Reactivity Index (RI) specifications. The FTIR was configured with a 4-meter path length gas cell for raw exhaust measurements, where as a 10-meter path length gas cell was used for measuring dilute exhaust samples. The raw sampling apparatus was heated to $185^{\circ} \mathrm{C}$ to prevent condensation of water and heavier hydrocarbons. The dilute samples were conditioned to $100^{\circ} \mathrm{C}$. Test results revealed that in most cases FTIR could provide a good estimate of transient NMOG levels when combined with modal mass flow data.

(Lee et al. 1996) conducted a FTIR based study on the role of methane on catalytic conversion of NOx. Nicolet REGATM 7000 FTIR operating in the mid-IR range of the spectrum was used in this study. The study favored sampling of raw exhaust as opposed to dilute exhaust due to the improved response rate and sensitivity achieved with raw sampling Results showed that FTIR transient data matched extremely well with results obtained by standard modal analysis. It was noticed that for THC, FTIR identified more than $85 \%$ of the total detected by the FID. But, it was observed that the FTIR underestimated NOx during idling conditions. At conditions other than idling the discrepancies were found to be acceptably small. 
Research was conducted at Volkswagen AG, Germany (Baronick et al. 1998) towards developing a System for emission sampling and measurement. The system comprised of an FTIR and a gas flow measurement device was designed to measure the modal and integral mass emissions of about thirty different exhaust gas components. The study indicated that the FTIR equipment yielded results comparable to those obtained by conventional analyzers.

(Heller et al. 1990) worked towards developing an emission sampling and measurement system that would have a measuring sensitivity ranging from low concentrations of several parts per million to high levels of several percent. The FTIR was employed as a multicomponent gas analyzer designed to measure and calculate modal and integral concentration values of twenty-five different exhaust gas components and was fitted with a simplified sampling unit. Researchers determined that the relationship between sample and reference spectra was non-linear for $\mathrm{CO}$, $\mathrm{CO}_{2}$, and $\mathrm{NO}$; correction factors were devised by experimentally determining the specific correction curves. These correction curves were found to be influenced by parameters such as spectral resolution, signal to noise ratio interferences, and wide spread of concentration ranges influencing the detector signal. Researchers discovered very good conformity between the integrated system results and the CVS bag results for THC, $\mathrm{CO}$ and NOx within the standard deviation of the FTP results obtained by the conventional analyzers.

(Bianchi et al. 1991) used an FTIR in a laboratory scale procedure to measure the transient formation of Nitrous-oxide $\left(\mathrm{N}_{2} \mathrm{O}\right)$ and Nitrogen-dioxide $\left(\mathrm{NO}_{2}\right)$; their main concern was to circumvent the issue of synchronization associated with using multiple analyzers for measuring transient effects. The conclusions were that the FTIR could be used as a single detector for a laboratory scale analysis, and is capable of rapid quantitative measurement of polluting gases. 
Research conducted at Honda R\&D Americas, Inc. (Jetter et al. 2000) was directed towards acquiring accurate real-time, on-road data at concentrations below 1ppm and has facilitated a better understanding of the applicability of FTIR spectroscopy for emissions system development work. Initial research suggested that given the size and weight challenges of an on-board installation, the in-built 2-m gas cell would not achieve the target limit of detection of $0.1 \mathrm{ppm}$. It was replaced with a 10-m gas cell and an immediate improvement in sensitivity was observed and the temporal resolution produced was adequate for experimental work.

(Daham et al. 2005) developed an on-road in-vehicle emissions measurement technique utilizing a relatively new, commercial, portable FTIR Spectrometer capable of identifying and measuring (at approximately 3 second intervals) up to 51 different compounds. To validate the FTIR data, standard analyzers were operated simultaneously for comparison with the FTIR and the standard analyzer results showed that most pollutants $\left(\mathrm{NOx}, \mathrm{CO}_{2}, \mathrm{CO}\right)$ were within $\sim 10 \%$ of a standard analyzer during steady state conditions and within $20 \%$ during transients. The exception to this was total $\mathrm{HC}$ which was generally $50 \%$ or less than actual total $\mathrm{HC}$, but this was due to the limited number of hydrocarbons measured by the FTIR. In addition to the regulated emissions, five toxic hydrocarbon species were analyzed and found to be sensitive to cold starts in varying proportions.

FID response for ethanol was investigated and emission testing of an E85-fuelled FFV (Flex Fuel Vehicle) was conducted and evaluated against a FTIR (Sandstroem-Dahl et al. 2010). The ethanol emissions were analyzed with FTIR and sampled in impingers (standardized method approved in the USA). The acetaldehyde emissions were analyzed with FTIR and sampled in DNPH (2,4-dinitrophenyl hydrazine)-cartridges (standardized method approved in the USA). The FTIR showed that high levels of unburned ethanol were emitted during the cold start phase. The 
percentage distribution of some of the components included in the total hydrocarbons measured by the FID was investigated. The proportion of unburned ethanol increased at cold climate testing - from $24 \%$ at $+22^{\circ} \mathrm{C}$ up to $53 \%$ at $-7^{\circ} \mathrm{C}$.

(Hadavi et al. 2013) used an in-vehicle FTIR measurement system to quantify 30 different volatile organic compounds (VOCs). The results showed that compounds that formed ozone were significantly higher in diesel exhausts and were higher than equivalent compounds in SI vehicles under cold start in real world urban driving. For B100 aldehyde emissions were higher than for diesel and this is a strong ozone forming gas. However, other VOCs that form ozone were lower than diesel. The higher VOCs with diesel compared to SI engines was mainly due to the oxidation catalyst not being active for much of the journey, whereas in SI engines VOC emissions were only significant during the cold start period.

(Wright, Osborne and Music 2016) quantified Exhaust emissions of non-methane hydrocarbon and methane from a Tier 3 dual-fuel demonstration locomotive running diesel-natural gas blend. Measurements were performed with the typical FID method and with an alternative FTIR Spectroscopy method. In the dual fuel tests, the FTIR measurement was $1-4 \%$ higher than the FID measurement of NMHC results between the two methods differed considerably, in some cases reporting concentrations as much as four times those of the FID. However, the FTIR method has several advantages over the FID method, so the differences do not necessarily represent error in the FTIR. Specifically, the FTIR avoids the increased error propagation of the difference method, and can include formaldehyde which is not visible to the FID, and can provide more accurate molar masses to use when converting concentrations to masses. 


\subsection{Environmental Effects on PEMS}

Different environmental conditions like pressure, temperature, humidity, electromagnetic and radio frequency interference (EMI/RFI), shock and vibration have an effect on PEMS instruments. In a combined research conducted by SwRI, CARB and US EPA, (EMI/RFI) and vibrations caused instrument failures much more commonly than measurement inaccuracies (Buckingham, Mason and Spears 2009). There is no indication in literature studies of a significant effect in measurement errors causes by (EMI/RFI), shock and vibration (Feist, Sharp and Spears 2009).

EPA conducted serval tests on Semtech-DS in a controlled environmental box to see the effects of temperature on gaseous emissions from PEMS instruments on HDD engines. The effect of temperature is very minimal on $\mathrm{CO}$ and $\mathrm{CO}_{2}(0.1 \%$ and $0.5 \%$ respectively). NMHC emissions were about 7.5\% higher. NOx emissions varied by 3\% (Feist, Sharp and Spears 2009).

Several tests have been conducted by EPA on two Semtech-DS instruments to see the effects of ambient pressure on gaseous emissions from PEMS instruments. NMHC and CO varied up to $7.5 \%$ and $0.7 \%$ respectively with the variation of pressure during the testing. So, NMHC and $\mathrm{CO}$ pressure error surfaces were included in the model designed for the PEMS measurement allowance program. For $\mathrm{NOx}$ and $\mathrm{CO}_{2}$, no correlation could be made between the delta data and the pressure profile or between the instruments. Therefore, the $\mathrm{NOx}$ and $\mathrm{CO}_{2}$ deltas were not likely affected by the changes in ambient pressure, and were not included in the model (Feist, Sharp and Spears 2009). Most PEMS instruments actively compensate for the effect of pressure which is why there is no significant error in NOx measurement results.

Higher concentrations of ambient hydrocarbons tend to have a positive interference with PEMS FID response to varying levels and compositions of hydrocarbons in the ambient air. 
NMHC emissions varied by $10 \%$ due to the changes in ambient hydrocarbon levels (Feist, Sharp and Spears 2009). 


\subsection{Factors Affecting Heavy-Duty Vehicle Emissions}

There are many factors which affect heavy-duty engine emissions like vehicle class and weight, driving cycle, vehicle vocation, fuel type, engine exhaust after treatment, vehicle age, terrain traveled during testing and engine controls like injection timing. A few of them are discussed in this section.

Very little information in available in literature on the effects of vehicle class. Research by (Graboski et al. 1998) for the Northern Front Range Air Quality Study reported emissions testing on 21 different heavy-duty vehicles using 5 different test cycles. The research concluded that a heavier vehicle uses more fuel and, thus, produces more exhaust gas on a $\mathrm{g} / \mathrm{km}$ basis. It was also noted that, as a vehicle following a cycle used more fuel, higher emissions were produced in units of $\mathrm{g} / \mathrm{km}$ for that cycle.

Local driving activity also affects heavy vehicle emissions but is difficult to quantify. WVU conducted tests on two delivery company's' tractor trucks as the drivers performed their respective tasks. Based on the route, average speed the emissions from these trucks varied significantly by a margin of 7-9\% NOx in the research by WVU (Clark et al. 1999). This is very close to the definition of vehicle vocations and also has an impact on the discussion on test cycles. Local driving habits will also affect the vehicle emissions due to driver-to-driver variations. The effect that these factors have on vehicle emissions is comparable with the effect of different driving cycles that mimic the driving patterns or vehicle uses (Graboski et al. 1998). In this study the comparison of the two trucks are route specific to try and reduce the errors.

Fuels other than conventional diesel can provide a means of reducing heavy-duty engine emissions. Using a reformulated diesel or a diesel equivalent fuel that does not require engine 
modifications can produce significant reductions in engine emissions. Fuel reformulation would affect all heavy-duty diesel vehicles and has the potential to reduce NOx and PM significantly. Diesel fuel additives have also been used for reduction of emissions as shown by (Lange et al. 1997) and (Green et al. 1997). Transient engine tests performed at WVU using the Fisher-Trope fuel along with federal No. 2 and California No. 2 diesel show a decrease in THC emissions to as much as $65 \%$. The comparison showed a maximum decrease of $66 \%$ in PM emissions for the fuels tested relative to federal No. 2 diesel (Clark et al. 1999).

To quantify the effect of terrain grade on heavy-duty diesel emissions theoretical power can be determined. The power can then be related to the emissions rate for a particular vehicle from experimental brake-specific emissions data. (Delgado, Clark and Thompson 2011) plotted the relation between axle power and NOx emissions rates for some typical diesel vehicles to see the effect of terrain on emissions. The results show that for ascending a grade, because NOx emissions are often linear with power, the emission rate is the same. The nonlinearity for CO, PM and HC makes the results uncertain for these constituents.

Emissions of NOx and PM are known to be affected strongly by the timing of the incylinder fuel injection in diesel engines. The more advanced timing at the same speed and load leads to higher NOx and lower PM. Deviations in timing during off-cycle operation may lead to emissions of NOx that are higher than those that would occur during the certification test at the same engine speed and load. (Clark et al. 2002) showed that injection timing variances can increase NOx emissions by a factor of 2 depending on operating conditions. The extent to which off-cycle emissions affect the measured emissions is difficult to predict, because the frequency and duration of off-cycle operation are obscure. 


\section{Experimental Equipment Review and Procedures}

Transportable Emissions Measurement System (TEMS) is designed and build by WVU which focuses towards on-road emissions measurement of advanced heavy-duty engines (Wang et al. 2000). The system is comprised of a dual, full-scale dilution tunnels with analytical systems designed in accordance with 40 CFR Part 1065. The TEMS system provides transportable flexibility along with laboratory flexibility. WVU CAFEE's TEMS is a $30 \mathrm{ft} .(9.1 \mathrm{~m})$ long cargo container which houses a high efficiency particulate filter (HEPA) primary dilution unit, two primary full-flow dilution tunnels, a subsonic venturi, a secondary particulate matter sampling system, a computer-based data acquisition and control system, chassis dynamometer control system along with heating, ventilating and air conditioning (HVAC) system (Wang et al. 2000). The two primary dilution tunnels inside the container, of $0.46 \mathrm{~m}$ (18 inches) inner diameter and $6.1 \mathrm{~m}$ (20 feet) long, were designed to provide dedicated measurement capability for both low PM emissions ("clean") vehicles (with the upper tunnel referred as "clean tunnel"), as well as traditional diesel-fueled vehicles with high PM levels (lower tunnel referred as "dirty tunnel") (Wu et al. 2009). This provision reduces tunnel history effects between test programs of differing exhaust emission composition. A stainless-steel plenum box houses two HEPA filters for filtering primary dilution air, as well as twin dual-wall exhaust transfer inlet tubes dedicated as exhaust inlets for the upper and lower tunnels. The HEPA plenum is connected into the main dilution tunnels, which are selectively connected to the subsonic venturi via stainless elbow sections. The air compressor and two vacuum pumps are installed inside a noise isolating overhead. An air tank stores compressed air and provides shop air to the zero-air generator (a device that removes PM and THC) for instrumentation use. A PM sampling box for the secondary dilution tunnels is located alongside the primary tunnels, downstream of tunnels' sample zones. The secondary PM dilution 
tunnel of either the dirty or clean tunnel is connected to the PM sampling box for PM measurement during the test (Wu et al. 2009). Figure 3 shows the TEMS container on the transportation trailer while performing real-world emissions testing.

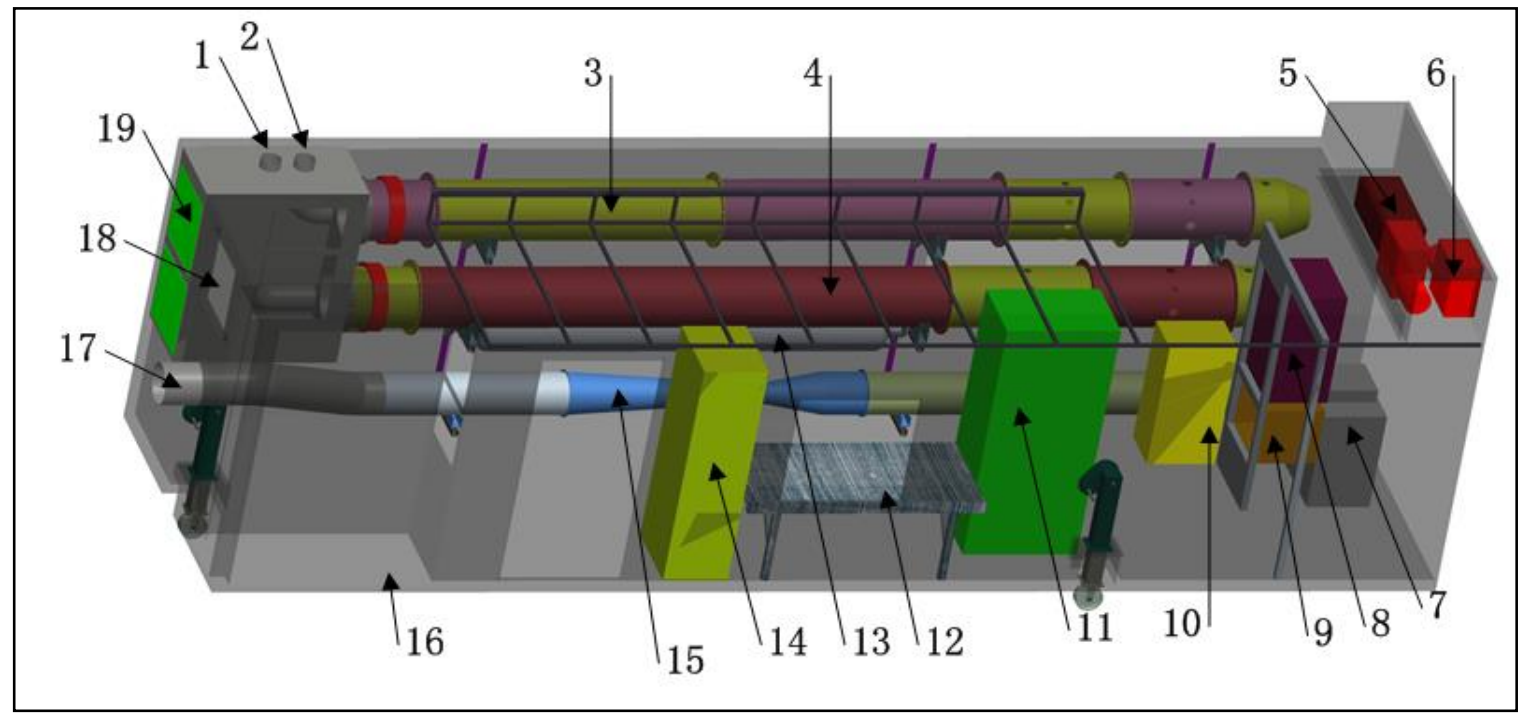

Figure 2: Schematic of the WVU TEMS. (Wu et al. 2009)

1- Exhaust inlet of dirty tunnel; 2- Exhaust inlet of clean tunnel; 3- Clean tunnel; 4- Dirty tunnel; 5Air compressor; 6- Vacuum pumps; 7- Oven; 8- PM sampling box; 9- Glove box; 10- Zero air generator; 11- MEXA-7200D motor exhaust gas analyzer; 12- Computer table; 13- Air tank; 14- DAQ rack; 15Subsonic venturi; 16- Air conditioner deck; 17- Outlet to blower; 18- Ventilation fan; 19- HEPA filters.

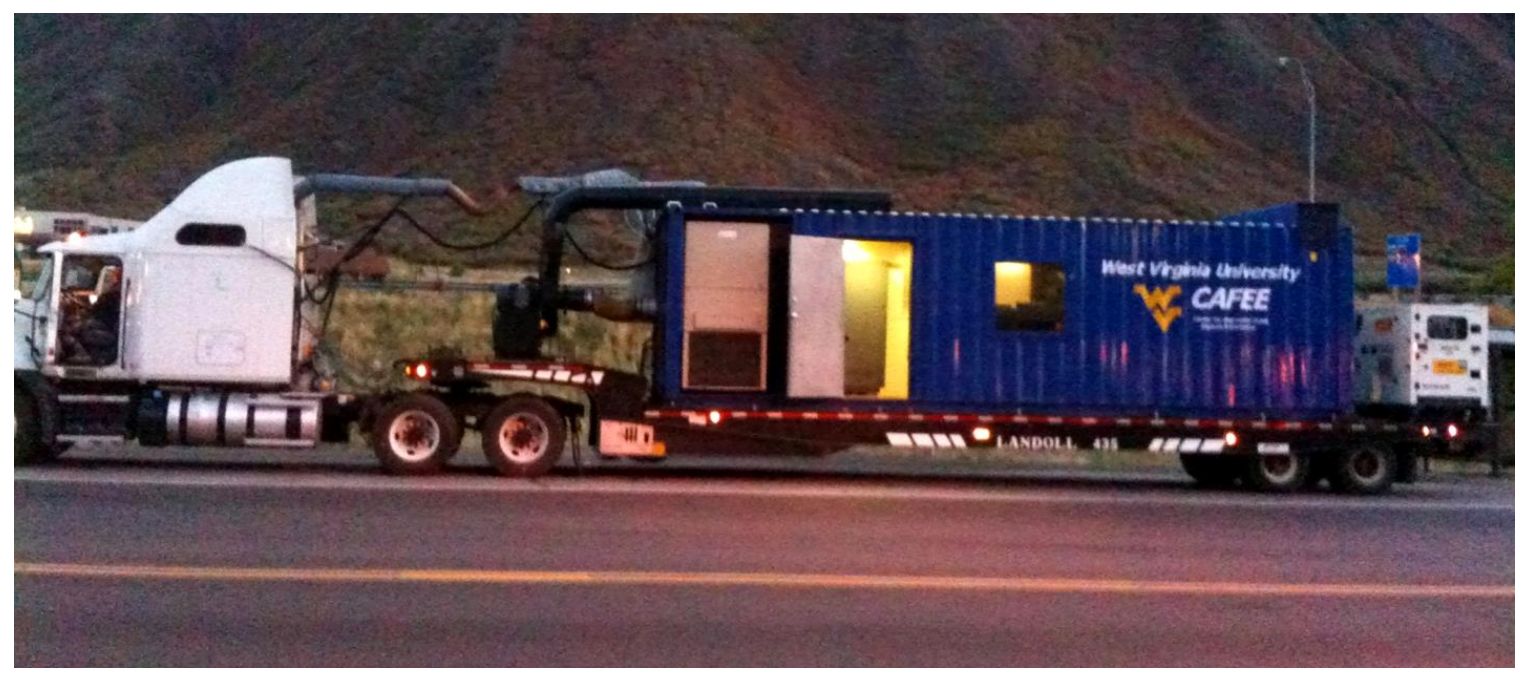

Figure 3: WVU TEMS performing real-world emissions testing. 


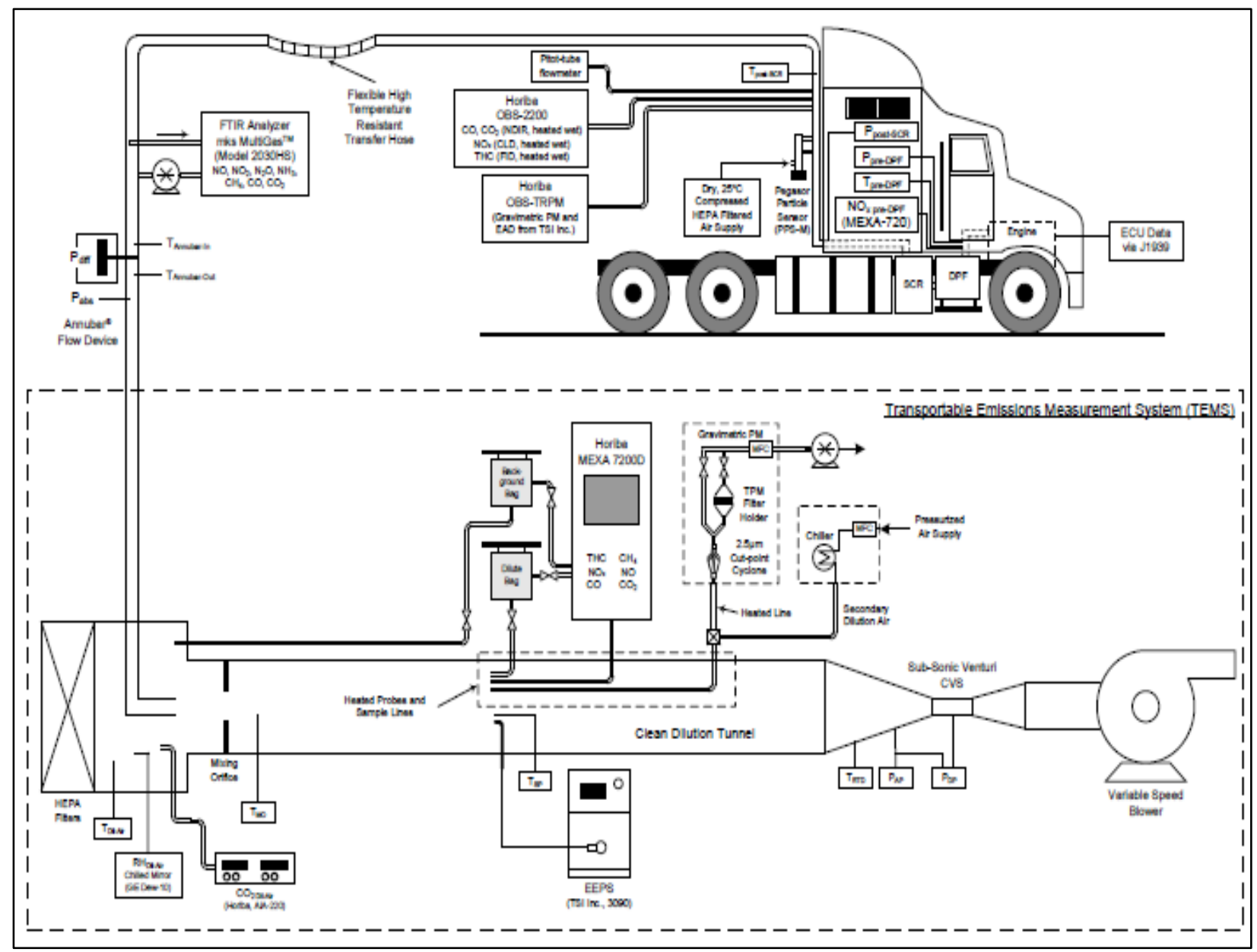

Figure 4: Schematic of CVS sampling setup for gaseous and PM sampling systems.

Figure 4 shows the detailed schematic configuration of the mobile laboratory, exhaust routing and instrument configuration. All test vehicles pulled the mobile laboratory, which was affixed to a flatbed trailer along with an on-board power generator, and other emissions measurement equipment. The mobile lab was equipped with a constant volume sampler (CVS), which was set to approximately $1800 \mathrm{ft}^{3} / \mathrm{min}$ (CFM), from which both gaseous and PM measurements were conducted. Raw exhaust was routed into the CVS of the mobile lab using a smooth walled flexible and insulated 5-in manifold. The laboratories CVS flow control is achieved through a subsonic venturi (SSV) and a variable speed blower. The flow rate of the SSV is calculated, in real time, using the equations in 40 CFR Part 1065.640 and 40 CFR Part 1065.642. HEPA filtered ambient air is used as the dilution air in the CVS. Ambient humidity and dew point 
are continuously monitored to calculate instantaneous NOx correction factors. Modal gaseous measurements were collected from diluted exhaust in the CVS using a MEXA-7200D (Horiba Ltd., Japan) laboratory grade bench analyzer reporting $\mathrm{CO}, \mathrm{CO}_{2}, \mathrm{THC}$ and $\mathrm{NOx}$ (Wu et al. 2009). All analyzer signals were post-processed per CFR guidelines for performing time alignment (1065.308), drift correction (1065.672), intake-air humidity NOx correction (1065.670), performing dry to-wet conversion of analyzers operating downstream of a chiller (1065.659), and for performing dilution air background correction (1065.667) CVS background-correction (Quiros et al. 2016). In addition to CVS the mobile lab also houses a MKS FTIR-2030 HS, Semtech-DS, OBS-2200, AVL MOVE-493 and TSI EEPS (Engine Exhaust Particulate Sizer). To address sampling losses and measurement artifacts the system is set up to sample raw exhaust directly from the exhaust stack for MKS FTIR-2030 HS, Semtech-DS, OBS-2200 and MOVE-493 analyzers. To prevent emissions like ammonia $\left(\mathrm{NH}_{3}\right)$ from dissolving in $\mathrm{H}_{2} \mathrm{O}$ and subsequently lead to irreversible sample losses, all the sample lines and sample conditioning components are maintained above dew point temperatures and controlled to about $191^{\circ} \mathrm{C}$ by means of Proportional Integral Derivative (PID) controllers. In this study, gaseous emissions data from FTIR-2030 HS and Semtech-DS are compared to CVS considering CVS as standard. The FTIR-2030 HS was chosen based on its operating principle, its capability to simultaneously measure NOx and THC in addition to most other gaseous components of diesel exhaust like $\mathrm{NH}_{3}$. Published literature and manufacturer specifications, which claimed high Minimum Detection Limits, and suitability for transient measurements also influenced the decision to select an FTIR as one of the instruments to be used in the study. On-road in-use emissions measured in this study are not representative of engine dynamometer cycles such as the FTP or SET, and when emissions exceed engine dynamometer certification limits, they still may be compliant with all relevant certification and in- 
use standards (Quiros et al. 2016). Still, engine emissions measured during on-road chassis-based operation are presented alongside engine certification standards to assess the relative levels of control achieved during on-road operation. Generally, on-road testing is critical to identify periods of inefficiency of emission control systems, as well as to better understand how chassis dynamometer testing can be improved to better represent on-road driving behavior. The first section of the chapter discusses in detail the operating principles, system components, and performance parameters of the three analyzers. The second section discusses the engine types and the test routes used in the study. 


\subsection{Component Description}

The following section describes the various analyzers' theory of operation, advantages and disadvantages.

\subsubsection{Fourier Transform Infrared Spectrometer (FTIR)}

Infrared Radiation: Infrared radiation (IR source) consists of a range of energy carrying rays, some of which can be detected, while the rest are invisible. Infrared (IR) radiation, which lies just beyond what the human eye can see, is an important component of the sun's invisible energy. IR, like visible radiation is a form of electromagnetic energy consisting of electric and magnetic fields that vibrate at right angles to each other. IR radiation, like other forms of electromagnetic radiation, has a unique property in that it is absorbed by some substances, reflected by some, and transmitted through the rest. The electromagnetic spectrum covers an immense range of wavelengths. The infrared regions are classified as follows:

$\begin{array}{ll}\text { Near Infrared } & \begin{array}{l}12,500 \text { to } 4,000 \mathrm{~cm}^{-1} \\ \text { Mid Infrared }\end{array} \\ \text { (0.8 to } 2.5 \mu \mathrm{m}) \\ \text { Far Infrared } & \text { (2.5 to } 50 \mu \mathrm{m}) \\ & 200 \text { to } 12.5 \mathrm{~cm}^{-1} \\ & (50 \text { to } 800 \mu \mathrm{m})\end{array}$

Most of the gaseous components in diesel and natural gas exhaust absorb in the mid infrared range $\left(4,000\right.$ to $\left.200 \mathrm{~cm}^{-1}\right)$ (Narasimhamurthy 2002).

Spectroscopy: The atoms in a molecule of any substance are perpetually vibrating. This could either be due to the vibrations of the chemical bonds holding the atoms together or due to the vibrations of the functional groups that make up the molecule. Each chemical bond or 
functional group requires a precise amount of energy to vibrate and this energy must be supplied to it in a single exchange. Each frequency of IR radiation provides energy in a precise amount. The molecule absorbs radiation if the frequency of the radiation provides energy in the specific amount required by one of the bonds or functional groups in the molecule. Furthermore, depending on the chemical make-up of any substance, that is, depending on the types of bonds or the chemical functional groups present in the substance, energy is absorbed at one or more specific frequencies (Narasimhamurthy 2002). For instance, an Ethyl Acetate molecule with its double bonds between Carbon and Oxygen atoms $(\mathrm{C}=\mathrm{O})$ absorbs energy at 1,750 wave numbers. Thus, if a substance sensitive to IR radiation were placed in the path of an IR beam, it would alter the make-up of the beam that is transmitted. Either the wavelength $(\mu \mathrm{m})$ or wave number $\left(\mathrm{cm}^{-1}\right)$ is used to measure the position of an infrared absorption. Any absorption band can be characterized by two parameters: the wavelength at which maximum absorption occurs and the intensity of absorption at this wavelength. In an absorption spectrum, the ordinate measures the intensity of the band, which is proportional to the number of molecules absorbed. This principle consequently leads to quantitative analysis. This is the basic principle of an IR spectrometer.

A Fourier transform infrared instrument measures light absorbed or emitted from a sample. The measurements provide valuable chemical composition information. The key components of a Fourier transform system are the source, the interferometer and the detector. The interferometer provides a means for the spectrometer to measure all optical frequencies simultaneously (Nussbaum 2007). The interferometer modulates the intensity of individual frequencies of radiation before the detector picks up the signal. Using a mathematical process called Fourier Transformation (FT), the system computer converts the interferogram into a spectrum. The spectrum shows the sample emission at all the frequencies measured and thus can be used to 
identify the sample. In many laboratories Fourier transform infrared (IR) spectroscopy on account of its sensitivity to functional groups and to highly polar bonds such as $\mathrm{O}-\mathrm{H}$ stretches, backbone structures and symmetric bonds such as $\mathrm{C}=\mathrm{C}$ is used for the speciation of a wide range of chemical species. Identification of what makes up the sample is called qualitative analysis, one of two major applications of FTIR spectrometry. The other application is quantitative analysis. The intensity of absorption is related to the concentration of the component (Nussbaum 2007). This relationship between absorbance of a chemical component and its concentration is given by a linear relationship referred to as the Beer-Lambert's law:

$\operatorname{Transmittance}(T)=\frac{I}{I i}$

$\operatorname{Absorbance}(\mathrm{A})=\log \left(\frac{1}{T}\right)=\log \left(\frac{I i}{I}\right)$

$A=e \times c \times L$

Where, $\mathrm{I}_{\mathrm{i}}=$ Intensity of incident radiation, $\mathrm{I}=$ Intensity of transmitted radiation, $\mathrm{e}=$ molar extinction coefficient, $\mathrm{c}=$ concentration $($ mole/I) and $\mathrm{L}=$ sample path length $(\mathrm{cm})$.

After the spectrometer is calibrated, which establishes how concentration changes affect absorbance changes, the absorbance measurement for an unknown sample can be used to calculate concentration. Intensity and frequency of sample absorption are depicted in a two-dimensional plot called a spectrum. Intensity is generally reported in terms of absorbance, the amount of light absorbed by a sample, or percent transmittance, the amount of light that passes through it. Frequency is usually reported in terms of wave numbers (Gable 2013). 


\section{A Simple Spectrometer Layout}

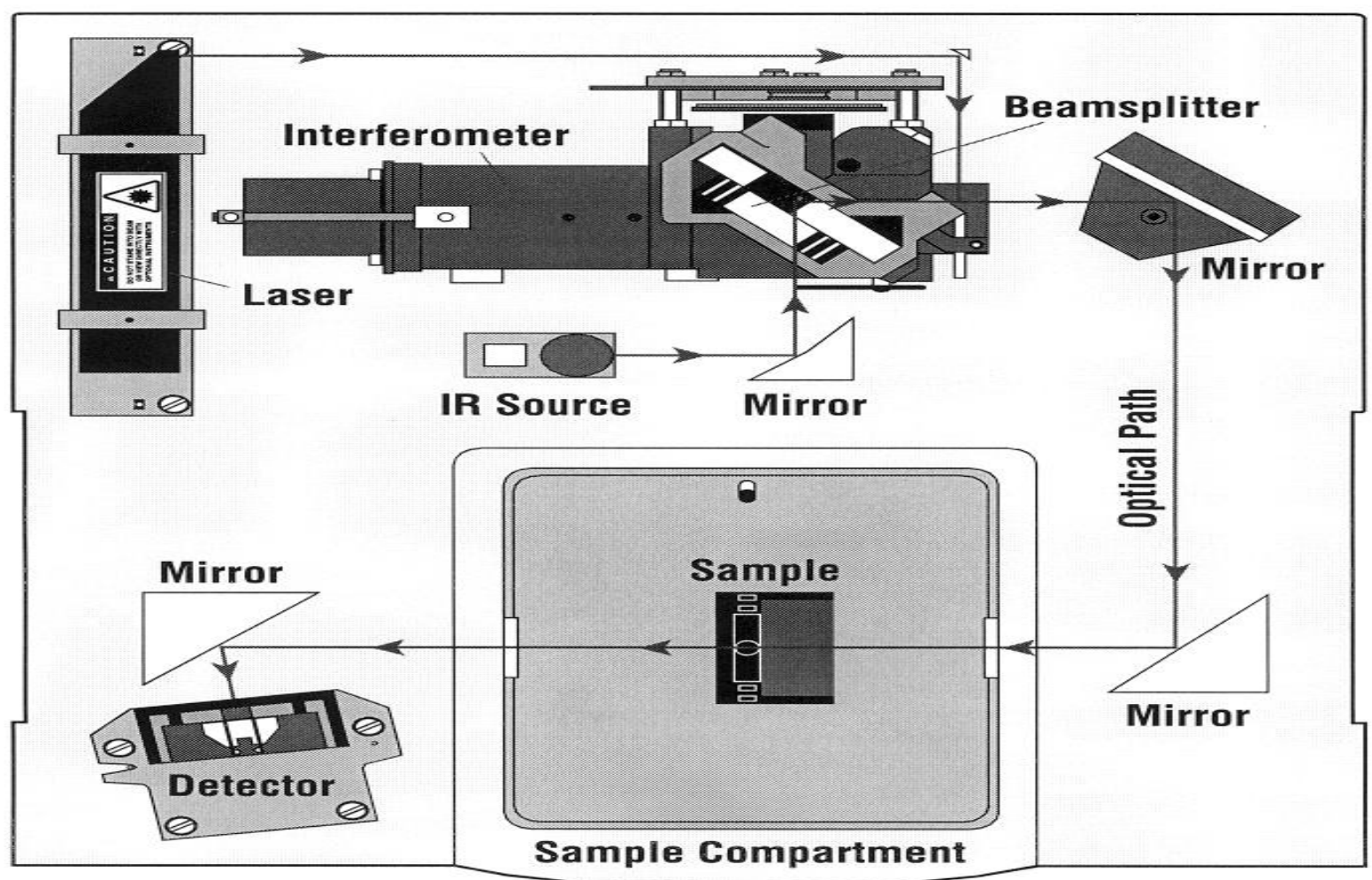

Figure 5: Components of an FT-IR spectrometer. (Narasimhamurthy 2002)

\subsubsection{Chemiluminescent Detector (CLD)}

A chemiluminescent analyzer is commonly used for measuring the $\mathrm{NO}$ and $\mathrm{NOx}$ components of automobile exhaust. The term chemiluminescence refers to the emission of light from an atom or molecule when it drops from excited state to a base state during a chemical reaction. The exhaust sample is passed through a chamber filled with excess ozone, which reacts with the NO. The $\mathrm{NO}_{2}$ is in an excited state and returns to a normal state and emits photon emissions. Chemiluminescent detection responds fast and has a wide dynamic measurement range (Baronick et al. 2001). It provides the concentration of $\mathrm{NO}$ and total $\mathrm{NO}_{\mathrm{x}}$ when equipped with a $\mathrm{NO}_{\mathrm{x}}$ convertor $\left(\mathrm{NO}_{2} \rightarrow \mathrm{NO}\right)$. It works on the main principle: 
$\mathrm{NO}+\mathrm{O}_{3} \rightarrow \mathrm{NO}_{2} *+\mathrm{O}_{2} \rightarrow \mathrm{NO}_{2}+\mathrm{O}_{2}+$ proton

Eq. (9)

The disadvantages over FTIR are the extra expenses required for an ozonizer, $\mathrm{NO}_{2} \rightarrow \mathrm{NO}$ convertor, additional operating gases, and converter efficiencies (90\%-100\%) (Baronick et al. 2001). Water and $\mathrm{CO}_{2}$ existing in the exhaust of this instrument stream can also adversely affect the CLD due to quenching (Gluck et al. 2003). Quenching occurs when the above reaction does not produce light emission; rather the energy is transferred, via collisions, to other molecules in the exhaust stream (i.e. $\mathrm{H}_{2} \mathrm{O}$ and $\mathrm{CO}_{2}$ molecules).

\subsubsection{Non-dispersive Ultraviolet Photometer (NDUV)}

The non-dispersive ultraviolet photometer is used to detect oxides of nitrogen. The technology is similar to that of a NDIR. Ultraviolet light has a shorter wavelength, but has a higher energy than infrared light. This technology is employed in the Semtech-DS analyzer for NO and $\mathrm{NO}_{2}$ measurements. The NDUV analyzer has a single sample cell that has two filters and two detectors at the exit, one to measure absorbed energy and the other to measure non-absorbed energy. The ratio of these two measurements is the concentration of the nitrogen oxides (Baronick et al. 2001).

\subsubsection{Flame Ionization Detector (FID)}

A FID is used to measure THC from the engine exhaust. A hydrogen flame is formed at the burner by fuel gas (generally a mixture of $\mathrm{H}_{2}$ and $\mathrm{HE}$ ) and combustion air. As the sample gas is introduced into the flame a portion of the HC's is ionized (Shade 2000). An electric potential is applied at the nozzle which generates electric current between the nozzle and the electrode due to $\mathrm{HC}$ ions in the flame. This ion current is nearly proportional to the amount of carbon atom introduced into the flame as HCs; hence, the HC concentration can be known as THC in ppmC unit. The FID has sensitivity for most HC's; and shows a wide dynamic range and sufficient 
linearity in its output. In the engine exhaust the FID sensitivity for each $\mathrm{HC}$ is represented by a "response factor" that indicates the relative sensitivity compared to propane as the calibration gas (Shade 2000).

\subsubsection{Non-Dispersive Infrared Detector (NDIR)}

The non-dispersive infrared detector is a spectrophotometer that is used to detect oxides of carbon i.e. $\mathrm{CO}$ and $\mathrm{CO}_{2}$. The term 'non-dispersive' refers to the fact that the light is not reflected or scattered, it is absorbed by the gas. The gas sample passes through a cell where it is bombarded with infrared light/energy. The energized gaseous compounds pass through a filter that only allows certain wavelengths of light to pass, since every gas absorbs infrared energy at different wavelengths. At the same time a separate cell has the same light passing through a static inert gas, such as nitrogen. The light source is pulsated with a chopper wheel, to allow for a 'continuous' measurement. After the light travels through the cells, it reaches a solid-state photoconductive detector, where the concentration is determined (Shade 2000).

\subsubsection{Analyzers Used in this Study}

Table 9 summarizes the individual components present in the instruments used for this study to measure gaseous emissions such as $\mathrm{CO}, \mathrm{CO}_{2}, \mathrm{NO}, \mathrm{NO}_{2}$ and THC.

Table 9: Components used for emissions measurement in the analyzers.

\begin{tabular}{|c|c|c|c|}
\hline Gaseous Emissions & FTIR-2030 HS & Semtech-DS & MEXA-7200D \\
\hline $\mathrm{CO}$ & IR Spectroscopy & NDIR & NDIR \\
\hline $\mathrm{CO}_{2}$ & IR Spectroscopy & NDIR & NDIR \\
\hline $\mathrm{NO}$ & IR Spectroscopy & NDUV & CLD \\
\hline $\mathrm{NO}_{2}$ & IR Spectroscopy & NDUV & CLD \\
\hline $\mathrm{THC}$ & IR Spectroscopy & FID & FID \\
\hline
\end{tabular}


The FTIR used in this study has a single sample cell of length $5.11 \mathrm{~m}$ which is maintained at around $191^{\circ} \mathrm{C}$. The FTIR measured raw exhaust emissions in wet conditions. All sampling system elements which are in contact with the sample (sampling lines, pumps, filters, valves) are also heated and maintained at temperatures of around $191^{\circ} \mathrm{C}$. Wet sampling means the analyzers are in heated condition to prevent losses due to condensation in the sampling and measurement system. Although the FTIR-2030 HS is capable of measuring 20+ gases simultaneously, this study mainly focuses on NOx and THC from diesel and natural gas engines.

The Semtech-DS is capable of measuring raw exhaust emissions. The Semtech-DS comprises of individual sub-components to quantify exhaust emissions. It comprises of a FID to quantify THC emissions, NDUV to measure NOx emissions and a NDIR to measure $\mathrm{CO}$ and $\mathrm{CO}_{2}$ emissions. The THC emissions are measured wet and all the remaining emissions are measured dry. Dry sampling means the analyzers require the sample to be dried and water vapor should be condensed and removed from the sample in a way that minimizes losses of acidic gases in the water.

The MEXA-7200D used in this study is a dilute emissions measurement system which extracts sample from a CVS system. The full flow CVS tunnel used for this study is designed to simulate the mixing of exhaust gas with ambient air conditions, maintains a nominally constant total molar flow rate of the diluted exhaust. To accurately measure and actively control the flow rate maintaining proportional sampling of the exhaust constituents, a SSV flow meter is used. MEXA-7200D comprises of a FID to quantify THC emissions, CLD to measure NOx emissions and a NDIR to measure $\mathrm{CO}$ and $\mathrm{CO}_{2}$ emissions. The THC emissions are measured wet and all the other emissions are measured dry in the MEXA-7200D. 


\subsection{Test Matrix}

\subsubsection{Test Engine and Vehicle Specifications}

This study involved testing of two trucks (diesel and natural gas (NG)), the engine and vehicles chosen for this study have been certified under the current US EPA 2010 standards and are within their useful life of operation. The two vehicles are equipped with newer model year heavy-duty engines with advanced after treatment systems that are known to produce very low emissions. All the vehicles chosen for this study are used for goods movement and are found to be used in large fleet operations. The vehicle and engine specifications are given below Table 10.

Table 10: Test vehicles specifications for chassis TEMS testing.

\begin{tabular}{|c|c|c|}
\hline Vehicle Manufacturer & Freightliner - Cascadia & Freightliner - Cascadia \\
\hline Vehicle Model Year & 2014 & 2014 \\
\hline Gross Vehicle Wt. (GVWR) & $80,000 \mathrm{lbs}$. & 80,000 lbs. \\
\hline Odometer Reading (miles) & 123,471 & 11,142 \\
\hline Engine Manufacturer & Cummins & Cummins \\
\hline Engine Model & ISX15 & ISX12G \\
\hline Engine Family & DCEXH0912XAT & DCEXH0729XBA \\
\hline Engine Model Year & 2013 & 2013 \\
\hline Engine Displacement (L) & 15 & 11.9 \\
\hline Engine Rated Power (hp) & $450 @ 1800$ rpm & $400 @ 1800$ rpm \\
\hline Fuel Type & $\begin{array}{c}\text { Ultra-Low Sulphur Diesel } \\
\text { (ULSD) }\end{array}$ & CNG (Stoichiometric) \\
\hline $\begin{array}{l}\text { CERT No. (NOx) } \\
\text { (g/bhp-hr) }\end{array}$ & $\begin{array}{l}0.22(\mathrm{FTP})^{1} \\
0.46(\mathrm{NTE})\end{array}$ & $\begin{array}{l}0.15 \text { (FTP) } \\
0.30 \text { (NTE) }\end{array}$ \\
\hline After-treatment System & $\mathrm{DOC}+\mathrm{DPF}+\mathrm{SCR}(\mathrm{EGR})$ & TWC (EGR) \\
\hline
\end{tabular}

${ }^{1}$ NOx standard for 2010 and later HD engines are at 0.20g/bhp-hr over an engine dynamometer FTP cycle. 


\subsubsection{Test Routes}

All the vehicles were driven in six distinct routes over at least 5 days and spanned around 1500 miles along some of the major freight corridors in California. Each day, trips were made lasting typically between 1-2 hours, and stops were generally made at the same locations for each truck. Thus, identical or similar trips were made across both vehicles in the study. The routes were classified as near-dock, local, regional, urban and interstate but this study discusses the findings from near-dock, local, and interstate routes. The trips near the near-dock and local routes were conducted during business hours to see the effect of any congested traffic on the emissions. The number of trips and mileage for the two vehicles discussed in the study varied; as Vehicle 2 that operated on Compressed Natural Gas $(\mathrm{CNG})$ has a limited range and therefore some trips were shortened. All the test vehicles discussed in this study were operated from the same starting and ending locations for each of the test routes discussed below.

The near-dock route shown in Figure 6 simulated the stop-and-go operations associated with cargo loading from ocean-going vessels followed by brief higher-speed driving onto local highways, and the local route shown in Figure 7 simulated transport to regional rail yards near downtown Los Angeles. Local and near-dock routes were chosen to study the emissions associated with freight movement leaving the Ports of Long Beach and Los Angeles. Figure 8 shows regional highway routes that included driving at speeds commonly around $55 \mathrm{mph}$, but also frequent periods of slower congested highway driving.

The routes classified as near-dock, local and highway are based on the percentage of type of operation mentioned in Table 11. Table 11 shows the percent of operation based on speed bins specified by European Commission for Read-Driving Emissions (RDE). The speed bins are classified as idle ( $<2 \mathrm{kmph})$, Urban $(\geq 2 \&<50 \mathrm{kmph})$, Rural $(\geq 50 \&<90 \mathrm{kmph})$ and motorway 
( $\geq 90 \mathrm{kmph}$ ). Near-dock has highest idle (63\% during Diesel testing and 52\% during CNG testing) and frequent start-stop operation. Local is a combination of idle and urban (low-speed) driving, where speeds less than $45 \mathrm{kmph}$ constitute to majority of this route testing and regional highway is more of rural and motorway driving where exhaust temperatures and speeds are higher (around 50 - 90kmph).

Table 11: Comparison of test routes and driving characteristics between test vehicles.

\begin{tabular}{|c|c|c|c|c|c|}
\hline Vehicle type & Route type & Idle (\%) & Urban (\%) & Rural (\%) & Motorway (\%) \\
\hline \multirow{3}{*}{ Diesel } & Near-dock & 63.549 & 25.665 & 10.778 & 00.008 \\
\cline { 2 - 6 } & Local & 10.063 & 70.884 & 16.701 & 02.352 \\
\cline { 2 - 6 } & Highway & 21.267 & 22.333 & 23.967 & 32.434 \\
\hline \multirow{3}{*}{ CNG } & Near-dock & 52.340 & 36.178 & 08.833 & 02.649 \\
\cline { 2 - 6 } & Local & 15.851 & 60.828 & 18.619 & 04.703 \\
\cline { 2 - 6 } & Highway & 10.451 & 43.829 & 19.190 & 26.530 \\
\hline
\end{tabular}




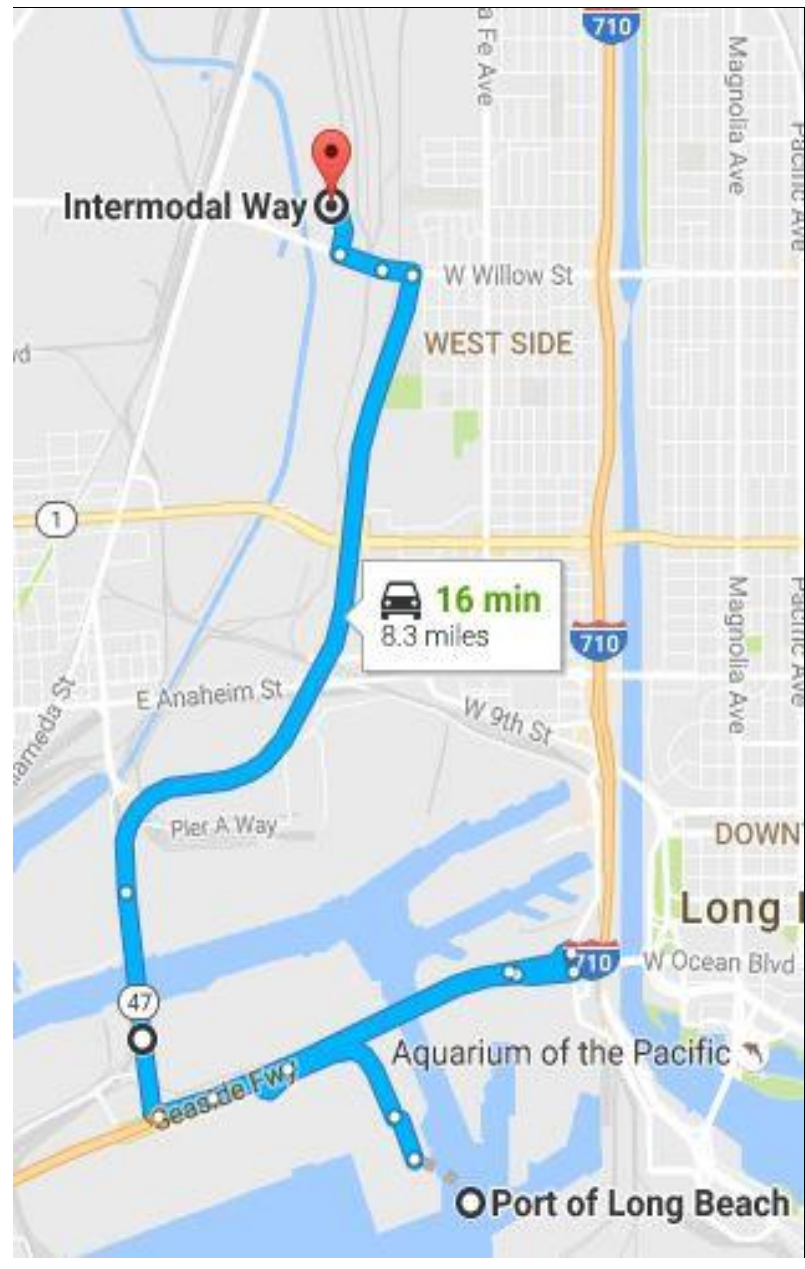

Figure 6: Testing route indicating Near- Dock driving.

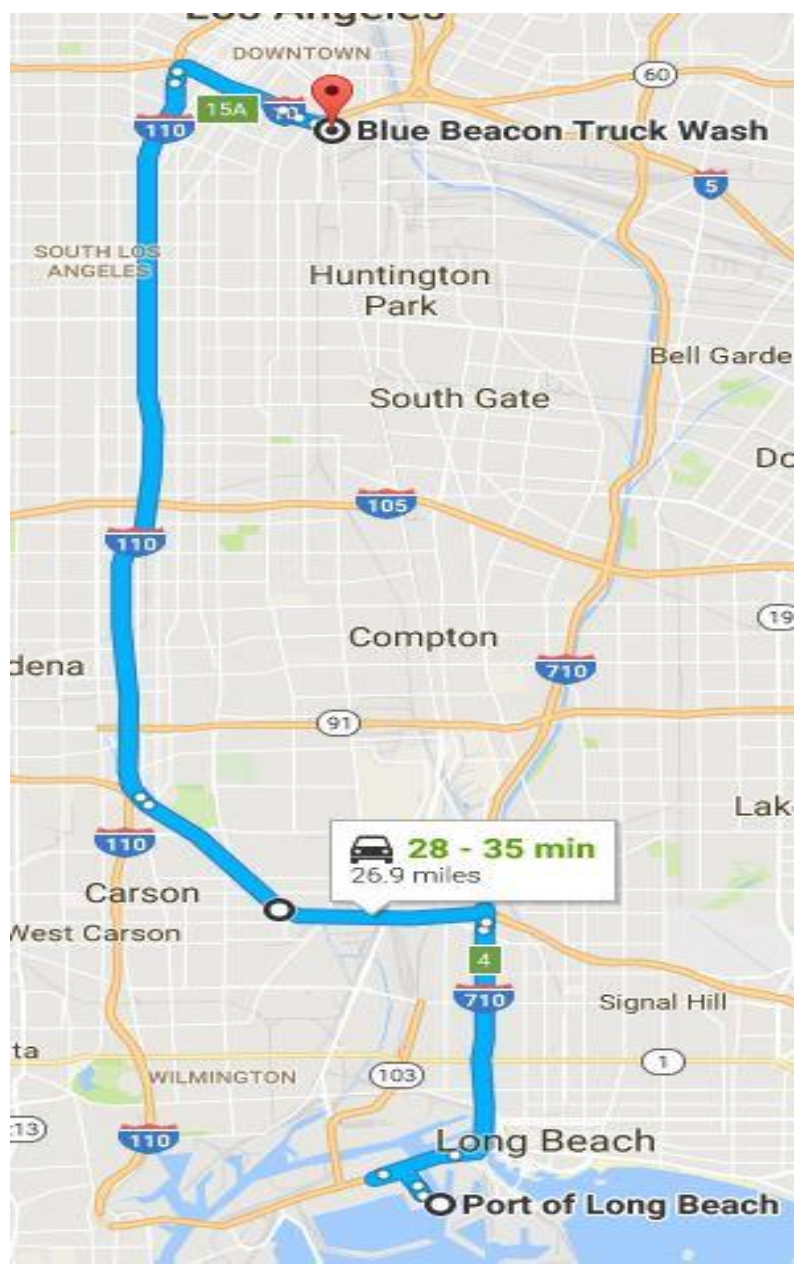

Figure 7: Testing route indicating Local driving.

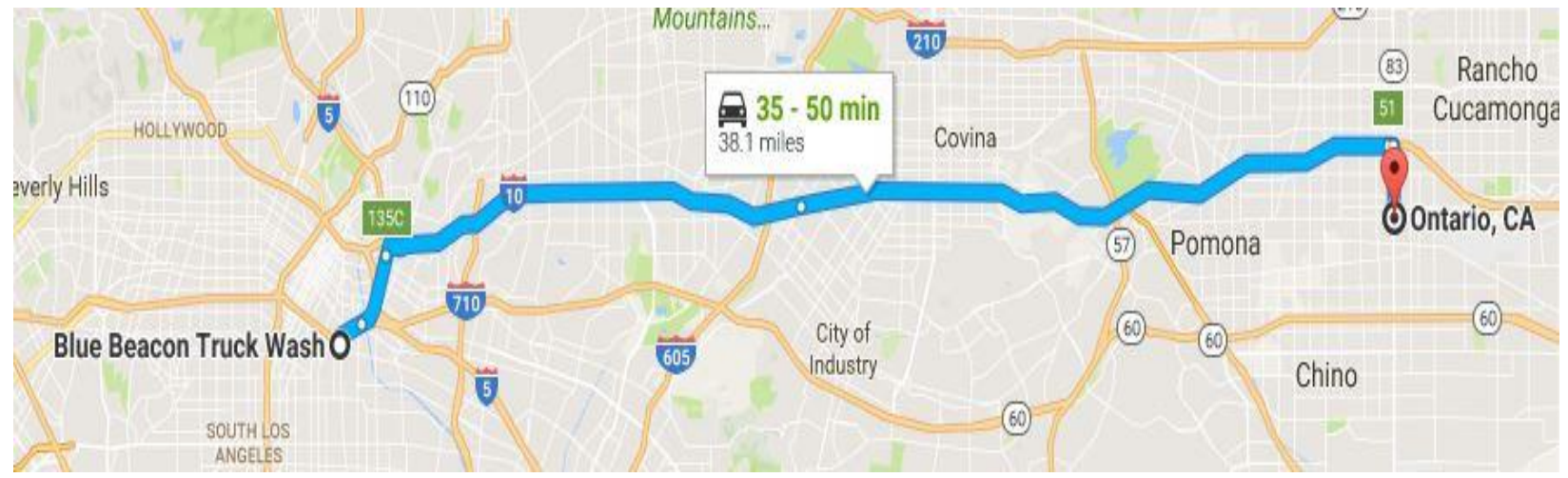

Figure 8: Testing route indicating Regional Highway driving conditons. 


\subsubsection{Analyzer Checks and Verifications}

Initial laboratory set-up procedures include complete measurement system verification followed by calibration. All required system verifications are performed as per requirements stated in 40 CFR, Part 1065, Subpart D. The Horiba MEXA 7200D Motor Exhaust Gas Analyzer is capable of automatically performing the required analyzer verification tests. The verification procedure and pass criteria of the tests were in accordance to the provisions described in $40 \mathrm{CFR}$ Part 1065, Subpart D. Table 12 lists the complete set of analyzer verification checks performed on field prior to the commencement of the testing. Table 13 lists the complete set of leak checks performed on the gaseous and PM measurement systems. All the analyzers $\left(\mathrm{CO}, \mathrm{CO}_{2}\right.$ and $\left.\mathrm{NOx}\right)$ are individually verified for linearity by passing the respective calibration gas and blended Nitrogen at 10 equally spaced ratios. Least squares regression analysis is performed between analyzer's response and theoretical calculations of calibration gas as per 40 CFR, Part 1065, Subpart D.

In addition, the heated sample lines used for raw measurement systems are checked for vacuum leak using a pressure calibration device and all the thermocouples using a thermocouple calibrator. Table 12 shows list of analyzer checks performed and their pass criteria.

The Semtech-DS (PEMS) is installed on test vehicles as shown in Figure 4. Every day before the start of the test, the PEMS and FTIR are warmed-up until they are stabilized thermally. After warm up and before testing on a route, zero and span checks were performed and these checks are automated during the test. PEMS performs zero and span checks and adjustments before and immediately after sampling. Analyzer drift values are recorded automatically to perform drift correction while calculating results. The exhaust flow-meter (EFM) was checked for response before the start of the test by pushing the acclerator pedal to observe the change in exhaust flow 
concentrations. The EFM is verified against a LFE to check for flow discrepancies before installing on the each test vehicle.

The FTIR sample line and cell temperatures were maintained at $191^{\circ} \mathrm{C}$ and the detector is cooled with liquid nitrogen. Liquid nitrogen is filled at regular intervals and the software to record FTIR data has a channel (Instrument Monitor) to see the level of liquid nitrogen and the signal intensity. The mirrors were cleaned if the signal intensity is lower. The cell pressure is maintained at close to ambient $(1 \mathrm{~atm})$ and is made sure at the start of the test to be within $0.97 \sim 1 \mathrm{~atm}$. The liquid nitrogen was filled at regular intervals to match the refenece before testing and the instrument was continously monitored.

Table 12: Gaseous analyzer verification checks.

\begin{tabular}{|l|l|}
\hline \multicolumn{1}{|c|}{ Analyzer Checks } & \multicolumn{1}{c|}{ Pass Criteria } \\
\hline THC1 Hang-up & \\
\hline THC2 Hang-up & Within $\pm 1 \%$ \\
\hline $\mathrm{CO}(\mathrm{L}), \mathrm{CO}_{2}$ Interference Check & Within $\pm 2 \%$ \\
\hline $\mathrm{THC}, \mathrm{O}_{2}$ Interference Check & Within $\pm 1 \%$ \\
\hline $\mathrm{CO}_{2}$ Quench $\mathrm{NO}_{\mathrm{x}} 1 \& 2$ & Within $\pm 1 \%$ \\
\hline $\mathrm{H}_{2} \mathrm{O}$ Quench $\mathrm{NO}_{\mathrm{x}} 1 \& 2$ & Efficiency $\geq 95 \%$ \\
\hline $\mathrm{NO}_{2} \rightarrow$ NO convertor Efficiency & PF $\mathrm{CH}_{4}>0.85$ and $\mathrm{PF}_{2} \mathrm{H}_{6}<0.02$ \\
\hline Non-Methane Cutter Efficiency & \\
\hline
\end{tabular}

Table 13: Gaseous and PM measurement system verification checks.

\begin{tabular}{|c|c|}
\hline Leak Checks & Pass Criteria \\
\hline $\begin{array}{c}\text { Leak and Delay Time Check (all } \\
\text { analyzers) }\end{array}$ & \multirow{3}{*}{$\begin{array}{c}\text { Within } \pm 5 \% \text { over } 30 \mathrm{sec} \\
\text { intervals }\end{array}$} \\
\hline PM System 1 Leak Check & \\
\hline PM System 2 Leak Check & \\
\hline
\end{tabular}




\subsubsection{Engine Speed and Torque Measurement}

As the emission standards for heavy-duty diesel engines are set based on brake-specific emission rates, it is imperative to measure or record the engine speed and torque. Engine speed and torque are measured using an engine dynamometer if it is tested in a test cell; whereas in the field, the engine speed and torque are recorded from the ECU as most of the engines that are subjected to in-use emission regulations are modern diesel engines controlled by ECU. The ECU engine speed and torque are broadcasted either via SAE J1939 or J1708 protocols based on the engine MY, post MY 2006 engines follow J1939 protocol.

The speed and torque information broadcasted through J1939 protocol are used to calculate the engine work using different methods based on the mode in which engine torque is broadcasted. Engine torque is determined using a combination of the following parameters based on the available data.

- Engine Percent Load at Current Speed - a ratio of actual engine percent indicated torque to maximum indicated torque at the given engine speed.

- Actual Engine Percent Torque - is the indicated torque of the engine transmitted as a percent of the reference torque. Note that the indicated torque will not be less than zero as it includes the torque required to overcome the friction.

- Nominal Friction Percent Torque - is the torque which represents the friction in the engine. It includes frictional and thermodynamic losses of the engine, pumping torque loss, fuel, oil and coolant pump losses. The frictional torque is also broadcasted as a percentage of reference torque.

- Engine Reference Torque - is a constant indicated torque value which serves as the $100 \%$ 
reference value for all defined indicated engine torque parameters. This value will not change even when different engine maps such as engine de-rate or thermal management maps become valid.

When the engine torque is broadcasted as actual engine-percent torque (which is the case in this testing), which is an indicated torque represented as a percentage of reference engine torque, it is used in conjunction with nominal friction-percent torque and reference engine torque to calculate the actual engine brake torque using the following equation (SAE J1939/71® 2014).

TBrake $=\left(\right.$ ActEng_\%T - NomFric_\%T $\left._{-}\right) \cdot \frac{1}{100} \cdot T_{\text {ref eng }}$

Once the engine brake torque is determined, the work produced by the engine at a given engine speed calculated using the following equation.

$W_{\text {Brake }}=\frac{N \times \text { TBrake }}{5252} \cdot \frac{1}{3600} \cdot \Delta t$

Where: WBrake $\quad$ engine brake work (hp-hr)

$N \quad$ engine speed (rpm)

TBrake engine brake torque (ft-lbs)

$\Delta t \quad$ data logging rate (s) 


\section{$4 \quad$ Results and Discussion}

The results chapter will discuss the on-road emissions for the criteria pollutants and $\mathrm{CO}_{2}$ from the two test vehicles in Section 3.2.1 for the pre-defined test routes (see Section 3.2.2) using three different instrumentation followed by an in-depth analysis of time alignment and its effects on NOx emissions. The gaseous emissions mass rates are presented in $[\mathrm{g} / \mathrm{s}]$ and distance specific emissions in [g/mile]. All the data is characterized as CVS (MEXA - 7200D), PEMS (Semtech DS) and FTIR (MKS - 2030HS). Since FTIR doesnot have a dedicated EFM, to remove the effect of variability in exhaust flow the FTIR emissions calculations were calculated using the flow measured by Semtech EFM. All emissions shown in section 4.1 were analyzed in work basis (g/bhp-hr) to compare the emissions from the two different vehicles. The work is calculated by analyzing the speed and torque values from ECU data as mentioned in section 3.2.4. All the other sections are represented in distance specific (g/mile) basis.

\subsection{Emissions Analyzed by CVS on Route Basis}

This section compares the overall emissions from both diesel and natural gas vehicle on 3 predefined test routes (Near-dock, Local and Highway). All tests were conducted on both the test vehicles and all the effects of variability (driver error, start-type, after-treatment conditions etc.) are tried to be minimized to as low as possible. Table 14 shows emission rates of regulated pollutants using the CVS system (see section 3.0) for the three different specified test routes. 
Table 14: Brake-specific emission rates of regulated pollutants during sepcific route operations.

\begin{tabular}{|c|c|c|c|c|c|c|c|c|}
\hline \multicolumn{9}{|c|}{ Emission rates (g/bhp-hr) } \\
\hline Emissions & \multicolumn{4}{|c|}{ Diesel } & \multicolumn{4}{|c|}{ Natural-gas (CNG) } \\
\hline Route-type & $\mathrm{CO}_{2} \times 10^{3}$ & $\mathbf{C O}$ & THC & NOx & $\mathrm{CO}_{2} \times 10^{3}$ & $\mathrm{CO}$ & THC & NOx \\
\hline Near-dock & 1.241 & 0.179 & 0.019 & 2.236 & 0.720 & 2.743 & 1.525 & 0.103 \\
\hline Local & 0.553 & 0.116 & 0.000 & 0.753 & 0.616 & 3.996 & 0.409 & 0.116 \\
\hline Highway & 0.479 & 0.076 & 0.009 & 0.212 & 0.494 & 3.239 & 0.400 & 0.060 \\
\hline
\end{tabular}

Figure 9 shows the emissions profile observed from both vehicles during Near-dock operation. $\mathrm{CO}_{2}$ emissions were slightly higher in the diesel vehicle $\left(1.241 \times 10^{3} \mathrm{~g} / \mathrm{bhp}\right.$-hr $)$ when compared to that of CNG $\left(0.720 \times 10^{3} \mathrm{~g} / \mathrm{bhp}-\mathrm{hr}\right)$ due to higher idle times as shown in Table 11 which is because of congested traffic during the testing. $\mathrm{CO}$ emissions from diesel are very low when compared to CNG but $\mathrm{CO}$ emissions mostly vary be engine load and speeds. The THC emissions for diesel vehicles were low raw concentrations (1-2ppm). The CNG vehicle emitted $1.525 \mathrm{~g} / \mathrm{bhp}$-hr THC for the Near-dock route. While these emissions might look higher they are unlikely to exceed NMHC gas standard as methane $\left(\mathrm{CH}_{4}\right)$ accounts for $\sim 95 \%$ of the THC signal for stoichiometric CNG engines equipped with TWC (Quiros et al. 2016). NOx emissions for Near-dock route for diesel truck were higher (2.236 g/bhp-hr) when compared to CNG test vehicle (0.103 $\mathrm{g} / \mathrm{bhp}-\mathrm{hr})$ which is due to SCR deactivation because of low exhaust temperatures. The NOx from CNG truck is around 22 times lower. Although the NOx emissions for diesel vehicle are higher than the NTE NOx standard of $0.46 \mathrm{~g} / \mathrm{bhp}-\mathrm{hr}$ (represented as NTE NOx) in Figure 9 and Figure 10, it must be understood that the limit of $0.46 \mathrm{~g} / \mathrm{bhp}-\mathrm{hr}$ is only applicable to the emissions measured when the engine is operating within the NTE region specified in section 2.3. The NTE 
NOx limit for CNG vehicle is at $0.30 \mathrm{~g} / \mathrm{bhp}$-hr which is represented as NTE NOx in Figure 9, Figure 10 and Figure 11. The NOx limit for both diesel and NG engines $(0.46 \mathrm{~g} / \mathrm{bhp}-\mathrm{hr}$ and 0.30 g/bhp-hr) operating over a NTE event is represented by the yellow dotted line in Figure 9, Figure 10 and Figure 11. The NOx limit for CNG is also only applicable to the emissions measured when the engine is operating within the NTE region. The NOx emissions tend to get lower which is observed in Figure 10 \& Figure 11 as exhaust temperatures increase which is shown in section 4.3 due to extended periods of high speed operations.

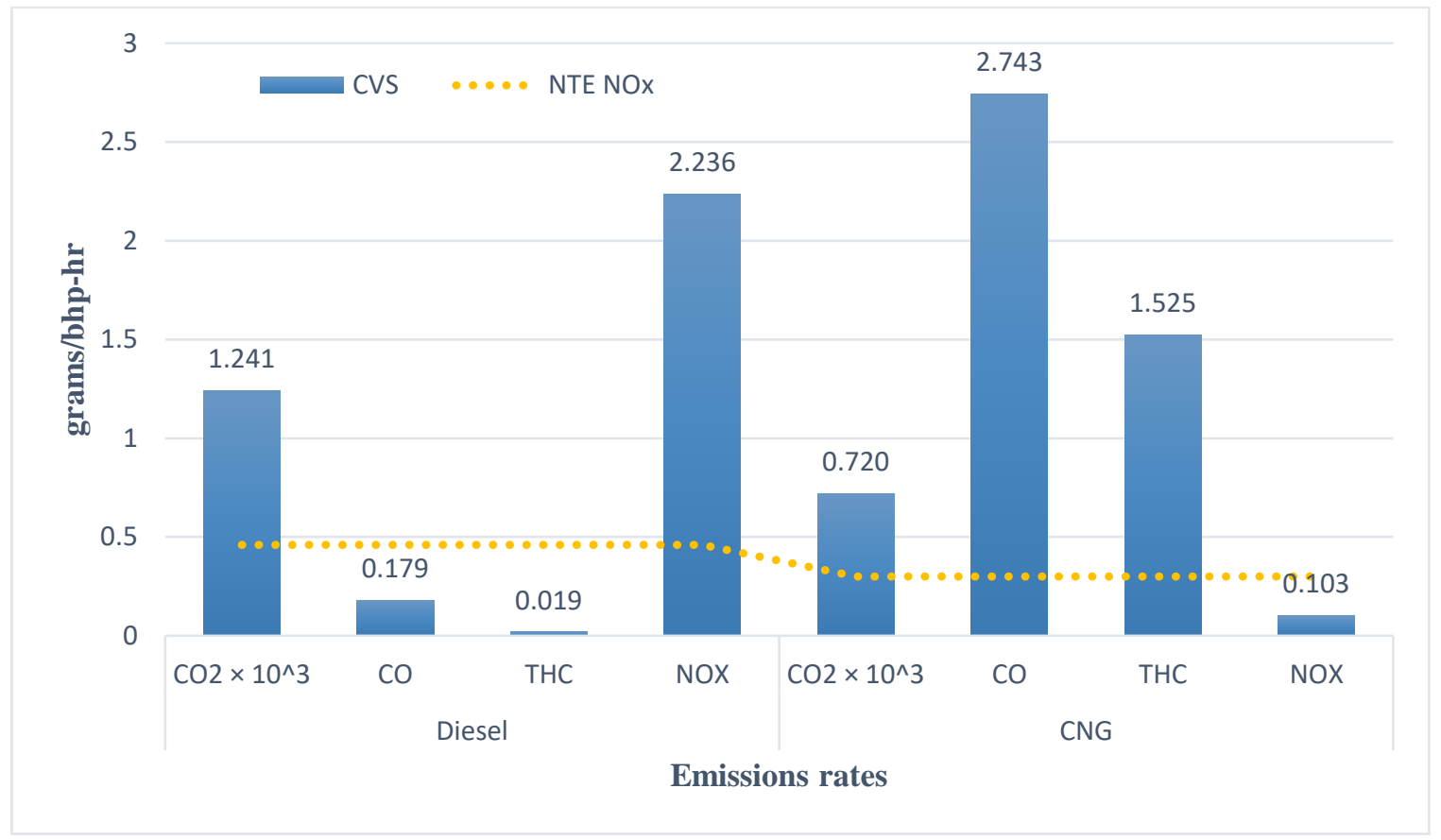

Figure 9: Brake-specific emission rates from diesel and natural gas vehicle for near-dock route.

Figure 10 shows the emissions profile observed from both vehicles during Local driving operation. $\mathrm{CO}_{2}$ emissions were similar for both the vehicles $\left(0.553 \times 10^{3} \mathrm{~g} / \mathrm{bhp}-\mathrm{hr}\right.$ for diesel and $0.616 \times 10^{3} \mathrm{~g} / \mathrm{bhp}-\mathrm{hr}$ for CNG truck). CO emissions were significantly lower for diesel when compared to CNG. The CO emissions were higher (3.996 g/bhp-hr) for CNG when compared to the results from Near-dock operation $(2.743 \mathrm{~g} / \mathrm{bhp}-\mathrm{hr})$. The THC emissions analyzed from diesel 
vehicles were typically around 1-2ppm concentrations. The measurement accuracy might be highly affected by background concentration in dilution air for a CVS system. More accurate THC measurement is achieved using a raw exhaust analyzer (PEMS) which is explained in the further sections. The CNG vehicle emitted lower THC emissions ( $0.409 \mathrm{~g} / \mathrm{bhp}-\mathrm{hr})$ and a lower trend is observed as the TWC temperature increases. NOx emissions for diesel truck were reduced by 3 times (0.753 g/bhp-hr) when compared to Near-dock operation (2.236 g/bhp-hr) but still higher when compared to $\mathrm{CNG}(0.116 \mathrm{~g} / \mathrm{bhp}-\mathrm{hr})$. A downward trend is observed in NOx emissions as exhaust temperature increases (see Figure 12).

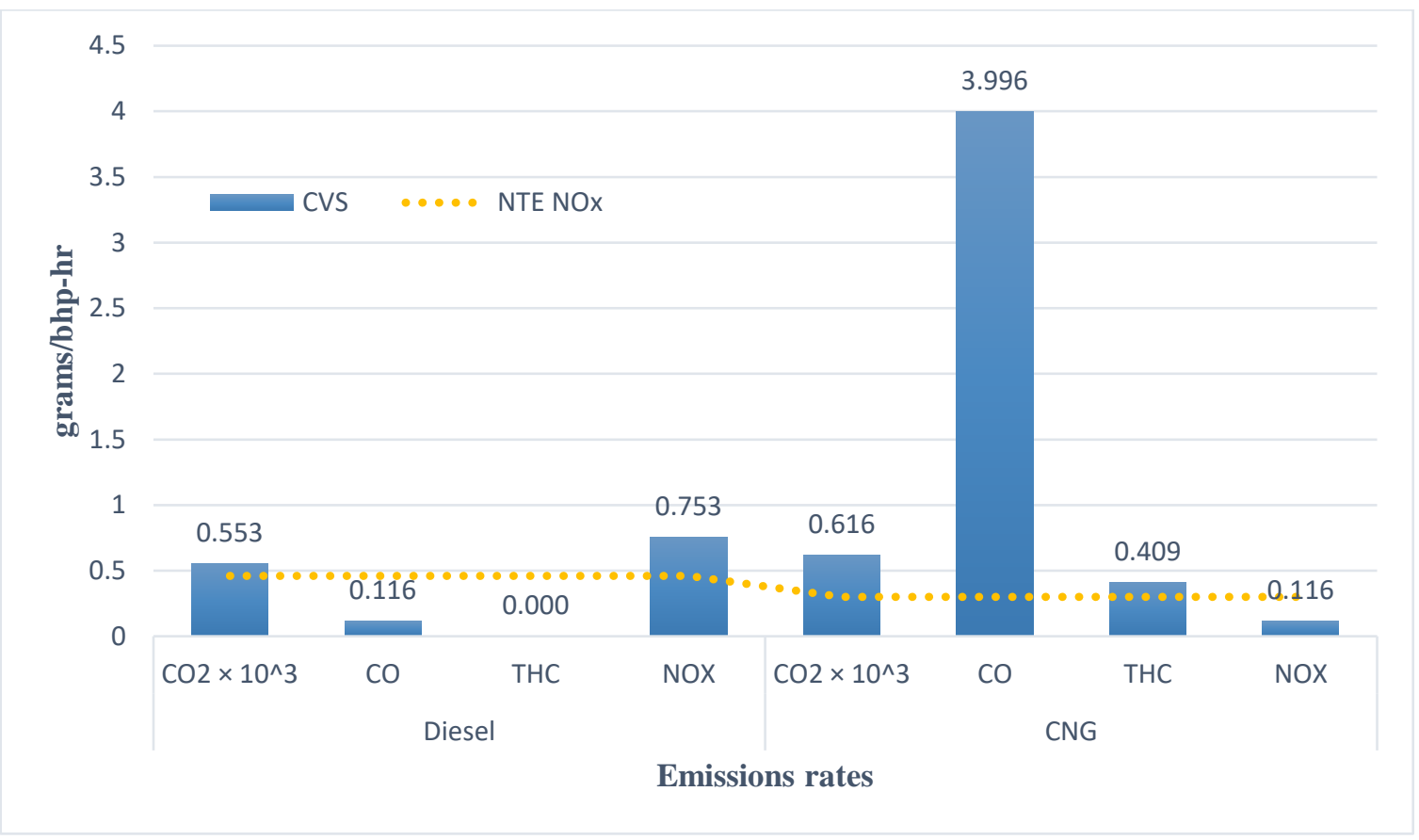

Figure 10: Brake-specific emission rates from diesel and natural gas vehicle for local driving route.

Figure 11 shows the emissions profile during Highway driving operation. $\mathrm{CO}_{2}$ emissions for both tests were similar which shows good correlation between engine fueling between the two vehicles. NOx emissions reduced to $0.212 \mathrm{~g} / \mathrm{bhp}-\mathrm{hr}$ for diesel vehicle during highway operation. 
The emission from $\mathrm{CNG}$ vehicle also reduced which relates to high exhaust temperatures due to high vehicle speeds and loads.

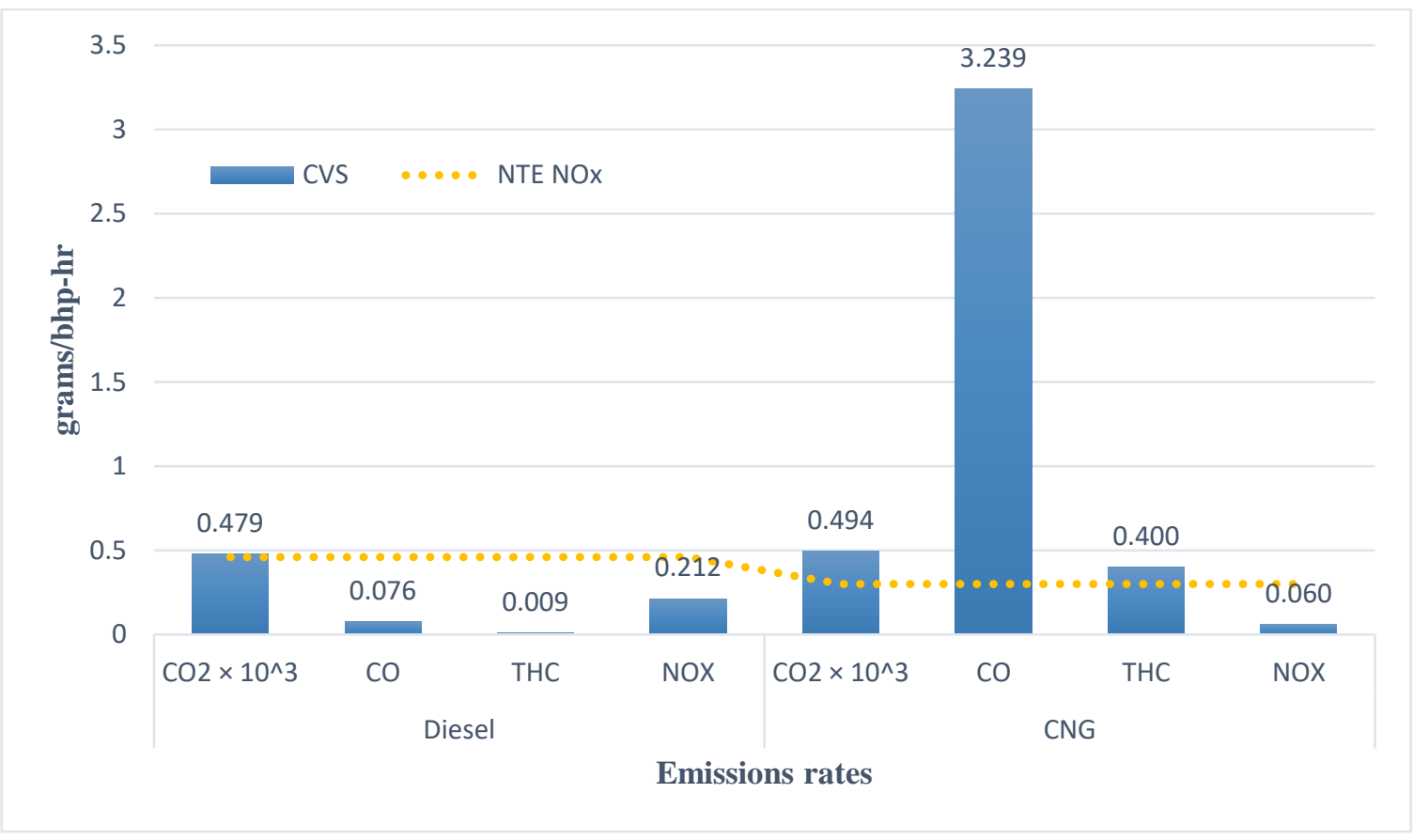

Figure 11: Brake-specific emission rates from diesel and natural gas vehicle for highway driving route.

Figure 12 shows the reduction in $\mathrm{NO}_{\mathrm{X}}$ emissions from a diesel vehicle associated with the nature of driving. The NOx emissions for Near-dock driving was $2.236 \mathrm{~g} / \mathrm{bhp}$-hr and the exhaust temperatures (exhtemp) observed during this route operation were around 132 degC. The NOx emissions dropped to $0.212 \mathrm{~g} / \mathrm{bhp}$-hr when the exhaust temperatures (exhtemp) of around 197 $\operatorname{degC}$ were observed during highway driving. This shows the importance of optimum aftertreatment temperatures for SCR functioning. NOx emissions from $\mathrm{CNG}$ vehicle also decreased but not as drastic as we see in diesel vehicles which is due to high after-treatment temperatures and SCR activity in diesel vehicles. An overall NOx reduction of about $90 \%$ is observed in diesel vehicle when compared from near-dock to highway operation. 


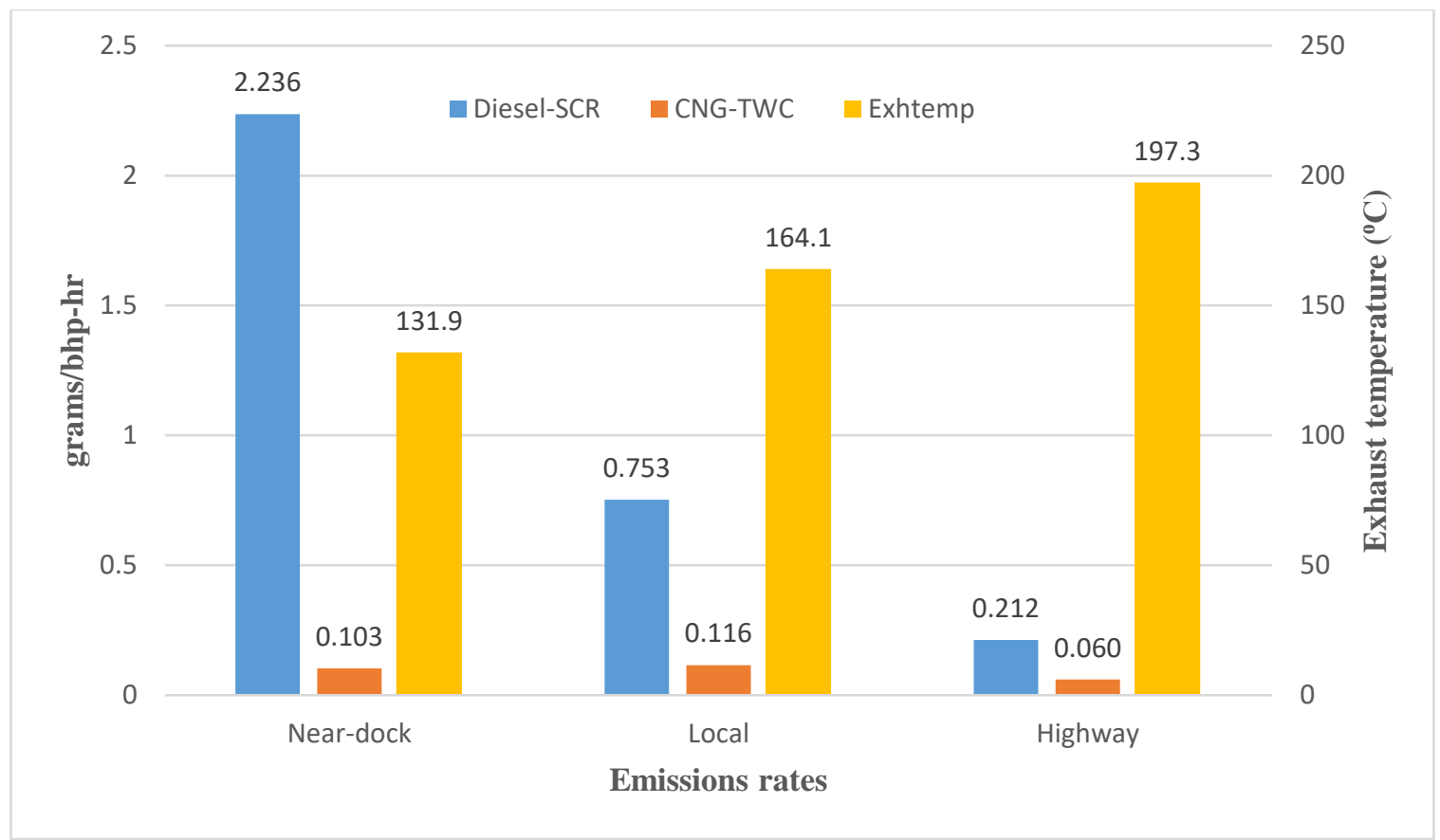

Figure 12: Comparison of NOx emissions rates b/w test vehicles based on driving routes. 


\subsection{Emissions Analyzed by 3 Different Measurement Techniques on Route}

\section{Basis}

This section compares the emissions analyzed by the 3 different test instruments (MEXA, PEMS, FTIR) from both diesel and natural gas vehicle on 3 predefined test routes. PEMS and FTIR systems used are raw measurement systems which are connected to the engine exhaust tailpipe and the MEXA is connected to a CVS dilute system. The results presented in this section are divided based on the 3 different testing routes. The emissions analyzed by the three different test instruments are presented in $\mathrm{g} / \mathrm{mi}$ basis and a graphical representation of these results is also shown. The tables presented in this section contain the percent difference between CVS and PEMS, CVS and FTIR, and PEMS and FTIR as PEMS is a certified test equipment for gaseous emissions during on-road HDD testing.

All the data is cross referenced to check for carbon balance error and it is seen that the carbon balance error between the ECU fuel flow rate and fuel flow calculated via carbon balance for CVS system are within $\pm 1 \%$ for highway route and the error is higher during Near-dock and Local driving routes. This is because the ECU fuel rate is calculated from the mapping of the injectors (which is done offline by the manufacturer) and knowing the duration of the injection. Based on the mapping model of the injector and the duration of injection the fuel flow rate is calculated. At low load conditions (near-dock and local operation) as the injected fuel quantity is very less there are high chances of error being magnified. This could be the reason for the error between fuel flow calculated via carbon balance and the ECU fuel flow rate.

Table 15 shows the emissions results in $\mathrm{g} / \mathrm{mile}$ from near-dock operation of both diesel and natural gas vehicles. $\mathrm{CO}_{2}$ emissions for diesel vehicle analyzed by CVS and PEMS are within $0.8 \%$ error which is a very good correlation between these instruments. FTIR is reading slightly 
higher (3.4\%). The $\mathrm{CO}_{2}$ emissions measured with PEMS and FTIR for CNG vehicle were higher by $7.9 \%$ and $6.8 \%$ respectively when compared to CVS. Stoichiometric combustion of methane produces more water than lean-burn engines. Although FTIR is a wet system the high amounts of water in natural gas exhaust might have caused a positive interference (strong $\mathrm{HOH}$ bonding) which in turn causes a higher $\mathrm{CO}_{2}$ reading.

Table 15: Emissions comparision between 3 different instruments in grams/mile during Near-dock operation.

\begin{tabular}{|c|c|c|c|c|c|c|c|c|}
\hline \multicolumn{9}{|c|}{ Emission rates (g/mile) } \\
\hline Emissions & \multicolumn{4}{|c|}{ Diesel } & \multicolumn{4}{|c|}{ Natural-gas (CNG) } \\
\hline Analyzers & $\mathrm{CO}_{2} \times 10^{3}$ & CO & THC & NOx & $\mathrm{CO}_{2} \times 10^{3}$ & $\mathrm{CO}$ & THC & NOx \\
\hline$C V S$ & 3.167 & 0.458 & 0.049 & 5.706 & 2.327 & 8.872 & 4.933 & 0.332 \\
\hline PEMS & 3.165 & 3.521 & 0.000 & 5.705 & 2.511 & 10.551 & 6.909 & 0.390 \\
\hline FTIR & 3.275 & 0.027 & 0.113 & 6.144 & 2.485 & 8.542 & 6.871 & 0.729 \\
\hline $\begin{array}{c}C V S v s \\
P E M S(\%)\end{array}$ & 0.076 & -669.260 & 99.420 & 0.026 & -7.909 & -18.923 & -40.068 & -17.552 \\
\hline $\begin{array}{c}C V S v s \\
\operatorname{FTIR}(\%)\end{array}$ & -3.425 & 94.181 & -133.580 & -7.674 & -6.753 & 3.726 & -39.293 & -119.75 \\
\hline $\begin{array}{l}\text { PEMS vs } \\
\text { FTIR (\%) }\end{array}$ & -3.504 & 99.244 & -40133 & -7.702 & 1.072 & 19.045 & 0.553 & -86.935 \\
\hline
\end{tabular}

$\mathrm{CO}$ and $\mathrm{THC}$ emissions from diesel engines are so low to decide on the error in measurement from the analyzers. CO concentrations from FTIR analyzer are very close to zero for diesel and close to CVS for CNG vehicle. As there is no much change in raw $\mathrm{CO}$ concentrations (1-2 ppm throughout) during diesel vehicle operation it can be inferred that FTIR might have calibration issues for CO in low ranges. THC in PEMS is a wet measurement using FID (ppmC) whereas FTIR it is still a wet measurement but THC is quantified by measuring different 
hydrocarbon species and each manufacturer has a unique algebraic function based on type of fuel to determine the total hydrocarbons from these different measured species. All the THC emissions reported in this paper are the THC broadcasted values by the FTIR instrument. Higher THC numbers from FTIR could be because of the complex algebraic equation calculations but it is to be noted that THC emissions from both diesel and natural gas engines are very low when compared to their respective limits.

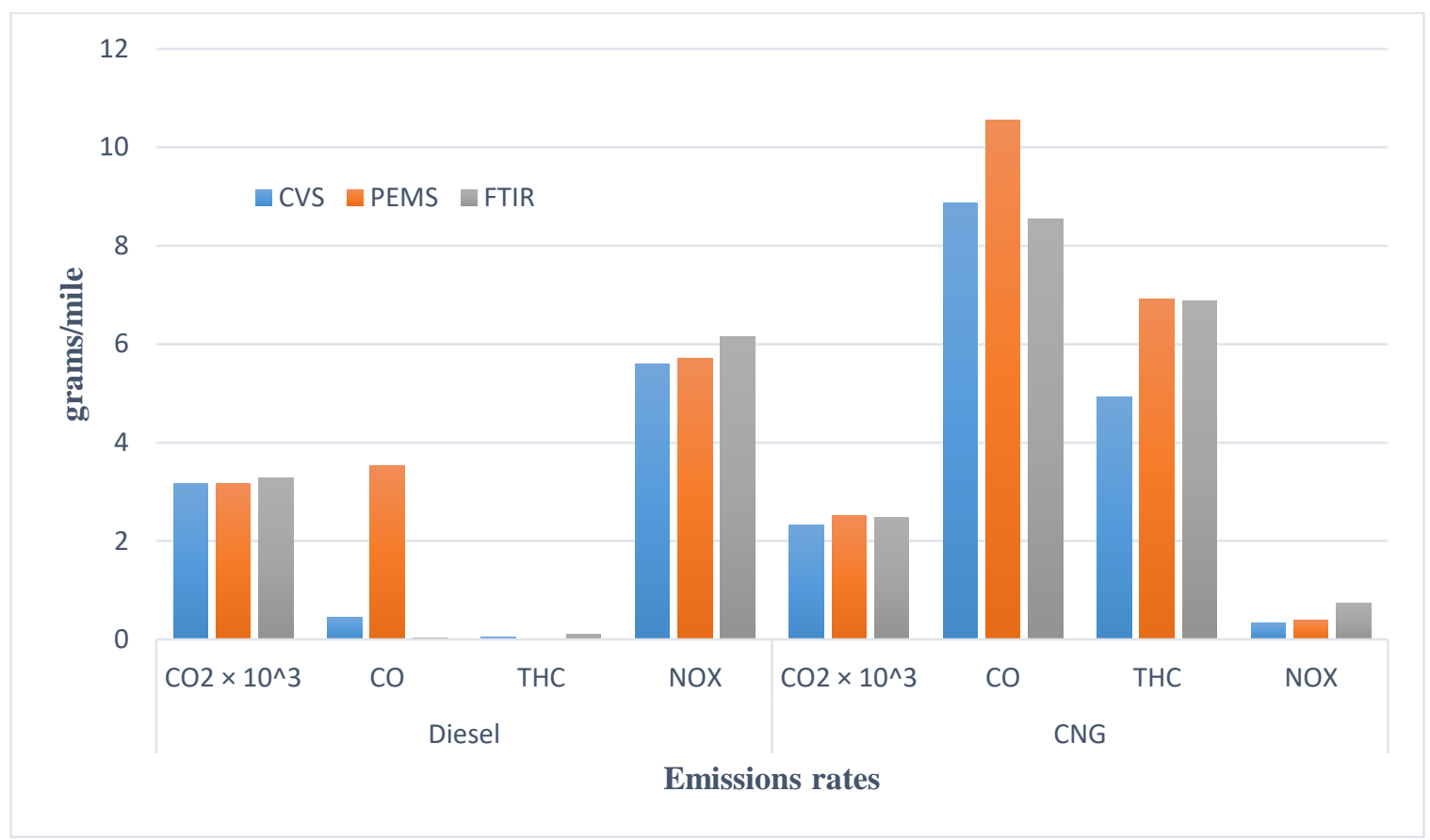

Figure 13: Emissions from Diesel and Natural Gas Vehicle for Near-dock route.

Figure 13 shows a graphical comparison between diesel and CNG vehicle during neardock operation. $\mathrm{CO}_{2}, \mathrm{CO}$, THC and $\mathrm{NO}_{\mathrm{x}}$ are shown from the 3 different instruments. NOx measurement in FTIR is also calculated using a manufacturer's proprietary algebraic function. $\mathrm{NO}_{2}$ is calibrated for higher and lower ranges and final NOx concentrations is calculated using $\mathrm{NO}$ and $\mathrm{NO}_{2}$ calculated emissions. The NOx emissions calculations based on these algebraic functions might have caused a higher error percent in the overall NOx emissions observed for FTIR. NOx 
emissions analyzed by PEMS are very accurate $(0.03 \%)$ during near-dock operation where there are high NOx numbers but error increases as NOx gradually decreases in other routes.

Table 16 shows the emissions results in $\mathrm{g} / \mathrm{mile}$ from local operation of both diesel and natural gas vehicles. $\mathrm{CO}_{2}$ emissions for diesel vehicle analyzed by CVS and PEMS are within $0.7 \%$ error which is a very good correlation between these instruments. FTIR is reading slightly higher $(3.9 \%)$ which could be due to the presence of water in the exhaust causing an interference. The diesel vehicle's fuel economy in mpg during local operation when calculated using $\mathrm{CO}_{2}$ emissions from FTIR (4.476 mpg) was lower when compared to PEMS (4.612 mpg) and CVS systems (4.648 mpg) due to the slight error in $\mathrm{CO}_{2}$ emissions from FTIR. The $\mathrm{CO}_{2}$ emissions measured with PEMS and FTIR for CNG vehicle were accurate within $1.7 \%$ and $1.6 \%$ respectively.

Table 16: Emissions comparison between 3 different instruments in grams/mile during Local operation.

\begin{tabular}{|c|c|c|c|c|c|c|c|c|}
\hline \multicolumn{9}{|c|}{ Emission rates (g/mile) } \\
\hline Emissions & \multicolumn{4}{|c|}{ Diesel } & \multicolumn{4}{|c|}{ Natural-gas (CNG) } \\
\hline Analyzers & $\mathrm{CO}_{2} \times 10^{3}$ & $\mathrm{CO}$ & THC & NOx & $\mathrm{CO}_{2} \times 10^{3}$ & $\mathrm{CO}$ & THC & NOx \\
\hline$C V S$ & 2.210 & 0.465 & 0.001 & 2.857 & 2.173 & 14.097 & 1.442 & 0.408 \\
\hline PEMS & 2.226 & 2.579 & 0.000 & 2.644 & 2.212 & 12.988 & 1.565 & 0.500 \\
\hline FTIR & 2.297 & 0.032 & 0.081 & 3.011 & 2.209 & 13.149 & 1.624 & 0.711 \\
\hline $\begin{array}{c}C V S \text { vs } \\
P E M S(\%)\end{array}$ & -0.698 & -454.782 & 98.945 & 7.458 & -1.787 & 7.870 & -8.576 & -22.656 \\
\hline $\begin{array}{c}C V S v s \\
\operatorname{FTIR}(\%)\end{array}$ & -3.909 & 93.015 & -15574.3 & -5.387 & -1.623 & 6.725 & -12.642 & -74.478 \\
\hline $\begin{array}{l}P E M S v S \\
F T I R(\%)\end{array}$ & -3.189 & 98.741 & -148537 & -13.881 & 0.161 & -1.243 & -3.745 & -42.249 \\
\hline
\end{tabular}


$\mathrm{CO}$ and THC emissions for diesel are still very low ( 2- $3 \mathrm{ppm})$ during this specific route testing which makes it very difficult to identify errors in instruments as they are near detection limit to these analyzers. THC emissions is higher in CNG vehicle but $\sim 87 \%$ of the total THC emissions accounts to $\mathrm{CH}_{4}$.

NOx emissions in diesel vehicle is underestimated by PEMS during this route operation. NOx emissions from PEMS is seen to vary as the emissions decrease. NO emissions were analyzed between the CVS and PEMS instrument to see the comparison as 75-80\% of NOx emissions from heavy duty vehicles consist of NO. It is observed that NO emissions quantified by CVS were at $2.654 \mathrm{~g} / \mathrm{mile}$ and that of PEMS were $2.658 \mathrm{~g} / \mathrm{mile}$. As PEMS uses an additive approach to quantify $\mathrm{NOx}\left(\mathrm{NO}+\mathrm{NO}_{2}\right)$ it is observed the error occurred in the $\mathrm{NO}_{2}$ quantification. A lot of drift in the $\mathrm{NO}_{2}$ emissions is observed and based on literature studies $\mathrm{NO}_{2}$ measurements from NDUV drift a lot (Gierczak et al. 2007). Although the data is drift corrected there might be issues as there are instances when the drift is not constant throughout the measurement cycle making it under or over estimate. $\mathrm{NO}_{2}$ can react with water that accumulates in the sample conditioning unit and dissolve to form nitrous and nitric acid and $\mathrm{NO}_{2}$ could readily adsorb to the chiller and not be detected by the instrument. 


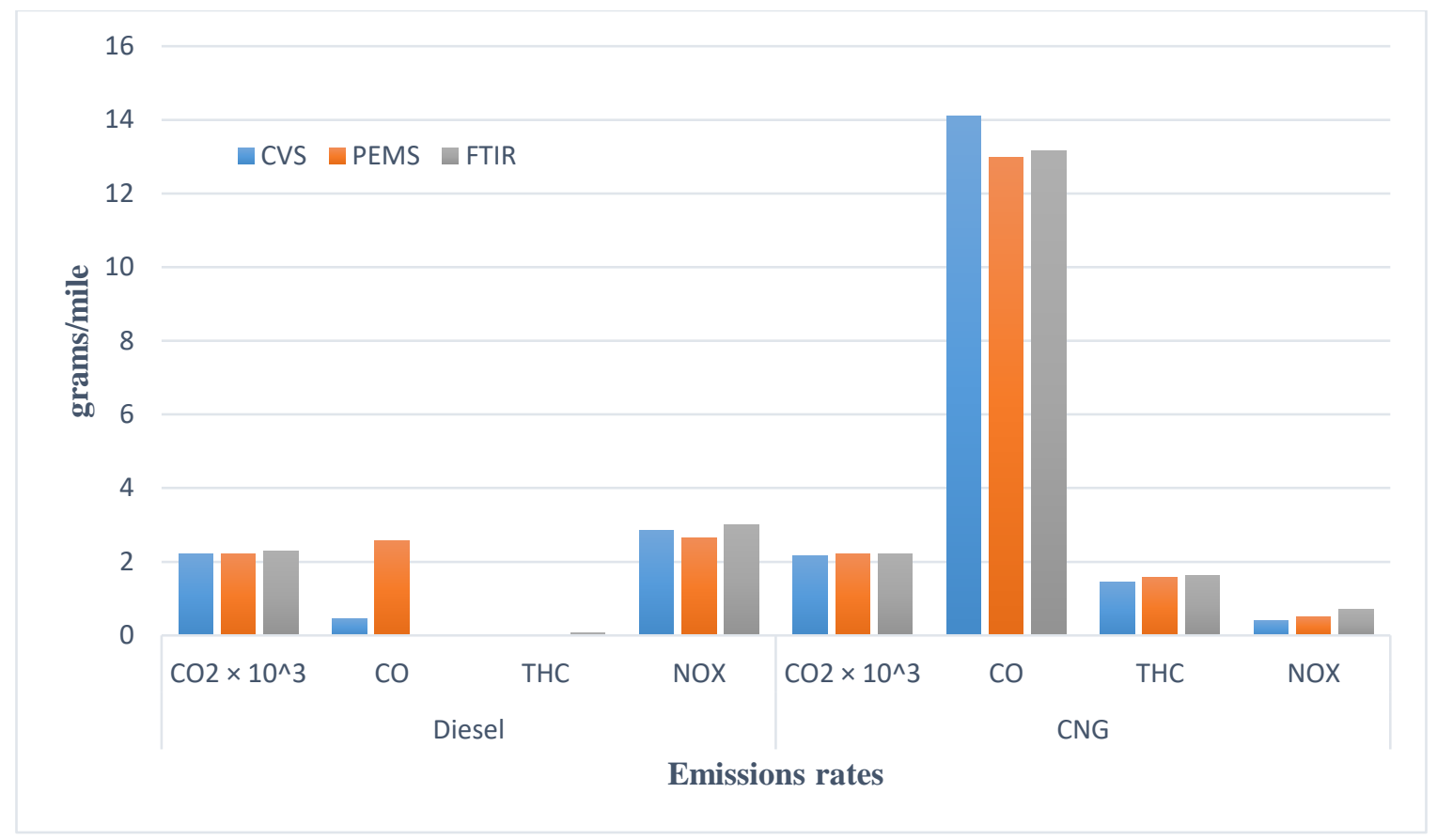

Figure 14: Emissions from Diesel and Natural Gas Vehicle for Local driving route.

Figure 14 shows a graphical comparison between Diesel and CNG vehicle during local driving operation. $\mathrm{CO}_{2}, \mathrm{CO}$, THC and $\mathrm{NO}_{\mathrm{x}}$ are shown from the 3 different instruments. NOx emissions for CNG vehicle analyzed by PEMS and FTIR is $22.66 \%$ and $72.48 \%$ higher when compared to CVS system. The PEMS used in this testing was a Semtech-DS which was designed for diesel exhaust and not for natural gas exhaust. Natural gas exhaust has higher water content and NDUV in PEMS can positively interfere with $\mathrm{HC}$ and $\mathrm{H}_{2} \mathrm{O}$. The positive interference between $\mathrm{HC}$ and $\mathrm{H}_{2} \mathrm{O}$ could be the reason for such a high difference. High water in exhaust can also remove $\mathrm{NO}_{2}$ (chiller penetration factor being reduced). This could be the potential reason for FTIR reading higher i.e. chiller $\mathrm{NO}_{2}$ penetration and $\mathrm{H}_{2} \mathrm{O}$ interference due to strong $\mathrm{HOH}$ bending.

Table 17 shows the emissions results in g/mile from highway operation of both diesel and natural gas vehicles. $\mathrm{CO}_{2}$ emissions for diesel vehicle analyzed by CVS and PEMS are within $0.7 \%$ error which is a very good correlation between these instruments. FTIR error percent is lower 
when compared to near-dock and local $(2.17 \%)$ and the error is mainly related to the measurement technique (wet measurement). The $\mathrm{CO}_{2}$ emissions measured with PEMS for CNG vehicle was off (higher) by $3.8 \%$ to CVS. This is mainly attributed to the length of operation and the high amount of water which makes it difficult for the chiller system to handle.

Table 17: Emissions comparison between 3 different instruments in grams/mile during Highway operation.

\begin{tabular}{|c|c|c|c|c|c|c|c|c|}
\hline \multicolumn{7}{|c|}{ Emission rates (g/mile) } \\
\hline Emissions & \multicolumn{3}{|c|}{ Diesel } & \multicolumn{3}{c|}{ Natural-gas (CNG) } \\
\hline Analyzers & $\mathbf{C O}_{2 \times 10^{3}}$ & CO & THC & NOx & CO $_{2 \times 10^{3}}$ & CO & THC & NOx \\
\hline CVS & 1.702 & 0.269 & 0.033 & 0.754 & 1.698 & 11.141 & 1.377 & 0.207 \\
\hline PEMS & 1.690 & 1.561 & 0.008 & 0.576 & 1.761 & 11.863 & 2.055 & 0.241 \\
\hline FTIR & 1.739 & 0.028 & 0.048 & 0.828 & 1.706 & 10.654 & 1.973 & 0.427 \\
\hline $\begin{array}{c}C V S \text { vs } \\
\text { PEMS }(\%)\end{array}$ & 0.696 & -479.39 & 76.620 & 23.595 & -3.755 & -6.477 & -49.186 & -16.337 \\
\hline $\begin{array}{c}C V S \text { vs } \\
\text { FTIR }(\%)\end{array}$ & -2.171 & 89.431 & -45.346 & -9.792 & -0.460 & 4.375 & -43.241 & -106.211 \\
\hline $\begin{array}{c}P E M S \text { v } \\
\text { FTIR }(\%)\end{array}$ & -2.886 & 98.176 & -521.670 & -43.669 & 3.176 & 10.192 & 3.985 & -77.249 \\
\hline
\end{tabular}

NOx emissions during the highway route are significantly lower when analyzed by the 3 instruments. NOx emissions analyzed from PEMS during Diesel operation shows a higher percent error which is due to the NO drift during the testing. FTIR NOx emissions are still reading higher and the error seems higher due to slight noise observed in emissions rates. The $\mathrm{NO}_{2}$ emissions from PEMS (NDUV) showed a higher drift during diesel vehicle testing. NOx emissions from CNG vehicle analyzed by PEMS is slightly higher during highway driving which strengthens the fact of positive interference between $\mathrm{HC}$ and $\mathrm{H}_{2} \mathrm{O}$ for NDUV. 


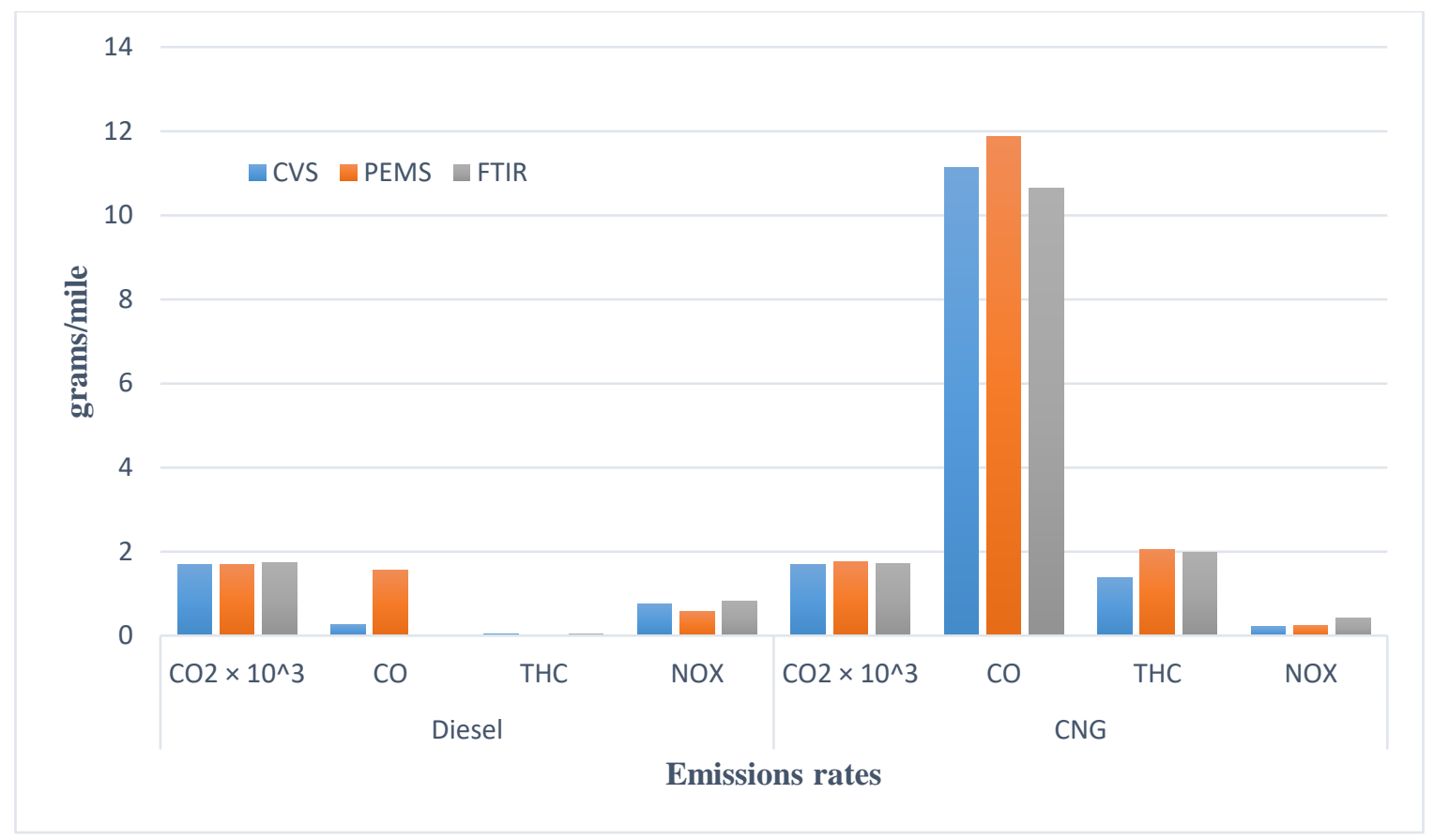

Figure 15: Emissions from Diesel and Natural Gas Vehicle for Highway driving route.

Figure 15 shows a graphical comparison between Diesel and CNG vehicle during highway driving operation. $\mathrm{CO}_{2}, \mathrm{CO}, \mathrm{THC}$ and $\mathrm{NO}_{\mathrm{x}}$ are shown from the 3 different instruments. It is observed that $\mathrm{CO}$ and THC emissions are still very low for the diesel vehicle. $\mathrm{CO}$ and THC emissions observed during CNG operation (higher concentrations) were in better comparison when compared to diesel operation as the concentrations observed during diesel operation was near detection limit ( 2-3 PPM). Table 18 and Table 19 shows the algebraic equations used to calculate THC emissions for diesel and natural-gas fuel from FTIR measurements. 
Table 18: FTIR NOx and THC calculations for Diesel Fuel.

\begin{tabular}{|l|l|}
\hline \multirow{3}{*}{ THC calculation } & $\begin{array}{l}1.1 \times\left(\frac{c 18}{1+e^{(300-c 18)} / 10}\right)+\left(c 17 \times\left(1-\frac{1}{1+e^{(300-c 18)} / 10}\right) \ldots\right. \\
+\frac{2 \times c 19}{1+e^{(0-c 19) / 0.001}}+\frac{1.9 \times c 16}{1+e^{(0-c 16) / 0.001}}+\frac{2.4 \times c 20}{1+e^{(0-c 20)} / 0.001} \ldots \\
+\frac{2.85 \times c 14}{1+e^{(0-c 14) / 0.001}}+\frac{1.35 \times c 15}{1+e^{(0-c 15) / 0.001}}\end{array}$ \\
\hline NOx calculation & $c 1+\frac{c 3}{1+e^{(170-c 2) / 5}+c 2 \times\left(1-\frac{1}{1+e^{(170-c 2)} / 5}\right)}$ \\
\hline
\end{tabular}

Where, C18=Methane high, C17=Methane low, C19=Ethane, C16=Ethylene, C20=Acetylene, $\mathrm{C} 14=$ Propylene, $\mathrm{C} 15=$ Propane, $\mathrm{C} 1=\mathrm{NO}, \mathrm{C} 2=\mathrm{NO}_{2}$ low and $\mathrm{C} 3=\mathrm{NO}_{2}$ high .

Table 19: FTIR NOx and THC calculations for Natural gas Fuel.

\begin{tabular}{|c|l|}
\hline & $\left(\frac{1.9 \times c 14}{1+e^{(0-c 14) / 0.001}}\right)+\left(\frac{2 \times c 13}{1+e^{(0-c 13)} / 0.001}\right)+\frac{2.4 \times c 15}{1+e^{(0-c 15) / 0.001}}$ \\
\hline NMHC calculation & $+\frac{3 \times c 16}{1+e^{(0-c 16) / 0.001}}+\frac{2.85 \times c 17}{1+e^{(0-c 17)} / 0.001}+\frac{4 \times c 18}{1+e^{(0-c 18)} / 0.001}$ \\
\hline $\mathrm{CH}_{4}$ calculation & $\frac{c 12}{1+e^{(300-c 12)} / 10}+c 11 \times\left(1-\frac{1}{1+e^{(300-c 12) / 10}}\right)$ \\
\hline NOx calculation & $c 1+\frac{c 3}{1+e^{(170-c 2)} / 5}+c 2 \times\left(1-\frac{1}{1+e^{(170-c 2)} / 5}\right)$ \\
\hline
\end{tabular}

Where, C14=Ethylene, C13=Ethane, C15=Acetylene, C16=Propane, C17=Propylene, $\mathrm{C} 12=$ Methane high, $\mathrm{C} 11=$ Methane low, $\mathrm{C} 1=\mathrm{NO}, \mathrm{C} 2=\mathrm{NO}_{2}$ low and $\mathrm{C} 3=\mathrm{NO}_{2}$ high. 


\subsection{NOx and THC Raw Emissions Comparison between PEMS \& FTIR}

This section compares the raw emissions analyzed by PEMS and FTIR for both NOx and THC. The NOx emissions considered in this sections are from diesel vehicle and THC from Natural Gas as THC emissions are near-zero in Diesel and NOx is very low in CNG. Both the systems used are raw measurement devices which are connected to the engine exhaust tailpipe. The PEMS used in this study measures NOx on dry basis. The raw data analyzed in this section from PEMS is converted from dry to wet basis using raw chemical balance procedure and since FTIR measures on wet basis the raw emissions are time-aligned and considered for the calculations.

Apart from continues concentrations this section also represents the results in the form of a quantile-quantile plot. A q-q plot is a plot of the quantiles of the first data set against the quantiles of the second data set. A q-q plot assesses whether two sets of sample data come from the same distribution. By a quantile, we mean the fraction (or percent) of points below the given value. That is, the 0.3 (or $30 \%$ ) quantile is the point at which $30 \%$ percent of the data fall below and $70 \%$ fall above that value. A 45-degree reference line is also plotted. If the two sets come from a population with the same distribution, the points should fall approximately along this reference line. The greater the departure from this reference line, the greater the evidence for the conclusion that the two data sets have come from populations with different distributions. Apart from the 45-degree reference line a solid red line joining the first and third quartiles is also plotted which is usually where bulk of the data points are present. Two sample t-test with unequal variances at $95 \%$ confidence interval were also performed to see the statistical correlation between the data represented by the instruments in this section. 


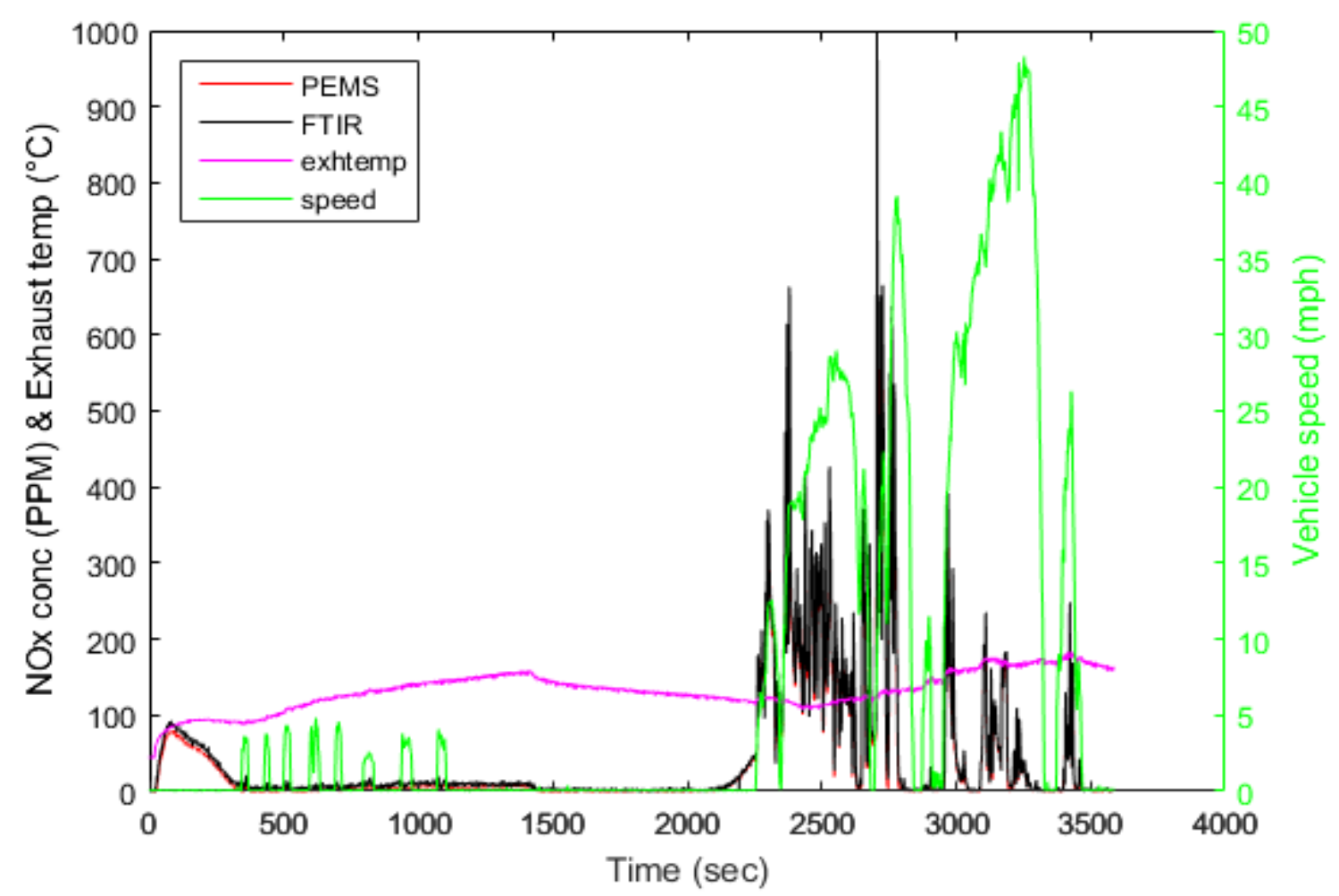

Figure 16: NOx emissions from PEMS and FTIR during Near-dock operation for Diesel vehicle.

Figure 16 shows the emissions from both FTIR and PEMS, exhaust temperatures (exhtemp) and Vehicle speed. Since it is a warm start larger NOx peak is observed during the engine startup and is close to zero during engine idling. Since Near-dock is a frequent start-stop kind of operation NOx emissions tend to rise as vehicle speed increases. The exhaust temperatures are below $150^{\circ} \mathrm{C}$ which makes SCR system unable to operate. It is observed that NOx emissions from FTIR and PEMS match well but slight noise (exhaust pulsations) is observed for FTIR. This is not observed in PEMS as exhaust is split and NOx portion must pass through a chiller before being analyzed and PEMS is made up of individual components which has different response times. It is also observed that during a sudden rise in NOx emissions FTIR slightly overreacts (reading higher) which causes the difference between PEMS and FTIR shown in Table 15. 
Figure 17 shows the quantile-quantile plot for the NOx emissions during near-dock operation for both PEMS and FTIR instrumentation. The mean for the data is 0.51 and the slope is 0.94. The solid red line represents the line joining the first $(\mathrm{Q} 1)$ and third $(\mathrm{Q} 3)$ quartiles of each distribution is superimposed on the plot. It is observed that both FTIR and PEMS are in good correlation during the near-dock (high concentration) operation for most of the ranges observed in this testing. The t-test rejects the null hypothesis at the 5\% significance level which means there is a significant difference between the two sample means (PEMS and FTIR). The scatter that is observed towards FTIR at higher ranges is because of lower flowrate of PEMS. The flowrate in PEMS is $2.5 \mathrm{~L} / \mathrm{min}$ and for FTIR it is at $10 \mathrm{~L} / \mathrm{min}$. Lower flowrates causes dispersive affects for sample which is why we don't see the spikes in PEMS. Since FTIR has higher flowrates where the cell's volume is exchanged at a higher flowrate we don't see the long transport delay which causes the sample to diffuse. 


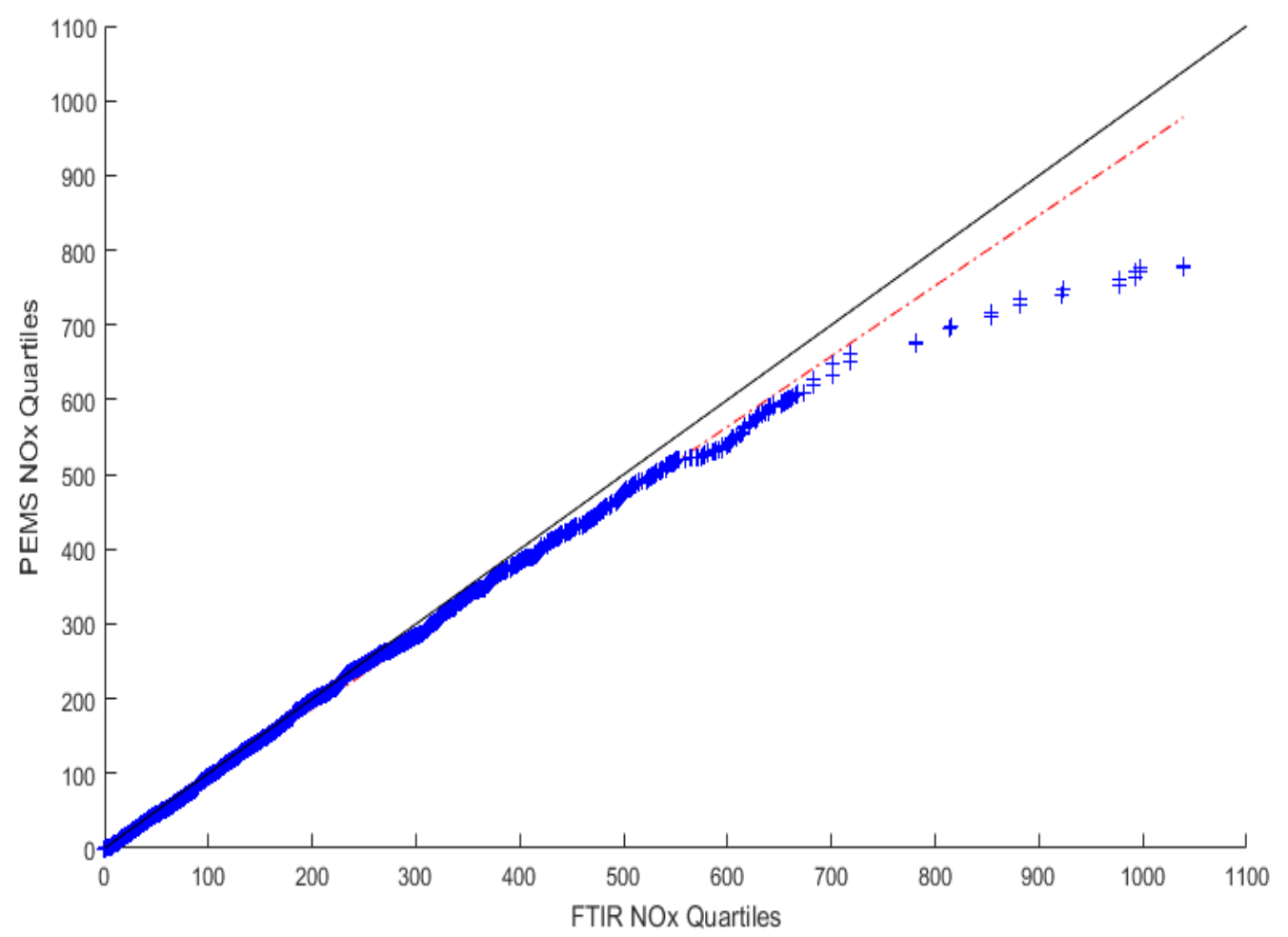

Figure 17: Quantile-Quantile plot between FTIR and PEMS during near-dock operation for diesel vehicle.

Figure 18 shows the emissions from both FTIR and PEMS, exhaust temperatures (exhtemp) and Vehicle speed. Since it is a warm start we see exhaust temperatures starting from around $60^{\circ} \mathrm{C}$. Since the Local operation is slightly more aggressive when compared to Near-dock the exhaust temperatures were higher and close to $200^{\circ} \mathrm{C}$. It is observed that NOx emissions from FTIR and PEMS match well during the test. A smooth pattern is observed for PEMS at low ranges but a slight noise is still observed in FTIR at very low concentrations (0-20ppm) which could be the result of instrument vibration or differences in cell pressure within the instrument during onroad testing. It is also observed that FTIR is fast responsive to the changes in the concentrations. This is due to the lower flowrate of PEMS, where we a slight sample dispersion is observed which causes a loss to the larger spikes. 


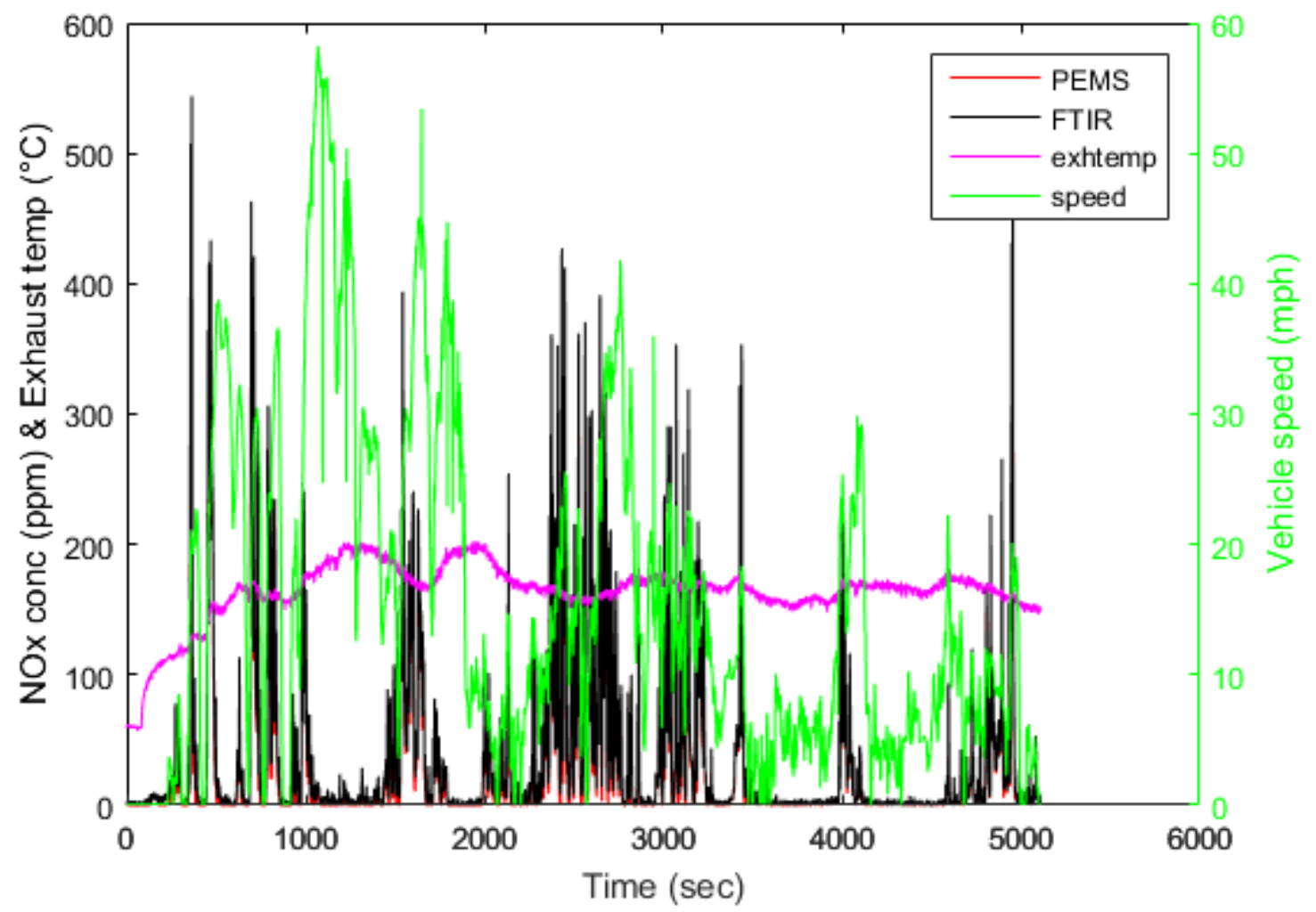

Figure 18: NOx emissions from PEMS and FTIR during Local operation for Diesel vehicle.

Figure 19 shows the quantile-quantile plot for the NOx emissions during local operation for both PEMS and FTIR instrumentation. The mean for the data is 0.43 and the slope is 0.88 . It is observed that FTIR is reading higher in NOx when compared to PEMS for higher concentration ranges (275 ppm and above). The data is skewed towards FTIR. The t-test rejects the null hypothesis at the $5 \%$ significance level which means there is a significant difference between the two sample means (PEMS and FTIR). 


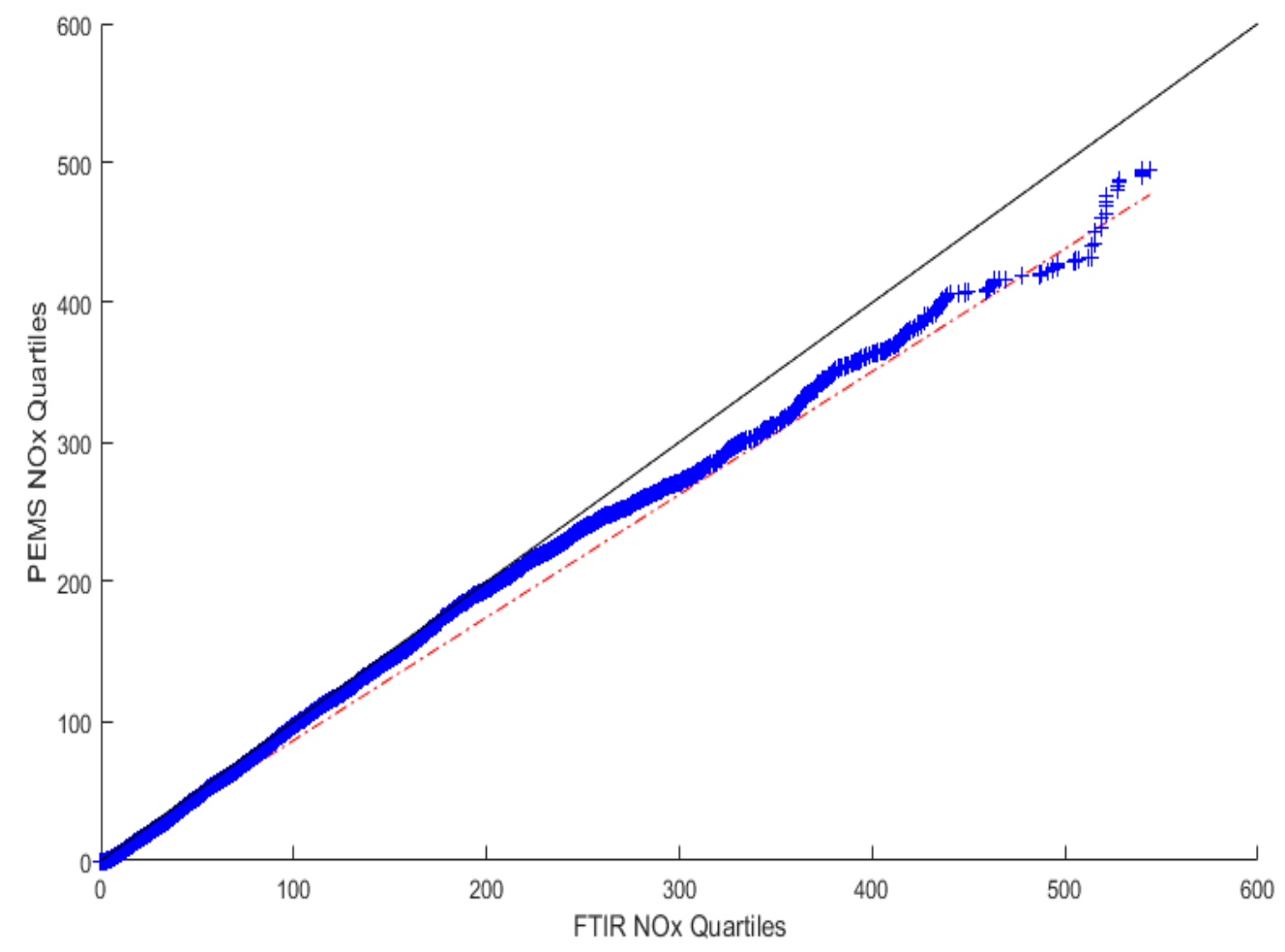

Figure 19: Quantile-Quantile plot between FTIR and PEMS during local operation for diesel vehicle.

Figure 20 shows the emissions from both FTIR and PEMS, exhaust temperatures (exhtemp) and Vehicle speed during highway driving. High exhaust temperatures are obtained by extended periods of high speed driving and very low NOx is observed with slight peaks due to braking and acceleration. Higher peaks are observed when the vehicle started accelerating from a stop due to congested traffic and a few minutes of high speed operation (around 55mph) increased the exhaust temperatures thereby reducing NOx. A slight drift is observed in PEMS during the last few minutes of idling which could be due to the analyzer reading near detection limits of both NO and $\mathrm{NO}_{2}$ for extending periods of test time. Although drift was observed in both $\mathrm{NO}$ and $\mathrm{NO}_{2}$ readings from PEMS, NO emissions constitute to most of the NOx emissions which is why we see a difference percent in NOx attributed to the drift in NO during the end of the test cycle. This could 
be the possible reason for a high error percent between CVS and PEMS and PEMS and FTIR observed in Table 17.

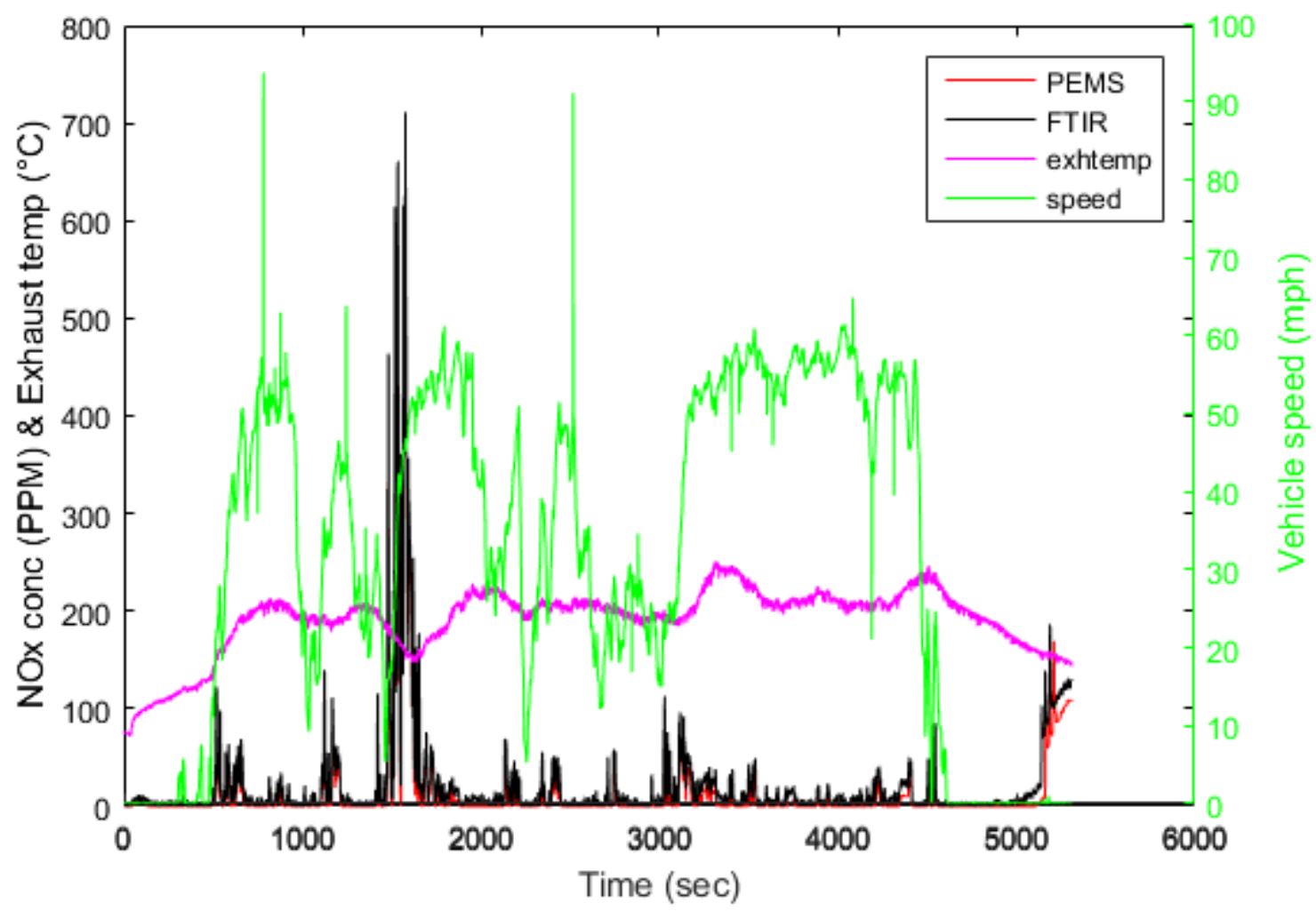

Figure 20: NOx emissions from PEMS and FTIR during Highway operation for Diesel vehicle.

Figure 21 shows the quantile-quantile plot for the NOx emissions during highway operation for both PEMS and FTIR instrumentation. The mean for the data is 0.17 and the slope is 0.35 . It is observed that there is no good correlation between the two instruments at highway operation when the concentrations are very low. It is observed that 50\% (Q1-Q3) of the data is very close to near-zero PPM levels. It can be concluded that both instruments differ at low concentration operation. The t-test rejects the null hypothesis at the 5\% significance level which means there is a significant difference between the two sample means (PEMS and FTIR). 


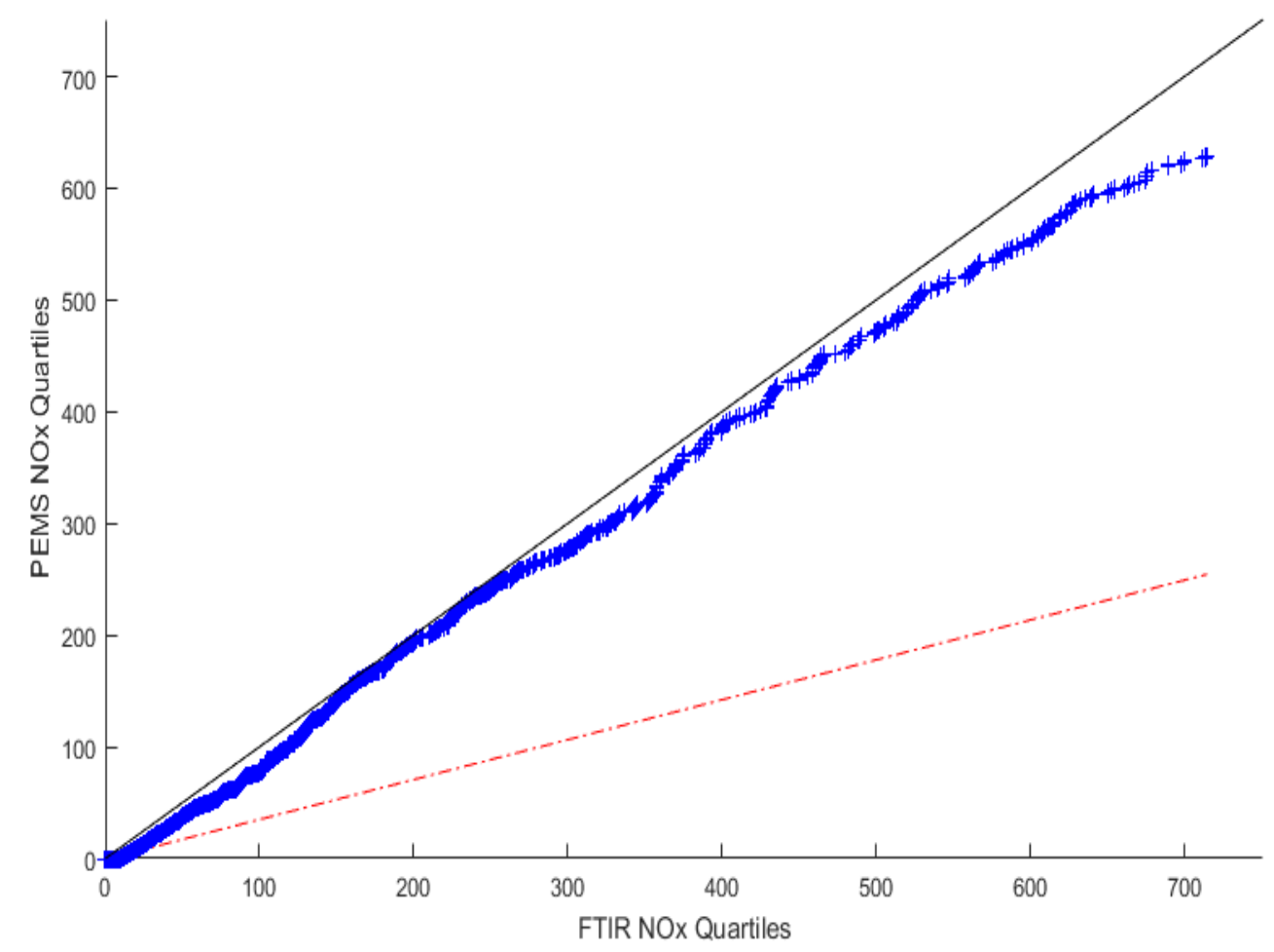

Figure 21: Quantile-Quantile plot between FTIR and PEMS during highway operation for diesel vehicle.

The THC emissions from CNG varied between $0.5 \%$ - 4\% between PEMS and FTIR during the testing (see Table 11-13). Figure 22 shows the THC emissions from both PEMS and FTIR and the exhaust temperatures (exhtemp) observed during the test. A good correlation is observed between the emissions concentration measurement for both the instruments. A similar pattern between the instruments is observed during Local and Highway driving. Higher THC emissions were observed during the start and the first few minutes of idling. As the vehicle speed increases and after-treatment temperature increases we see a decrease in the hydrocarbon emissions. The sudden spikes in THC emissions could be due to a sudden acceleration event. 


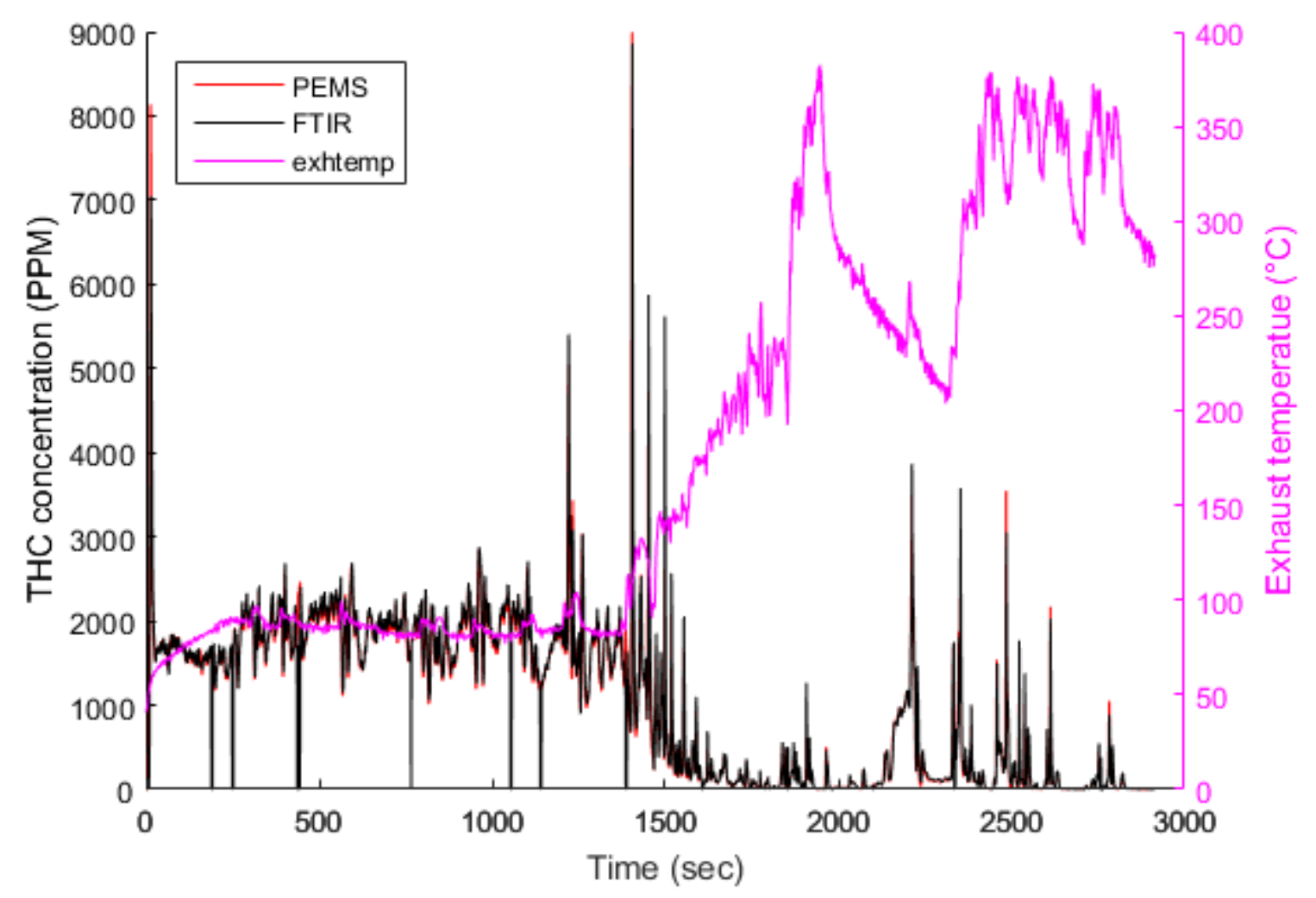

Figure 22: THC emissions from PEMS and FTIR during Near-dock operation for CNG vehicle.

Figure 23 shows the quantile-quantile plot for the THC emissions during near-dock operation for both PEMS and FTIR instrumentation. The mean for the data is 1.09 and the slope is 0.98 . The mean and slope obtained from the plot suggest the similarity in the data observed between the two instruments. It is seen that both the instruments have a good correlation at high concentration ranges observed in the near-dock operation. This is also proved by the t-test statistics. The t-test doesn't reject the null hypothesis at the 5\% significance level which means there is no significant difference between the two sample means (PEMS and FTIR). 


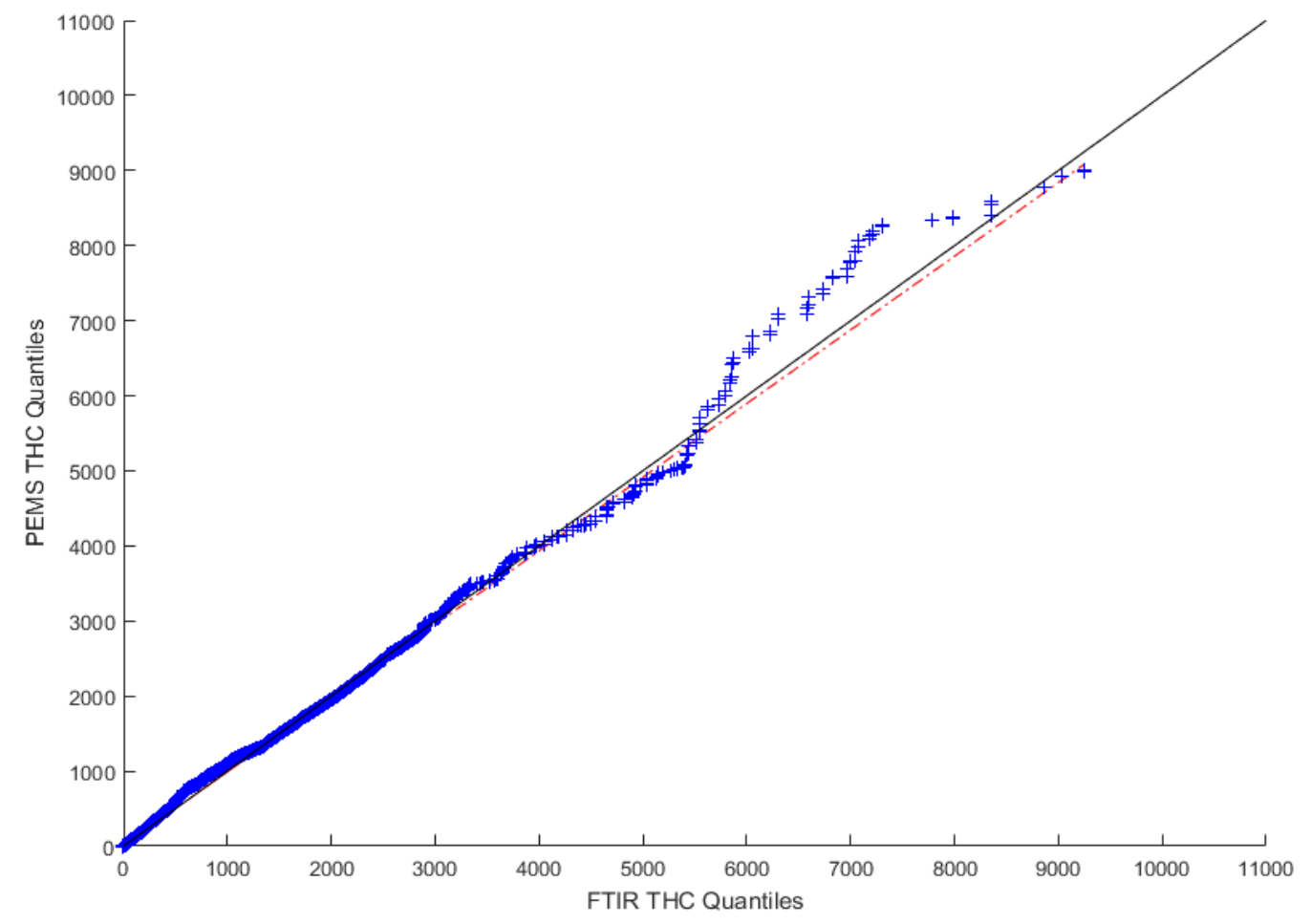

Figure 23: Quantile-Quantile plot between FTIR and PEMS during near-dock operation for natural-gas vehicle.

Figure 24 shows the quantile-quantile plot for the THC emissions during local operation for both PEMS and FTIR instrumentation. The mean for the data is 0.68 and the slope is 0.98 . The mean and slope obtained from the plot suggest that there is variation in the data observed between the two instruments. It is seen that FTIR is reading higher at higher concentrations. The t-test rejects the null hypothesis at the 5\% significance level which means there is significant difference between the two sample means (PEMS and FTIR). 


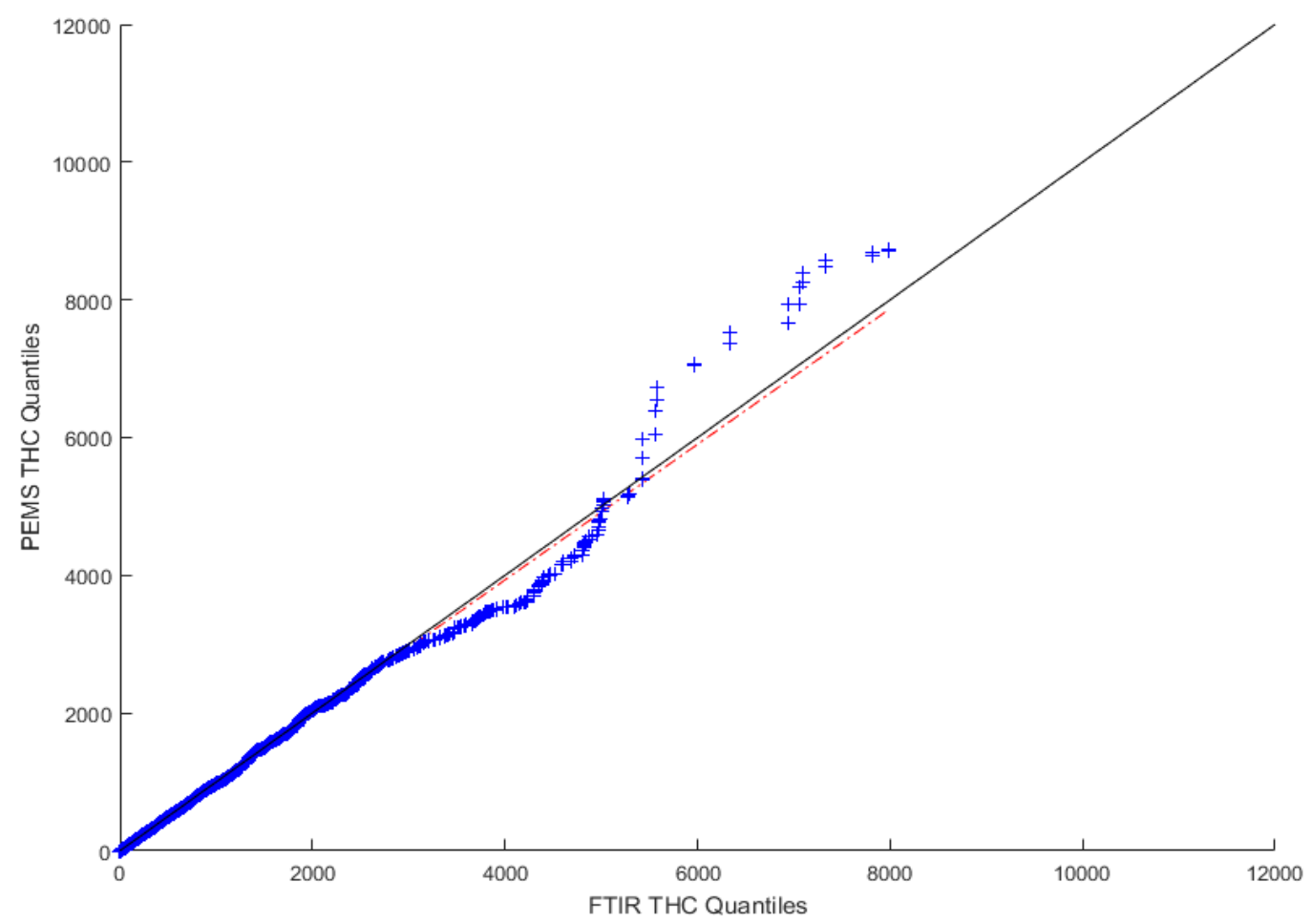

Figure 24: Quantile-Quantile plot between FTIR and PEMS during local operation for natural-gas vehicle.

Figure 25 shows the quantile-quantile plot for the THC emissions during highway operation for both PEMS and FTIR instrumentation. The mean for the data is 1.11 and the slope is 1.13. The mean of 1.11 indicated that PEMS instrument is recording slightly higher concentrations when compared to FTIR but overall it is observed that both the instruments have a good correlation during this specific route testing. This is also proved by the t-test statistics. The t-test doesn't reject the null hypothesis at the 5\% significance level which means there is no significant difference between the two sample means (PEMS and FTIR). 


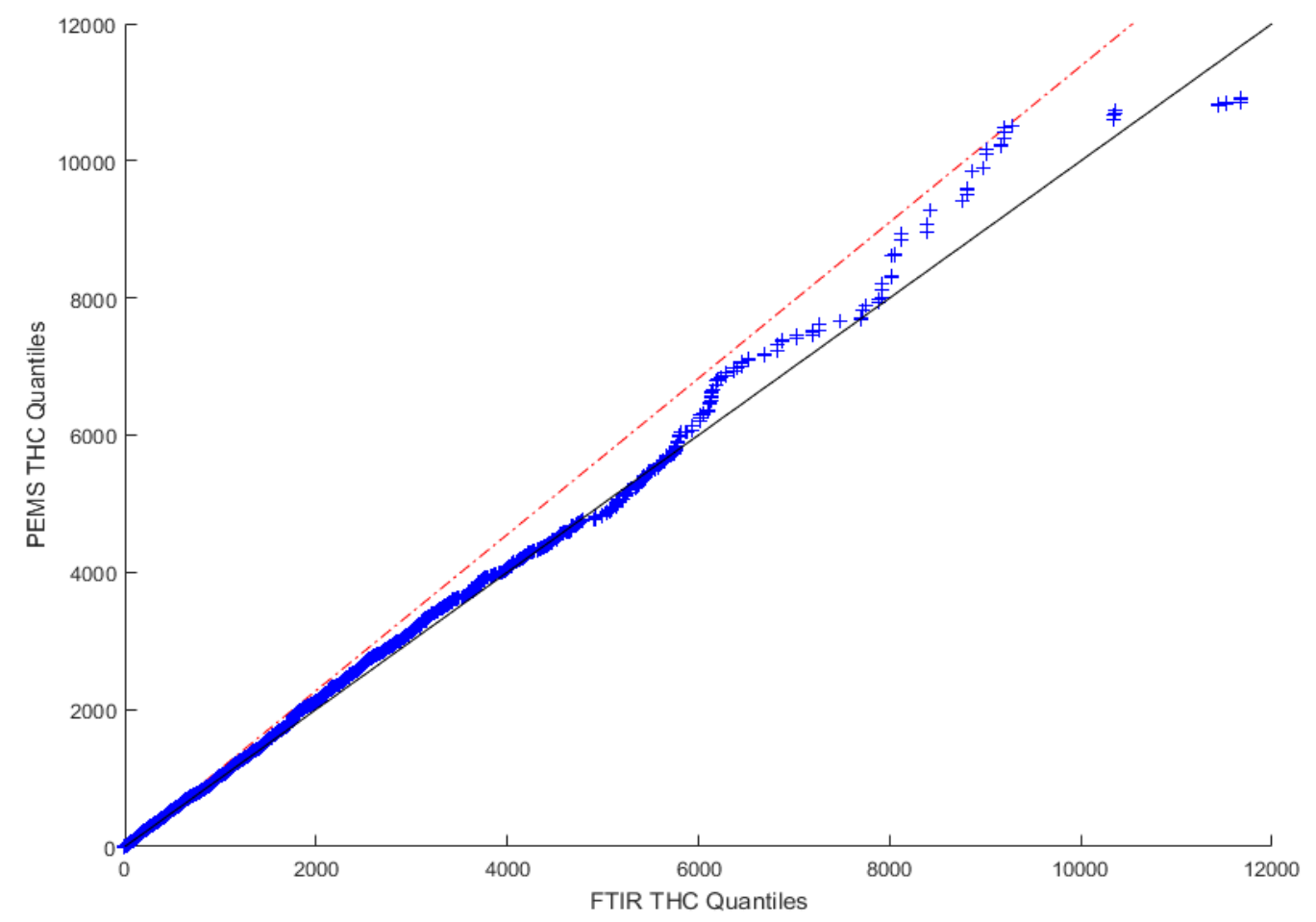

Figure 25: Quantile-Quantile plot between FTIR and PEMS during highway operation for natural-gas vehicle.

The PEMS used in this study is not equipped with dual-FID to quantify the $\mathrm{CH}_{4}$ emissions. Since FTIR uses an additive approach to quantify THC emissions and $\mathrm{CH}_{4}$ is reported separately, the $\mathrm{THC}$ and $\mathrm{CH}_{4}$ emissions were plotted with respect to time to see if $\mathrm{CH}_{4}$ contributes to most of the emissions. Figure 26 shows the THC and $\mathrm{CH}_{4}$ emissions from FTIR during a Highway operation. $\mathrm{CH}_{4}$ emissions constitute to the major portion of $\mathrm{THC}$ number. When calculated the $\mathrm{CH}_{4}$ emissions for the highway route accounted for $87.8 \%(1.732 \mathrm{~g} / \mathrm{mi})$ of the total hydrocarbon emissions. The $\mathrm{CH}_{4}$ emissions averaged between $85-88 \%$ of the THC emissions for all the test routes mentioned in section 3.2.2 and the CNG vehicle used in this testing was not under the greenhouse regulation compliance requirement. 


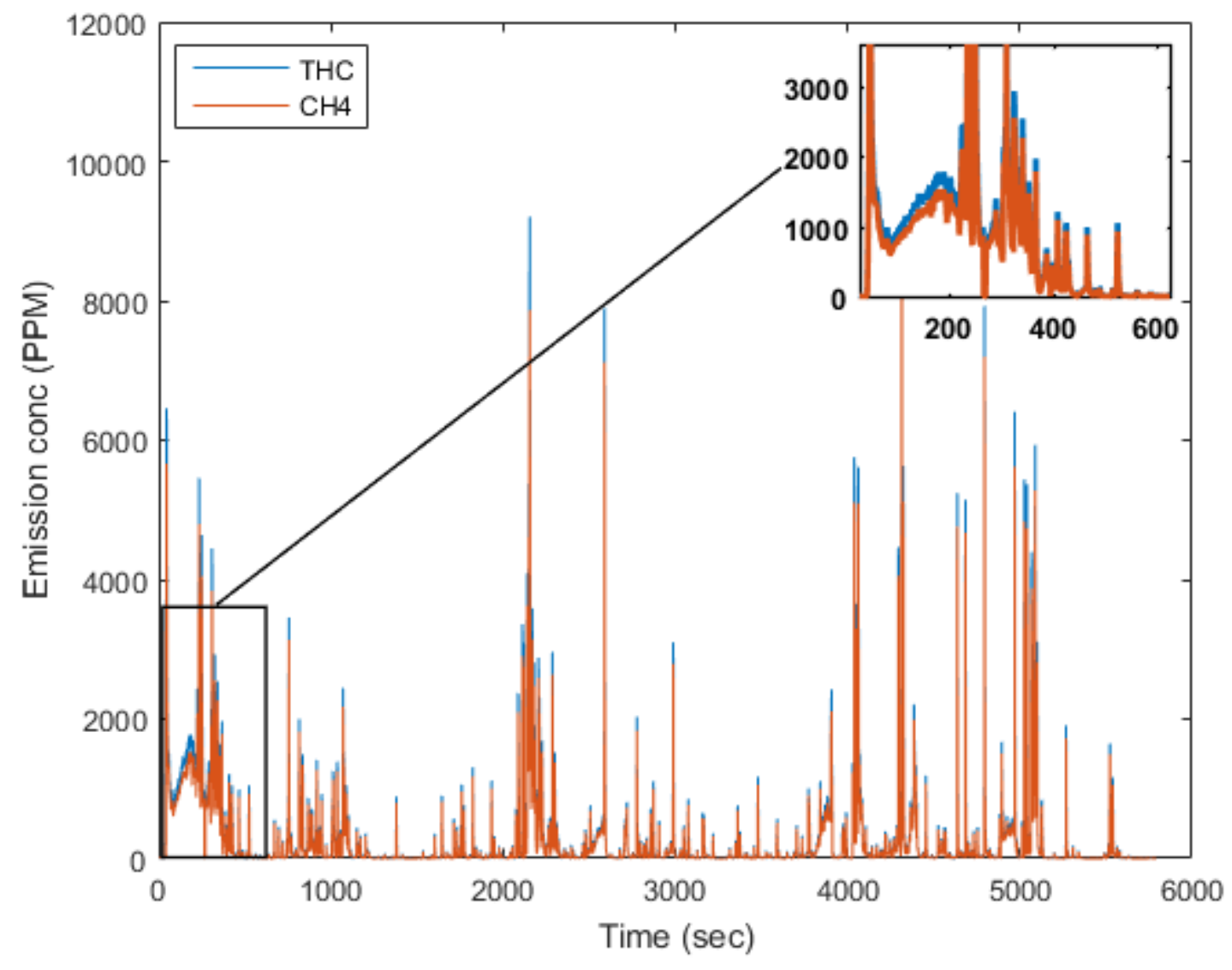

Figure 26: $\mathrm{THC}$ and $\mathrm{CH}_{4}$ emissions during Highway testing for $\mathrm{CNG}$ vehicle. 


\subsection{Effect of Time-Alignment on NOx Emissions from FTIR}

The time aligning of data from the different analyzers, communication devices, and flow measurement signals is an important step in the testing process. Time shifts as small as $2-3$ seconds can cause significant errors. These errors stem from different exhaust configurations. Each vehicle's exhaust system varies in length, therefore resulting in longer or shorter travel times for the exhaust through the FTIR and flow measurement system. For instance, improperly aligned data will result in EFM flowrates not matching up with gas concentrations, and NOx values will be

well under or over the actual mass emission flowrate. Since FTIR is a single box instrument, only $\mathrm{CO}_{2}$ is time-aligned with exhaust flow measurement and all other components are shifted based on $\mathrm{CO}_{2}$. All other instruments used in this study (SEMTECH -DS and MEXA-7200D) are aligned with respect to the $\mathrm{CO}_{2}$ instrument of the FTIR instrument. This section compares the effects of time alignment based on two methods (regression and visual) on FTIR emissions and the error caused by improper time alignment for up to 5 seconds on properly aligned (regressions based) emissions. There is no regulation in place by EPA mandating the use of a time-alignment technique.

\subsubsection{Time-Alignment based on Regression Method}

NOx emissions from FTIR are time aligned with the exhaust flow meter used in this study. To be more precise, the continuous $\mathrm{CO}_{2}$ concentrations are aligned with exhaust flowrate using Mat-lab cross-correlation to find the shift between the two signals. The $\mathrm{CO}_{2}$ emissions are adjusted for the shift and are checked to see for the maximum $\mathrm{R}^{2}$ (coefficient of determination). All other emissions are checked with $\mathrm{CO}_{2}$ emissions and are adjusted accordingly. All the emissions reported in this document are time aligned based on Mat-lab cross-correlation. Table 20 shows the 
emissions calculated based on regression technique from FTIR measurement in grams/mile during different driving operations which were discussed in the section 4.2.

Table 20: NOx emissions analyzed from diesel vehicle using regression time-alignment technique.

\begin{tabular}{|c|c|}
\hline \multicolumn{2}{|c|}{ Emission rates (g/mi) } \\
\hline Route-type & NOx \\
\hline Near-dock & 6.144 \\
\hline Local & 3.011 \\
\hline Highway & 0.828 \\
\hline
\end{tabular}

\subsubsection{Time-Alignment based on Visual Method}

In this section, NOx emissions from FTIR are time aligned with the exhaust flow meter used in this study. The continuous $\mathrm{CO}_{2}$ concentrations are aligned with exhaust flowrate using visual technique. The $\mathrm{CO}_{2}$ emissions are adjusted for the shift and are checked to see if they are matching properly. All other emissions are checked with $\mathrm{CO}_{2}$ emissions and are adjusted accordingly. Although the emissions presented in this document were time-aligned using a different technique (regression) but a good understanding into the differences in emissions rates based on different time-aligning techniques is important. Table 21 shows the emissions calculated based on visual technique from FTIR measurement in grams/mile during different driving operations discussed in section 4.2 . 
Table 21: NOx emissions analyzed from diesel vehicle using visual time-alignment technique.

\begin{tabular}{|c|c|}
\hline \multicolumn{2}{|c|}{ Emission rates (g/mi) } \\
\hline Route-type & NOx \\
\hline Near-dock & 6.019 \\
\hline Local & 3.139 \\
\hline Highway & 0.797 \\
\hline
\end{tabular}

From the results shown in Table 20 and Table 21 the importance of proper time-alignment on emissions data is clearly depicted. An error of about $2 \%$ to $4 \%$ is observed from the emissions calculated using regression and visual methods.

\subsubsection{Effect of Time-Alignment on Emissions}

To evaluate the effects of time-alignment on emissions from FTIR, tests have been conducted on the properly aligned data to see possible error due to time shifting. Time-aligned NOx emissions are shifted up to \pm 5 seconds for both Diesel and CNG vehicle during Local operation (see section 4.2) with reference to exhaust flow and the emissions are distance-specific emissions are calculated. Figure 27 shows the percent difference in emissions from Local driving for both diesel and CNG. It is observed that during diesel operation the NOx emissions rate (g/mi) decreases for both positive and negative time-shifting. 


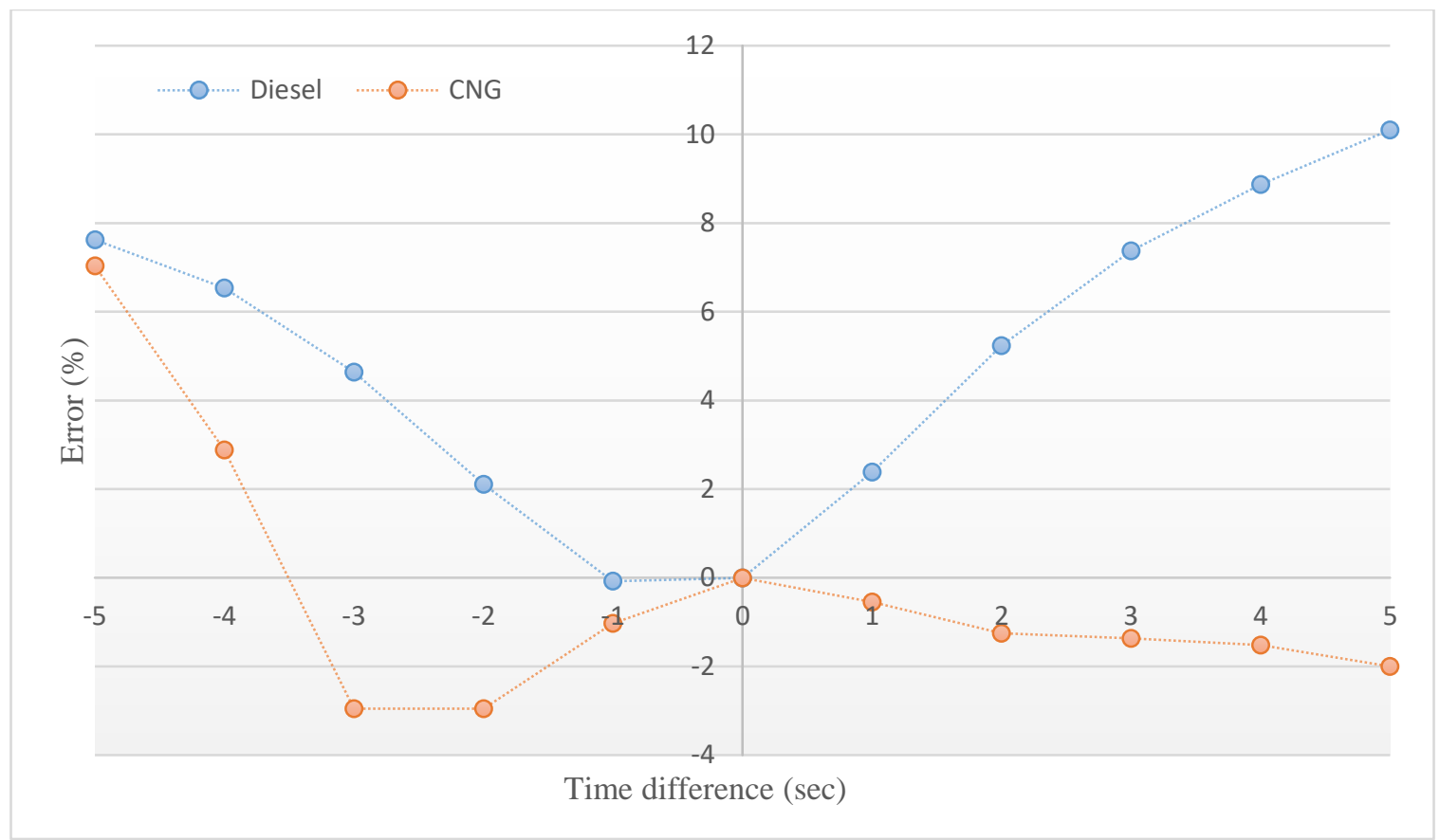

Figure 27: Error caused due to time-alignment in NOx emissions from FTIR.

During positive shifting a maximum error of $10.1 \%$ (lower emissions) is observed. The error percent increases as time shift between the data is increased. For CNG vehicle during local operation it is observed that improper time-alignment gives a higher number during positive shifting. A higher number is observed during first few seconds ( 3 seconds) during negative shifting and the emissions rate (g/mi) drops drastically during the last 2 seconds. Emissions rates vary from test to test based on raw concentrations, exhaust flows etc. A similar pattern might not be visible for different datasets but overall time alignment errors can cause emissions to vary significantly. 


\section{Conclusion}

Two heavy-duty vehicles equipped with Diesel and Natural-gas engines, certified to USEPA 2010 emissions standards were operated over a variety of pre-defined test routes exhibiting diverse driving conditions pertinent to major US population centers located in the state of California. Gaseous emissions of NOx, $\mathrm{CO}$, THC and $\mathrm{CO}_{2}$ were measured using WVU TEMS which houses different analyzers to measure gaseous and PM emissions for these vehicles. The study included the comparative testing of Sensors Inc. Semtech-DS (PEMS) and MKS FTIR-2030 HS (FTIR) against the reference CVS measurement system utilizing a MEXA-7200D analyzer.

Comparative measurements between CVS and PEMS instruments show an overall agreement in distance-specific measurements of $\mathrm{CO}_{2}$ and $\mathrm{NOx}$ for the diesel vehicle over low vehicle speed operation i.e. near-dock route. However, some tests during the local and highway route indicated larger deviations in NOx measurements between CVS and PEMS instrumentation which is mainly due to $\mathrm{NO}_{2}$ drift in the PEMS instrument. NOx emissions from FTIR were slightly higher for diesel which is due to the dispersive effect which is observed in CVS and PEMS systems. NOx emissions for CNG vehicle showed large differences between FTIR and other instrumentation which is due to the low NOx emissions from $\mathrm{CNG}$ vehicle. A low pass filter might help, but care must be taken to not loose actual transient data, compared to CNG operation, such as concentration spikes during acceleration events. The error for THC and CO measurements during diesel operation between the three instruments are higher and this can be attributed to very low emissions concentrations. The $\mathrm{CO}_{2}$ emissions measured with PEMS and FTIR for the CNG vehicle varied from $1 \%$ to $6 \%$ respectively, when compared to CVS. In the case of natural gas engines, the higher water content of the exhaust resulted in positive interference in the NDIR analyzer of the Semtech-DS which was observed mainly during Near-dock operation. 
Stoichiometric combustion of methane produces more water than lean-burn engines. Although the FTIR is a wet system, the high amounts of water in natural gas exhaust might have caused a positive interference (strong $\mathrm{HOH}$ bonding) which in turn resulted in a drift in $\mathrm{CO}_{2}$ readings. The error in NOx from FTIR for natural-gas operation is significant due to sudden spikes observed during the vehicle operation. A constant high error in NOx emissions from natural-gas analyzed from FTIR is observed. The THC emissions between FTIR and PEMS are in good agreement which makes FTIR suitable for higher THC concentrations like natural-gas operations.

Raw emissions between PEMS and FTIR were compared to investigate into the possibility of using FTIR as an alternative to PEMS instrumentation. NOx concentration measurements from diesel vehicle and THC concentration measurements from CNG vehicle for both PEMS and FTIR match well which is supported by the mean and slope of 1 for the q-q plots. In general, THC emissions from CNG varied between $0.5 \%$ - $4 \%$ between PEMS and FTIR during the testing. A good correlation is observed between the emissions concentration measurement for both the instruments. A similar pattern between the instruments is observed during local and highway driving.

The results also highlight the importance of proper time-alignment as time shifts as small as 2-3 seconds can result in significant errors in the emissions mass calculations. An error of about $\sim 2 \%$ to $4 \%$ was observed from the emissions calculated using two different time-alignment techniques. Also, an error of up to $10 \%$ was observed during a shift in the exhaust flow and raw concentrations.

The results of the study also show that the Diesel vehicle equipped with SCR exhibited close to $90 \%$ reduction during Highway operation in NOx emissions when compared to Near-dock operation. Natural gas vehicle equipped with a TWC showed significant lower NOx emissions 
compared to SCR equipped diesels over all the test routes. Natural gas vehicle exhibits an order of magnitude lower NOx emissions compared SCR equipped diesels over near-dock test route characterized by the lowest average speed and load. Natural-gas vehicles had more THC emissions but $\sim 90 \%$ of the THC emissions from CNG vehicle was methane which is a greenhouse gas and not regulated for this vehicle. 


\section{References}

Akard, Michael, Hiroshi Nakamura, Shintaro Aoki, Nobutaka Kihara, and Masayuki Adachi. 2005. "Performance Results and Design Considerations for A New In-Use Testing Instrument". SAE Technical Paper Series. doi:10.4271/2005-01-3606.

Baronick, J. D., B. Heller, G. Lach, F. Bogner, U. Gerspach, H. Schimpl, D. Gruber, W. Fabinski, M. Moede, and M. Zöchbauer. 2001. "Evaluation of an UV Analyzer for $\mathrm{NO}_{\mathrm{X}}$ Vehicle Emission Measurement". SAE Technical Paper Series. doi:10.4271/2001-01-0213.

Baronick, J., B. Heller, G. Lach, and H. Luf. 1998. "Modal Measurement of Raw Exhaust Volume and Mass Emissions by SESAM". SAE Technical Paper Series. doi:10.4271/980047.

Bentz, Alan P. 1997. Final Summary Report on Project 3310, Marine Diesel Exhaust Emissions (Alternative Fuels). CG-D-08-98. Washington, D.C.

Bentz, Alan P. and Elizabeth Weaver. 1994. "Marine Diesel Exhaust Emissions Measured by Portable Instruments". SAE Technical Paper Series. doi:10.4271/941784.

Bianchi, D., J. L. Gass, C. Bouly, and D. Maret. 1991. "Determination of Efficiency of Exhaust Gas Catalyst by F.T.I.R. Spectroscopy". SAE Technical Paper Series. doi:10.4271/910839.

Bougher, Thomas, Imad A. Khalek, Steven Trevitz, and Michael Akard. 2010. "Verification of A Gaseous Portable Emissions Measurement System with A Laboratory System Using the Code of Federal Regulations Part 1065". SAE Technical Paper Series. doi:10.4271/2010-01-1069.

Buckingham, Janet P., Robert L. Mason, and Matthew W. Spears. 2009. "Determination of PEMS Measurement Allowances for Gaseous Emissions Regulated Under the Heavy-Duty Diesel Engine In-Use Testing Program Part 2 - Statistical Modeling and Simulation Approach". SAE Int. J. Fuels Lubr. 2 (1): 422-434. doi:10.4271/2009-01-0939. 
Butler, J.W., T.J. Kornisk, A.R. Reading, and T.L. Kotenko. 1999. "Dynamometer Quality Data On-Board Vehicles for Real-World Emission Measurements". In Ninth CRC On-Road Vehicle Workshop.

Clark, Nigel N., Justin M. Kern, Christopher M. Atkinson, and Ralph D. Nine. 2002. "Factors Affecting Heavy-Duty Diesel Vehicle Emissions". Journal of The Air \& Waste Management Association 52 (1): 84-94. doi:10.1080/10473289.2002.10470755.

Clark, Nigel, James J. Daley, Ralph D. Nine, and Christopher M. Atkinson. 1999. "Application of The New City-Suburban Heavy Vehicle Route (CSHVR) To Truck Emissions Characterization". SAE Technical Paper Series. doi:10.4271/1999-01-1467.

Daham, Basil, Gordon E. Andrews, Hu Li, Rosario Ballesteros, Margaret C. Bell, James Tate, and Karl Ropkins. 2005. "Application of A Portable FTIR for Measuring On-Road Emissions". SAE Technical Paper Series. doi:10.4271/2005-01-0676.

Delgado, Oscar F., Nigel N. Clark, and Gregory J. Thompson. 2011. "Modeling Transit Bus Fuel Consumption on the Basis of Cycle Properties". Journal of The Air \& Waste Management Association 61 (4): 443-452. doi:10.3155/1047-3289.61.4.443.

Dickerson, R. R., A. C. Delany, and A. F. Wartburg. 1984. "Further Modification of a Commercial NOx Detector for High Sensitivity". Review of Scientific Instruments 55 (12): 1995. doi:10.1063/1.1137694.

Englund, M. S. 1982. "Field Compatible NOX Emission Measurement Technique". SAE Technical Paper Series. doi:10.4271/820647.

Feist, Michael D., Christopher A. Sharp, and Matthew W. Spears. 2009. "Determination of PEMS Measurement Allowances for Gaseous Emissions Regulated Under the Heavy-Duty Diesel Engine In-Use Testing Program: Part 1 - Project Overview and PEMS Evaluation Procedures". SAE Int. J. Fuels Lubr. 2 (1): 435-454. doi:10.4271/2009-01-0940. 
Gable, K. 2013. "FTIR Instrumentation and Theory". Chemistry.Oregonstate.Edu. http://chemistry.oregonstate.edu/courses/ch361-464/ch362/irinstrs.htm.

Gierczak, Christine A., Thomas J. Korniski, Timothy J. Wallington, and Carl D. Ensfield. 2007. "Simultaneous Real-Time Measurements of NO and NO2 in Medium Duty Diesel Truck Exhaust". SAE Technical Paper Series. doi:10.4271/2007-01-1329.

Gluck, Steven, Chuck Glenn, Tim Logan, Bac Vu, Mike Walsh, and Pat Williams. 2003. "Evaluation of NO X Flue Gas Analyzers for Accuracy and Their Applicability for LowConcentration Measurements". Journal of The Air \& Waste Management Association 53 (6): 749-758. doi:10.1080/10473289.2003.10466208.

Graboski, M.S., R.L. McCormick, J. Yanowitz, and L. Ryan. 1998. Heavy-Duty Diesel Vehicle Testing for The Northern Front Range Air Quality Study. Fort Collins, CO: Colorado School of Mines.

Green, Gary J., Timothy J. Henly, Michael E. Starr, Dennis N. Assanis, Michalis Syrimis, and Fadi Kanafani. 1997. "Fuel Economy and Power Benefits of Cetane-Improved Fuels in HeavyDuty Diesel Engines". SAE Technical Paper Series. doi:10.4271/972900.

Hadavi, Seyed, Gordon E. Andrews, Hu Li, Grzegorz Przybyla, and Mohammadmohsen Vazirian. 2013. "Diesel Cold Start into Congested Real World Traffic: Comparison of Diesel and B100 for Ozone Forming Potential". SAE Technical Paper Series. doi:10.4271/2013-01-1145.

Heller, Beate, Horst Klingenberg, Gerhard Lach, and Jürgen Winckler. 1990. "Performance of A New System for Emission Sampling and Measurement (SESAM)". SAE Technical Paper Series. doi:10.4271/900275.

Human, David M. and Terry L. Ullman. 1992. "Development of an I/M Short Emissions Test for Buses". SAE Technical Paper Series. doi:10.4271/920727. 
Jetter, Jeff, Shinji Maeshiro, Seiji Hatcho, and Robert Klebba. 2000. "Development of an OnBoard Analyzer for Use on Advanced Low Emission Vehicles". SAE Technical Paper Series. doi:10.4271/2000-01-1140.

Johnson, Kent C., Thomas D. Durbin, David R. Cocker, J. Wayne Miller, Rey J. Agama, Nate Moynahan, and Guru Nayak. 2008. "On-Road Evaluation of PEMS for Measuring Gaseous In-Use Emissions from A Heavy-Duty Diesel Vehicle". SAE International Journal of Commercial Vehicles 1 (1): 200-209. doi:10.4271/2008-01-1300.

Kelly, Nelson A. and Peter J. Groblicki. 1993. "Real-World Emissions from A Modern Production Vehicle Driven in Los Angeles". Air \& Waste 43 (10): 1351-1357. doi:10.1080/1073161x.1993.10467209.

Kihara, Nobutaka, Tokihiro Tsukamoto, Koichi Matsumoto, Kozo Ishida, Masao Kon, and Takao Murase. 2000. "Real-Time On-Board Measurement of Mass Emission of NOx, Fuel Consumption, Road Load, And Engine Output for Diesel Vehicles". SAE Technical Paper Series. doi:10.4271/2000-01-1141.

Lange, W. W., J. A. Cooke, P. Gadd, H. J. Zürner, H. Schlögi, and K. Richter. 1997. "Influence of Fuel Properties on Exhaust Emissions from Advanced Heavy-Duty Engines Considering the Effect of Natural and Additive Enhanced Cetane Number". SAE Technical Paper Series. doi:10.4271/972894.

Lee, G. R., C. R. McDonald, K. A. Widdicombe, and P. J. van den Brink. 1996. "The Role of Methane on Catalyst Conversion of NOx: A Study Based On FTIR". SAE Technical Paper Series. doi:10.4271/961155.

Narasimhamurthy, Praveen R. 2002. "Investigation of Techniques to Improve Measurement Accuracy of $\mathrm{NO}, \mathrm{NO}_{2}$ and NOx Emissions from Heavy Duty Diesel Engines". M.S. Thesis, West Virginia University. 
Nussbaum, Nicholas J. 2007. "In-Plume Measurements of Combustion Exhaust". M.S. Thesis, University of Nevada.

Oestergaard, Karl, Mike Akard, Scott Porter, and Daniel Carder. 2004. "Further Investigation into The Performance of Two Different On-Board Emissions Measurement System Compared to Laboratory Measurements". SAE Technical Paper Series. doi:10.4271/2004-01-3480.

Quiros, David C., Arvind Thiruvengadam, Saroj Pradhan, Marc Besch, Pragalath Thiruvengadam, Berk Demirgok, Daniel Carder, Adewale Oshinuga, Tao Huai, and Shaohua Hu. 2016. "RealWorld Emissions from Modern Heavy-Duty Diesel, Natural Gas, And Hybrid Diesel Trucks Operating Along Major California Freight Corridors". Emiss. Control Sci. Technol. 2 (3): 156-172. doi:10.1007/s40825-016-0044-0.

Riddle, Wesley.C. 2001. "Design and Evaluation of the Emissions Measurement Components for A Heavy-Duty Diesel Powered Vehicle Mobile Emissions Measurement System (MEMS)". M.S. Thesis, West Virginia University.

Roberts, Jay P. and S.R. Lowry. 1994. "Modal Measurements of Some Important NMOG Species by FT-IR Spectroscopy". SAE Technical Paper Series. doi:10.4271/940739.

SAE J1939/71®. 2014. "Vehicle Application Layer-J1939-71 (through1999)”. SAE Standard.

Sandstroem-Dahl, Charlotte, Lennart Erlandsson, Jan Gasste, and Magnus Lindgren. 2010. "Measurement Methodologies for Hydrocarbons, Ethanol and Aldehyde Emissions from Ethanol Fuelled Vehicles". SAE International Journal of Fuels and Lubricants 3 (2): 453466. doi:10.4271/2010-01-1557.

Shade, Benjamin.C. 2000. "A Performance Evaluation of MEMS-An On-Road Emissions Measurement System Study". M.S. Thesis, West Virginia University.

Shade, Benjamin C., Daniel K. Carder, Gregory J. Thompson, and Mridul Gautam. 2008. "A Work-Based Window Method for Calculating In-Use Brake-Specific NOx Emissions of 
Heavy-Duty Diesel Engines". SAE International Journal of Engines 1 (1): 778-793. doi:10.4271/2008-01-1301.

Sharp, Christopher A., Michael D. Feist, Christopher A. Laroo, and Matthew W. Spears. 2009. "Determination of PEMS Measurement Allowances for Gaseous Emissions Regulated Under the Heavy-Duty Diesel Engine In-Use Testing Program Part 3 - Results and Validation". SAE International Journal of Fuels and Lubricants 2 (1): 407-421. doi:10.4271/2009-01-0938.

Shore, P. R. and R. S. deVries. 1992. "On-Line Hydrocarbon Speciation Using FTIR and CI-MS". SAE Technical Paper Series. doi:10.4271/922246.

Thompson, Gregory J., Daniel K. Carder, Nigel Clark, and Mridul Gautam. 2008. "Summary of In-Use NOx Emissions from Heavy-Duty Diesel Engines". SAE International Journal of Commercial Vehicles 1 (1): 162-184. doi:10.4271/2008-01-1298.

US EPA, 2008. In-Use Testing for Heavy-Duty Diesel Engines and Vehicles; Emission Measurement Accuracy Margins for Portable Emission Measurement Systems and Program Revisions. Federal Register 73:50. www.epa.gov.

US EPA, 2016. Greenhouse Gas Emissions and Fuel Efficiency Standards for Medium- And Heavy-Duty Engines and Vehicles- Phase 2. Federal Register / Vol. 81, No. 206. www.epa.gov.

US EPA, 2008. Determination of PEMS Measurement Allowance for Gaseous Emissions Regulated Under the Heavy-Duty Diesel Engine In-Use Testing Program. EPA420-R-08-005.

US EPA, CARB, and EMA. 2005. Test Plan to Determine PEMS Measurement Allowances for The Gaseous Emissions Regulated Under the Manufacturer-Run Heavy-Duty Diesel Engine In-Use Testing Program. www.epa.gov.

US EPA, 2005. " Control of Emissions of Air Pollution from Highway Heavy-Duty Engines". Federal Register 54693-54730. https://www.epa.gov/otaq/regs/hd-hwy/1997frm/frhwy.pdf. 
US EPA, 2007. "Emission Standards and Supplemental Requirements for 2007 And Later Model Year Diesel Heavy-Duty Engines and Vehicles.". https://www.gpo.gov/fdsys/pkg/CFR-2011title40-vol18/pdf/CFR-2011-title40-vol18-sec86-007-11.pdf.

US EPA, CARB, and EMA. 2005. Memorandum of Agreement: Program to Develop Emission Measurement Accuracy Margins for Heavy Duty In-Use Testing.

Vojtisek-Lom, Murray. and J.T. Cobb. 1998. "On-Road Light-Duty Vehicle Emission Measurements Using a Novel Inexpensive On-Board Portable System". In Eighth CRC OnRoad Vehicle Workshop.

Vojtisek-Lom, Michal and Joseph E. Allsop. 2001. "Development of Heavy-Duty Diesel Portable, On-Board Mass Exhaust Emissions Monitoring System with $\mathrm{NOx}, \mathrm{CO}_{2}$ and Qualitative PM Capabilities". SAE Technical Paper Series. doi:10.4271/2001-01-3641.

Wang, W. G., D. W. Lyons, N. N. Clark, M. Gautam, and P. M. Norton. 2000. "Emissions from Nine Heavy Trucks Fueled by Diesel and Biodiesel Blend Without Engine Modification". Environmental Science \& Technology 34 (6): 933-939. doi:10.1021/es981329b.

Weaver, Christopher S. and Marco V. Balam-Almanza. 2001. "Development of the 'RAVEM' Ride-Along Vehicle Emission Measurement System for Gaseous and Particulate Emissions". SAE Technical Paper Series. doi:10.4271/2001-01-3644.

Wright, Nolan, Dustin Osborne, and Nathan Music. 2016. "Comparison of Hydrocarbon Measurement with FTIR and FID in a Dual Fuel Locomotive Engine". SAE Technical Paper Series. doi:10.4271/2016-01-0978.

Wu, Yubin, D. Carder, B. Shade, R.J. Atkinson, N.N. Clark, and M. Gautam. 2009. "A CFR1065Compliant Transportable/On-Road Low Emissions Measurement Laboratory with Dual Primary Full-Flow Dilution Tunnels". In ASME Internal Combustion Engines Division Meeting, ASME ICES2009 - 76090. 